\title{
Cooling Water Issues and Opportunities at U.S. Nuclear Power Plants
}

December 2010

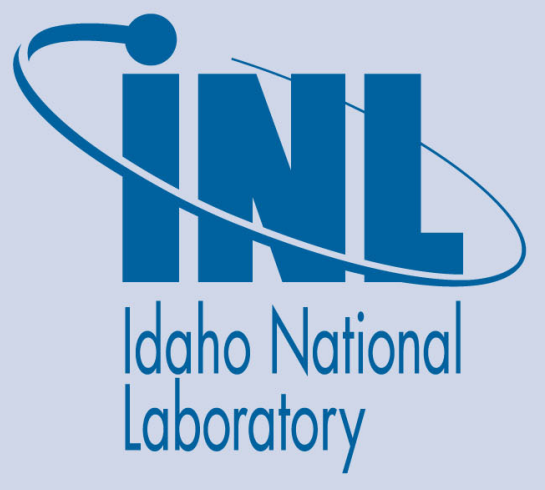

The INL is a U.S. Department of Energy National Laboratory operated by Battelle Energy Alliance 
INL/EXT-10-20208

Rev. 1

\title{
Cooling Water Issues and Opportunities at U.S. Nuclear Power Plants
}

December 2010

\author{
Idaho National Laboratory \\ Idaho Falls, Idaho 83415
}

http://www.inl.gov

Prepared for the

U.S. Department of Energy

Office of Nuclear Energy

Under DOE Idaho Operations Office

Contract DE-AC07-05ID14517 


\section{Cooling Water Issues and Opportunities at U.S. Nuclear Power Plants}

A Report to the U.S. Department of Energy Office of Nuclear Energy

December 2010

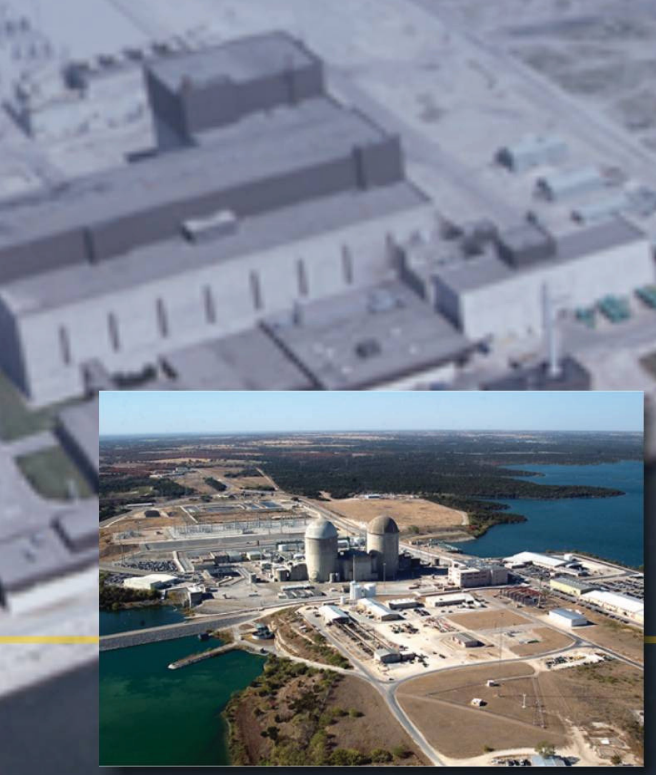




\title{
COOLING WATER ISSUES AND OPPORTUNITIES \\ AT U.S. NUCLEAR POWER PLANTS
}

\author{
A Report to the U.S. Department of Energy \\ Office of Nuclear Energy
}

Revision 1

December 2010 


\section{PURPOSE}

This report has been prepared for the Department of Energy, Office of Light Water Reactor Technologies within DOE's Office of Nuclear Energy (DOE-NE), for the purpose of providing a status report on the challenges and opportunities facing the U.S. commercial nuclear energy industry in the area of plant cooling water supply. The report was prompted in part by recent Second Circuit and Supreme Court decisions regarding cooling water system designs at existing thermo-electric power generating facilities in the United States (primarily fossil power plants and nuclear power plants). At issue in the courts have been Environmental Protection Agency regulations that define what constitutes "Best Technology Available" for intake structures that withdraw cooling water that is used to transfer and reject heat from the plant's steam turbine via cooling water systems, while minimizing environmental impacts on aquatic life in nearby water bodies used to supply that cooling water. The report was also prompted by a growing recognition that cooling water availability and societal use conflicts are emerging as strategic energy and environmental issues, and that research and development (R\&D) solutions to emerging water shortage issues are needed. In particular, cooling water availability is an important consideration in siting decisions for new nuclear power plants, and in evaluating the pros and cons of retrofitting cooling towers at existing nuclear power plants.

Because of the significant ongoing research on water issues already being performed by industry, the national laboratories and other entities, this report relies heavily on ongoing work. In particular, this report has relied on collaboration with the Electric Power Research Institute (EPRI), including its recent work in the area of EPA regulations governing intake structures in thermoelectric cooling water systems.

\section{ACKNOWLEGEMENTS}

In addition to the assistance and comprehensive reviews of drafts of this report by DOE and EPRI staff, the individual utility Points of Contact (POCs) at each nuclear utility were invaluable to the preparation of this report. These POCs provided data, insights, recommendations, and critical review of report drafts.

Prepared by: Gary Vine

Longenecker \& Associates

December, 2010 


\section{TABLE OF CONTENTS}

Executive Summary

1. Introduction

1.1 Water Issues at the Global Level

1.2 Water Issues in the United States: Key Players and Initiatives

1.3 Water Issues in the United States: Overview of Challenges

2. Background for Study

2.1 Relevant Facts on Nuclear Power in the United States

2.2 Basics on Water Withdrawal vs. Water Consumption, and on Once-Through Condenser Cooling vs. Closed-Cycle Condenser Cooling

2.3 Option for Dry Cooling as a Strategy to Address Cooling Water Issues

2.4 Intake and Discharge Structures to Supply and Return Water to/from Water Bodies

2.5 Comparison of Water Usage Rates Among Competing Forms of Electricity Generation

2.6 Comparison of Water Usage Rates Among Other Energy Sources (e.g., Transportation Fuels)

2.7 Electricity Use for Water Management

3. Federal Regulations on Clean Water and Relevant Court Decisions

3.1 The U.S. Environmental Protection Agency

3.2 The Clean Water Act: 1970 s to Date

3.3 The Role of the U.S. Nuclear Regulatory Commission

4. Categorizing U.S. Nuclear Power Plants Based on their Cooling Water Systems

5. EPRI Reports on § 316(b) Phase II Rule Impacts and Potential for Closed-Cycle Cooling Retrofit

6. Interviews with Nuclear Power Plant Experts

6.1 Cooling Tower Designs for Nuclear Power Plants

6.2 Condenser Re-Optimization as Part of Cooling Tower Retrofit Projects

6.3 General Comments Regarding Environmental Protection and Future R\&D Needs

6.4 Specific Comments, Organized by Cooling Water Situation 
7. Discussion: What Next after the U.S. Supreme Court Decision?

7.1 National Performance Standards

7.2 Restoration

7.3 Water Consumption

7.4 Short Term Planning Assumptions

8. Long Term Planning Assumptions and Strategic Priorities

8.1 Long Term Planning Assumptions: Estimating Freshwater Needs for Thermoelectric Generation

8.2 Long Term Planning Assumptions: Expansion of Nuclear Energy - National Picture

8.3 Siting of New Reactors

8.4 High Temperature Gas Reactor Considerations

8.5 Strategic Planning

9. Recommendations

9.1 Water Conservation and Siting Strategies, Including Appropriate Use of Once-Through Cooling

9.2 Energy/Water Nexus, Water Use Conflicts, and R\&D to Support Water-Related Policy Initiatives

9.3 Cooling System Technologies, including R\&D Opportunities

9.4 Alternate or "Non-Traditional" Sources of Cooling Water

9.5 Fish and Aquatic Species Protection; §316(B) Issues

9.6 Collaboration, Benchmarking, and Coordination Initiatives

9.7 Collaboration with Industry

Appendix A: U.S. Nuclear Reactor Listing, by Unit and by USGS Water Resource Region ...........A-1

Appendix B: U.S. Nuclear Reactor Listing, by Site and by Site Situation/Cooling Method ...........B-1

Appendix C: Summary Tabulation of Number of NPPs in Each Situation (per App. B).................-1

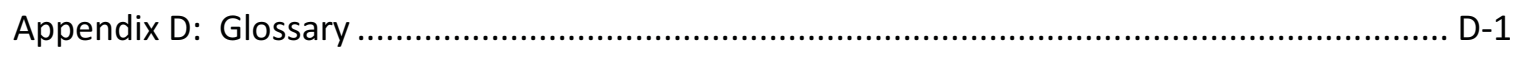

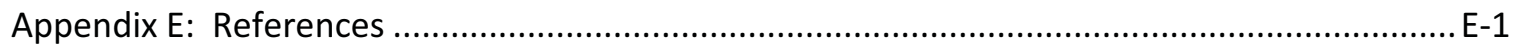

Attachment 1: "Program on Technology Innovation: Power Generation and Water Sustainability. Technical Brief - a Research Program for the Electric Power Industry," EPRI, Sept. 2007

Attachment 2: "Status and Outlook for Nuclear Energy in the United States," Nuclear Energy Institute, July 2010

Attachment 3: "Running Dry at the Power Plant," EPRI Journal, Summer 2007 


\section{LIST OF FIGURES}

Figure 1-1: Global Distribution of Water, from Energy Vision Update 2009 - "Thirsty Energy" (World Economic Forum \& CERA, Dec. 2008)

Figure 1-2: Excerpt from Energy Policy Act of 2005, Subtitle G--Science

Figure 1-3: Water Shortages and Population Growth (EPRI, 2003)

Figure 1-4: Survey of Likely Water Shortages over Next Decade under Average Conditions (GAO, 2003)

Figure 1-5: Estimated Fresh Water Consumption by Sector, 1995 (DOE, 2006)

Figure 1-6: Estimated Fresh Water Withdrawals by Sector, 2000 (DOE, 2006)

Figure 2-1: Average Capacity Factor by Energy Source, 2007

Figure 2-2: Typical Water Losses from Cooling Towers, at Varying Cycles of Concentration, EPRI

Figure 2-3: "Electricity Industry Value Chain - Water Consumption" (WEF, 2008)

Figure 3-1: The NPDES Permitting System (EPA Website)

Figure 4-1: USGS Water Resource Regions 


\section{LIST OF TABLES}

Table 1-1: Examples of Declining Groundwater Levels (DOE, 2003)

Table 2-1: Baseload Generation Production Costs by Technology, 2009

Table 2-2: Alternative Intake Structure Technologies for Minimizing Impacts on Aquatic Life

Table 2-3: Cooling Water Withdrawal and Consumption (Evaporation to the Atmosphere) Rates for Common Thermal Power Plant and Cooling System Types

Table 2-4: Water Intensity for Various Power Generation Technologies

Table 2-5: Water Consumption and Cooling Duty Factors for Thermoelectric Power Plants

Table 2-6: Non-Conventional Transportation Fuel Connections to Water (Source: Sandia National Lab)

Table 3-1: NRC Regulation Part 51: Category 2 Environmental Issues Requiring Site Specific Analysis

Table 4-1: Number of U.S. Reactors by USGS Water Resources Region

Table 4-2: Number of U.S. Nuclear Plant Sites, Organized by Cooling Water Situation

Table 4-3: Summary of U.S. Nuclear Power Plant Cooling System Types

Table 8-1: Case Descriptions for the Water Needs Analysis (NETL)

Table 8-2: Selected Regional Water Consumption Data from NETL Report 


\section{EXECUTIVE SUMMARY}

Energy and water are both essential to sustainable development and economic productivity. Ample supplies of water are essential to energy production, and water management is dependent on ample supplies of energy for water treatment and transportation. The critical nexus between energy and water has been recognized in a variety of recent studies, but the policy and regulatory machinery that this nexus depends on is not keeping up with the growing challenges.

Population growth and societal demand for improved quality of life will require more clean water for drinking and sanitation, more water for irrigation of crops to feed more people, expanding supplies of affordable and reliable energy to meet basic human needs and to enable substantial growth in industry and commerce. In contrast, the fresh water resources needed for the many aspects of sustainable development are limited and essentially un-expandable.

In future decades, this growing demand for fresh water and increasingly stressed water resources, along with a growing number of users competing for these resources, will lead to water use conflicts. Just as energy is increasingly seen as a national security issue, water resources will increasingly emerge as strategic assets that nations and sub-jurisdictions within nations will compete for and protect.

On both a global and national basis, the largest consumer of water is agriculture. Water taken from fresh water sources for irrigation is effectively lost to other purposes, such as municipal water supplies. Almost $85 \%$ of water consumption in the U.S. is dedicated to agriculture. In contrast, even though about $98 \%$ of U.S. electricity generation requires water for cooling or for direct use in generation, most of the water withdrawn for electricity production by the typical thermoelectric power plant is returned to the water body from which it was withdrawn, where it can be used again for other purposes. Only $3.3 \%$ of water consumption in the U.S. is dedicated to the cooling of thermoelectric power plants (i.e., plants that produce electricity by thermal processes, including nuclear plants, coal plants, and natural gas plants, most of which use steam-driven turbines to generate power). Note that if measured on the less relevant basis of water withdrawal rates instead of water consumption rates, thermoelectric plants take in (and return to the source water body) a much larger percentage of the total available fresh water.

On a gallon per megawatt-hour basis, nuclear energy currently uses slightly more water than comparable fossil-fired plants, in both the once-through cooling mode and the closed-cycle cooling mode. Nuclear energy consumes much more water than some sources of renewable energy, such as wind and photovoltaic solar, but generally less water than other sources of renewable energy, such as geothermal and concentrating solar. Retrofitting of emissions control systems on fossil plants are already increasing their water consumption rates. When fossil plants begin to deploy carbon capture and sequestration to reduce $\mathrm{CO}_{2}$ emissions, their water consumption rates will increase even more, with consumption rates exceeding those of nuclear energy. It is also important to note that most of the emerging technologies being advocated to reduce U.S. reliance on foreign sources of oil and gas (e.g., ethanol, bio-diesel, oil shale, hydrogen) are in fact heavy consumers of water, well in excess of traditional oil and gas production requirements. Clearly, there are no "silver bullets" when it comes to either energy production or water usage. 
The U.S. Congress recognized the importance of issues at the nexus of energy and water, and asked the Secretary of Energy in Dec. 2004 for "a report to Congress on the interdependency of energy and water, focusing on the threats to national energy production resulting from limited water supplies..." A similar request was repeated in the Energy Policy Act of 2005. These requests resulted in a December 2006 Report to Congress from DOE entitled "Energy Demands on Water Resources: A Report to Congress on the Interdependency of Energy and Water." That report discussed a parallel effort to prepare an action plan - an Energy-Water Research and Development (R\&D) Roadmap, a draft of which is currently under review at DOE.

Both the U.S. Environmental Protection Agency (EPA) and the U.S. Nuclear Regulatory Commission (NRC) provide regulatory oversight over nuclear plant environmental matters, including water. In addition, state water authorities provide oversight over each power plant within its jurisdiction, via the National Pollutant Discharge Elimination System (NPDES) permitting process managed by the EPA and implemented by delegated states.

\section{Clean Water Act}

Recently built thermoelectric plants are required by the Federal Clean Water Act (CWA) (as interpreted and implemented by the EPA, state permitting authorities and the courts), to achieve environmental protection of aquatic species in the plant's source water body equivalent to closed-cycle cooling. Closed-cycle cooling is achieved through the use of cooling towers or cooling ponds that reject heat to the atmosphere, predominantly by means of evaporation. Closed-cycle cooling actually consumes significantly more water than traditional "once-through" cooled plants, which simply return the water to its source about $10-20^{\circ} \mathrm{F}$ warmer. In closed-cycle systems, the majority of heat rejection is through evaporation of the circulating water. Today, $60 \%$ of the 104 operating U.S. reactors use once-through cooling; $40 \%$ use closed-cycle cooling. All new plants proposed to date will use closed cycle cooling.

The CWA addresses water usage and pollutant discharge for all users, including thermoelectric power plants. Section 316(a) addresses thermal discharge to U.S. waters, and provides for a variance process for thermal discharge limits established elsewhere in the CWA, and by state or regional permitting authorities. Section 316(b) of the CWA addresses water intake structures, by requiring that the location, design, construction and capacity of cooling water intake structures reflect the best technology available for minimizing adverse environmental impact. Cooling water intake structures can potentially cause adverse environmental impacts by passing fish and shellfish or their eggs through a power plant's cooling system ("entrainment"). There, small organisms may be killed or injured by heat, physical stress, or by chemicals used to clean and protect the cooling system. Larger organisms may be killed or injured when they are trapped against screens at the front of an intake structure ("impingement").

Three relatively recent CWA § 316(b) rulemaking phases by EPA address cooling water intakes:

- Phase I rule, promulgated in 2001, covers new facilities

- Phase II rule, promulgated in 2004, covers large existing electric generating plants

- Phase III rule, promulgated in 2006, covers certain existing facilities and new offshore and coastal oil and gas extraction facilities. 
The Phase I rule requires new facilities to meet closed-cycle cooling standards of environmental protection, as discussed above. However, the 2004 Phase II rule did not require existing electric generating plants that currently use once-through cooling to shift to closed-cycle cooling, for a number of reasons, including the site-specific difficulties in retrofitting cooling towers at a once-through-cooled facility, as well as cost considerations (retrofits technically and economically unjustified). Instead, the Phase II rule specified national performance standards and provided for a combination of technology options to reflect the best technology available (BTA), including relocation of intakes, fine mesh passive screens, double-entry single-exit traveling screens, velocity caps, and barrier nets, as alternatives to closed cycle cooling.

The Phase II rule was challenged in the courts. In January 2007, the Second Circuit Court of Appeals reversed and remanded virtually all of the important features of the Phase II regulation. The industry and several states successfully sought review of the Second Circuit decision by the U.S. Supreme Court. The Supreme Court granted certiorari in April 2008, but limited its review to the question of EPA's authority to conduct a cost-benefit analysis. Oral arguments were made before the Supreme Court in December 2008, and the court issued its decision in April 2009. In a 6-3 decision, the Supreme Court "conclude[d] that the EPA permissibly relied on cost-benefit analysis in setting the national performance standards and in providing for cost-benefit variances from those standards as part of the Phase II regulations." ... "The judgment of the Court of Appeals is reversed and the cases are remanded for further proceedings consistent with this opinion."

It is important to note that the Supreme Court did not mandate the use of cost-benefit analysis by EPA in decision-making under $\S 316(\mathrm{~b})$. Rather, it said that the EPA is allowed to use cost-benefit analysis in deciding what cooling water intake structure features are used by operating thermoelectric plants.

The Electric Power Research Institute (EPRI), which has conducted research on a broad range of cooling water issues for several decades, including technologies that address impingement and entrainment of fish and shellfish, was asked by member companies to examine in closer detail the potential impacts on the utility industry from a potential requirement to retrofit closed-cycle cooling towers on all existing U.S. fossil and nuclear plants that come under the Phase II rule. The goal was to develop accurate, upto-date and objective data that EPA could use in its rulemaking process. Five projects were chartered, to address the costs of retrofitting, a quantification of adverse environmental and social impacts associated with closed-cycle cooling compared to impingement and entrainment losses, a study of impacts on energy production and supply including the risks of facility closure, impacts on transmission system reliability resulting from such closures, and environmental benefits and costs of retrofitting.

Nuclear Utility Expert Interviews: Clean Water Act Implementation and Longer Term Strategic Issues

Given the importance of these ongoing EPRI studies to this assessment of cooling water issues at nuclear power plants, DOE and EPRI agreed to collaborate on some aspects of data collection and analysis in support of this report. With the assistance of EPRI's Chief Nuclear Officer and EPRI's Nuclear Power Council, Points of Contact (POCs) were identified for each U.S. nuclear power plant for the purpose of supporting the development of this report. Most POCs were plant experts in environmental 
management, plant cooling water systems or both. Nuclear power plant POCs were asked to provide plant data, and to discuss possibilities for near term and longer term actions, including R\&D, that might be appropriate for industry, DOE, or both, which could assist industry in meeting compliance obligations, addressing anticipated challenges in water availability and management, etc. The results of these interviews are summarized in this report and were used extensively in developing recommendations.

The context for this report on water issues at nuclear power plants is the expectation that nuclear energy will continue to be a critical part of the nation's energy supply and that it will be called upon increasingly in the years ahead to provide affordable and emission-free baseload electricity to meet increased demand. Nuclear energy generates $20 \%$ of U.S. electricity, without generating air pollution or greenhouse gases, and accounts for over $70 \%$ of all emission-free electricity generated in the United States. Nuclear energy is also the lowest cost producer of baseload electricity in the United States.

Nuclear energy is increasingly being viewed as an essential element of national and global energy plans to reduce reliance on fossil fuels, a necessary step in addressing concerns over potential global warming. Emission-free nuclear energy is poised to expand in the U.S., with applications for 22 new reactors before the NRC for review and approval. However, siting of new reactors in the U.S. to support projected growth in nuclear energy will be very challenging, in large part because of limitations on water use by new plants that make it difficult to site new reactors in key regions of the U.S. (e.g., coastal zones), as well as in regions where the increased water consumption rates of closed-cycle cooling are a problem - primarily the Southern U.S., stretching from California through the Southwest and Texas, to Florida. Unfortunately, these regions with concerns over water consumption are also the regions predicted to experience the greatest population growth and increased energy demand in the decades ahead. These new plant siting issues have brought into focus a strategic issue that will grow in importance in the years ahead - conflicts among societal users over the consumptive use of water.

\section{$\underline{\text { Recommendations }}$}

A number of recommendations are offered to address challenges associated with energy-water use conflicts, growing concern over the consumptive use of water by thermoelectric power plants, new plant siting, etc. These recommendations focus on the need for comprehensive research to address a range of technology approaches to minimizing nuclear power plant cooling water issues. They also address a range of broader strategic study needs, decision methodology development efforts, and collaborative initiatives with other strategic partners to improve water management and conservation. $R \& D$ programs need to produce flexible decision methodologies that can determine which approaches work best for various types of water bodies in various regions of the country, and then advance the most promising technologies to improve their performance, minimize their adverse impacts on plant reliability, and resolve their implementation obstacles for application in untested configurations and environments. These methodologies should recognize and factor into decision processes the fact that environmental impacts are typically negligible when the affected water body is considered holistically.

The Report's primary recommendation addresses the need for a decision methodology for energy-water interface issues that could help decision-makers weigh the competing environmental goals of clean air, 
clean water, climate change mitigation and other relevant national objectives associated with energy supply. Such a methodology could be applied by national and state decision makers to the technology choices associated with CWA § 316(b) implementation, as well as to other decision processes (e.g., generation technology policy incentives) that need a more holistic and science-based evaluation of energy-water conflicts and trade-offs.

This report suggests continuation and expansion of existing research into alternate or "non-traditional" sources of cooling water for thermoelectric power plant cooling, such as brackish water, saline aquifers, reclaimed municipal ("gray") water effluent, "produced" water from energy production (oil and gas wells and mine pool water in abandoned coal mines), irrigation run-off, etc. - with a focus on which options are most promising for specific regions of the country.

Regarding new plant siting, this report suggests a study of siting options in coastal regions where thermoelectric power plant siting is becoming increasingly difficult, as well as a re-examination of the relative advantages of closed-cycle cooling vs. once-through cooling on the Great Lakes - a region with growing concerns over the water consumption rates associated with industrial operations. As a related matter, Federal agencies should work with state agencies and industry on drought mitigation planning, to better assure continued delivery of electricity in the case of severe drought.

In anticipation of the inevitable growth in collaboration between electric utilities and water utilities, as well as the agencies that regulate both, this report recommends collaborations among these entities, which could then foster local and regional water conservation initiatives and integrated resource planning. Similarly, collaborations among state permitting authorities are recommended, with a focus on energy security and reliability matters, assisted by industry.

Much of the work on water issues facing the electricity industry is being done by the private sector. In many cases, this should continue, based on the short-term nature of the R\&D or the need for close interactions with and among plant operators. However, the growing challenges at the intersection of energy and water issues demands more timely and coordinated action, particularly at the policy and regulatory level, and particularly in situations where pursuit of single issues or single solutions have created conflicting strategies or unintended consequences with impacts on energy security.

Given the research work to date by industry (primarily EPRI), as well as the national laboratories and some universities, it is important to thoroughly understand what has already been done, what is underway, and what remains to be done before embarking on new or expanded R\&D.

As is the case with many areas of strategic R\&D in the energy field, the necessary work on the energywater nexus would benefit greatly from joint planning between public and private sector researchers and research sponsors, in order to understand and build consensus on research priorities and timing of needs, to avoid R\&D gaps or duplication of effort, and to better coordinate demonstration and technology transfer. DOE and industry would also benefit from reaching agreement on which areas of research are best handled by industry, which areas are best handled by government, and which areas present opportunities for joint efforts, including cost-sharing and technology transfer demonstrations. 
ES-6 


\section{INTRODUCTION}

With increased attention to energy and environmental issues by policy leaders in both government and industry around the world, it is important to focus greater attention to one of the most critical resources at the nexus of energy and environmental policy - water.

Ample supplies of water are critical to energy production, and water management is dependent on ample supplies of energy for water treatment and transportation. The critical nexus between energy and water has been recognized in recent studies as essential to sustainable development, but the policy and regulatory machinery that this nexus depends on is not keeping up with the growing challenges.

\subsection{Water Issues at the Global Level}

Consider the following facts, presented first at a global level, followed by a focus on the United States:

- Population growth and societal demand for improved quality of life will require more clean water for drinking and sanitation, more water for irrigation of crops to feed more people, expanding supplies of inexpensive and reliable energy to meet basic human needs, and to enable growth in industry and commerce. For example, a recent report by DOE's Energy Information Administration (EIA) estimates that world energy consumption will grow by $49 \%$ between 2007 and $2035 .{ }^{1}$

In contrast, fresh water resources are limited and essentially un-expandable. Although $3 / 4$ of the earth's surface is covered with water, only $3 \%$ of global water resources are "fresh" and available for human use. Nearly $70 \%$ of that fresh water is locked away in glaciers and icecaps, leaving less than $1 \%$ of the earth's water available for human use. ${ }^{2}$ In many countries, the damming of rivers to store fresh water in reservoirs is well developed, leaving limited opportunities to expand storage capacity.

Figure 3

Global Distribution of Water

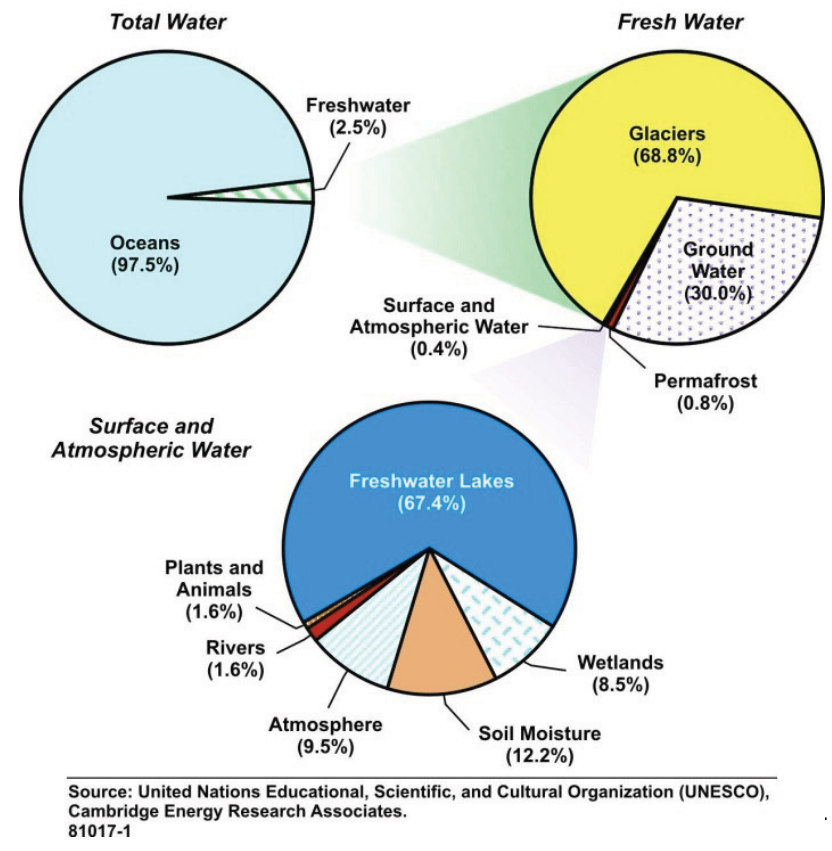

Figure 1-1: Global Distribution of Water, from Energy Vision Update 2009 - "Thirsty Energy" (World Economic Forum \& CERA, Dec. 2008)

"Take one world already being exhausted by 6 billion people. Find the ingredients to feed another 2 billion people. Add demand for more food, more animal feed and more fuel. Use only the same amount of water the planet has had since creation. And don't forget to restore the environment that sustains us. Stir very carefully."

Margaret Catley-Carlson

Patron Global Water Partnership, 2008-2009 Chair of World Economic Forum Global Agenda Council on Water Security 
- Rainwater and runoff are unevenly distributed, and water resources are not always present in those regions of the world where the needs are greatest. As a result, many regions of the world are already stressed by water scarcity - at levels well below human needs. Regions of the world with the greatest water stress include North Africa, Central Asia (stretching from the Middle East through Pakistan, India, Mongolia and North China), and the United States, particularly the Southwestern states stretching from California to Texas, plus Florida.

- In future decades, this mismatch between growing demand for fresh water and increasingly stressed water resources will lead to water use conflicts among competing societal users - a problem that is becoming acute in densely populated areas. Water resources are emerging as a top geopolitical issue. "Water is the oil of the $21^{\text {st }}$ Century" declares Andrew Liversis, CEO of Dow Chemical Co. ${ }^{3}$ Just as energy is increasingly seen as a national security issue, water resources will increasingly emerge as strategic assets that nations and sub-jurisdictions within nations will compete for and protect.

- At the World Economic Forum held on 24 January 2008, Ban Ki-moon, Secretary General of the United Nations, pledged action on water resources. "Our experiences tell us that environmental stress, due to lack of water, may lead to conflict, and would be greater in poor nations." The Secretary-General cited a recent report by International Alert identifying 46 countries, home to 2.7 billion people, where climate change and water-related crises create a high risk of violent conflict.

- Water is difficult and expensive to transport in large quantities. As a result, water management is an inherently local matter. In contrast, managing other environmental issues (e.g., greenhouse gases) can be done on a more regional or even global basis. With regard to the energy-water nexus, it is less expensive to locate energy production facilities (e.g., thermoelectric power plants for generating electricity, refineries for creating fossil fuels, agricultural lands for production of biofuels) close to the water supplies needed for these processes and then transport the resulting electricity and transportation fuels to the population centers where they are needed - than to transport water over long distances to energy facilities positioned closer to end-users.

- On both a global and national basis, the largest consumer of water is agriculture. Water taken from fresh water sources for irrigation is effectively lost to other purposes, such as municipal water supplies. In contrast, most of the water withdrawn for electricity production by thermal power plants that have been operating for decades is returned to the water body from which it was withdrawn, where it can be used again for other purposes. Recently built thermoelectric power plants that use closed-cycle cooling intended to achieve better protection of aquatic species actually consume significantly more water than traditional "once-through" cooled plants, because most of the cooling water is lost to evaporation. (Details on water withdrawal vs. water consumption, and open vs. closed cooling cycles are presented later.)

Two of the best recent studies on the coming global crisis over water and on energy and water issues on a global scale have been published by the World Economic Forum (WEF). Both are available at http://www.weforum.org/en/index.htm. Spokesmen for the WEF Initiative on Water quoted on this 
website predict that "we will run out of water long before we run out of fuel," and that "the seriousness of the water crisis will impinge on our lives much earlier than climate change."

The two World Economic Forum studies are:

- "Energy Vision Update 2009 - Thirsty Energy: Water and Energy in the $21^{\text {st }}$ Century," Dec. 2008

- "Managing Our Future Water Needs for Agriculture, Industry, Human Health and the Environment: The Bubble Is Close to Bursting: A Forecast of the Main Economic and Geopolitical Water Issues Likely to Arise in the World during the Next Two Decades," Jan. 2009.

To summarize the global picture, the following quote is taken from the second reference's "Overview:"

"Water security is the gossamer that links together the web of food, energy, climate, economic growth and human security challenges that the world economy faces over the next two decades.

There is a structural problem in how we manage water across the web of our global economy. Worsening water security will soon tear into various parts of the global economic system. It will start to emerge as a headline geopolitical issue. The volatility in food prices in 2008 should be treated as an early warning sign of what is to come.

In many places around the world, we have consistently under-priced water, wasting and overusing it as a result. We have depleted stocks of groundwater at the expense of our future water needs. In effect, we have enjoyed a series of regional water "bubbles" to support economic growth over the past 50 years or so, especially in agriculture. We are now on the verge of water bankruptcy in many places with no way of paying the debt back. In fact, a number of these regional water bubbles are now bursting in parts of China, the Middle East, and the southwestern US and India; more will follow. The consequences for regional economic and political stability will be serious.

This set of regional challenges becomes a fast approaching global crisis, when placed against future needs for water. As the world economy expands, demand for water will rise and continue to outpace population growth. This means that there will not be enough water to do all the things we want as inefficiently as they are done now. Unlike energy, water has no substitutes or alternatives. We simply cannot manage water in the future as we have in the past or the economic web will collapse."

\subsection{Water Issues in the United States: Key Players and Initiatives}

The U.S. situation regarding water resources and water usage largely parallels the global picture cited above. Water use conflicts are growing in number across the U.S., no longer limited to the Southwest. Groundwater aquifers are being depleted, and recent drought conditions, particularly in the Southeast, have highlighted the challenges we face in the U.S. in the management of precious water resources. Although this report focuses on the nexus between energy and water in the U.S., the backdrop for this energy-water interface includes the broader demands on water from all users, particularly agriculture, as well as the connections between water management and clean air, climate change mitigation, and other environmental issues. In short, energy-water issues cannot be managed in isolation. 
Before reviewing the water resource situation in the U.S., it's appropriate to review the recent efforts by government and industry to examine the issues and bring recommendations to policymakers for action.

The U.S. Congress recognized the importance of the energy-water nexus in the U.S. when it asked the Secretary of Energy in Dec. 2004 for "a report to Congress on the interdependency of energy and water, focusing on the threats to national energy production resulting from limited water supplies, utilizing where possible the multi-laboratory Energy-Water Nexus Committee." This letter request to DOE came from the chairmen and ranking members of the House and Senate Subcommittees on Energy and Water Development Appropriations. (A similar request was repeated in the Energy Policy Act of 2005, Section 979 (see next page)). The request resulted in a report to Congress from DOE entitled "Energy Demands on Water Resources: A Report to Congress on the Interdependency of Energy and Water," dated December 2006. This report is an excellent study of the various conflicts and regional needs in all areas of energy production, and was a primary resource for this report. It is worth noting that the Congressional committee structures that link energy and water issues in both the House and Senate are a fortuitous arrangement that has helped highlight the interdependencies of energy and water.

The process that followed the Congressional request for this study of threats to national energy production led to a wide-ranging effort in 2005-2006 to collect information from experts across the country through the use of regional workshops and extensive outreach to all stakeholders. This effort was managed by the National Laboratories (Sandia coordinated), through the DOE. About 350 participants from 40 states attended the workshops, representing energy companies, electric utilities, water utilities, regional, state and local water managers, energy regulators, environmental groups, etc. The intent of this effort was to produce two reports, one focused on defining the issues and needs (the Report to Congress) and one focused on an action plan (the Energy Water Roadmap). The workshops were completed in late 2006 and the Report to Congress was issued shortly thereafter. The Roadmap was drafted and submitted to DOE for approval in early 2007, but never published. In addition to the joint national lab effort described above, many of the national labs have pursued additional projects aimed at the energy-water interface. The National Energy Technology Laboratory (NETL) has been quite aggressive over the last few years in this area. Although NETL is focused primarily on fossil energy matters, it has done work on water issues that is relevant to U.S. nuclear power plants. Finally, many of the nation's colleges and universities are pursuing programs on water availability, quality and use some exploring the energy-water nexus. These university programs are very important, because they tend to focus on local, state and regional perspectives. 


\section{Figure 1-2: Excerpt from Energy Policy Act of 2005, Subtitle G--Science}

\section{SECTION 979, ENERGY AND WATER SUPPLIES}

(a) IN GENERAL. - The Secretary shall carry out a program of research, development, demonstration and commercial application to-

(1) Address energy-related issues associated with provision of adequate water supplies, optimal management, and efficient use of water

(2) Address water-related issues associated with the provision of adequate supplies, optimal management and efficient use of energy, and

(3) Assess the effectiveness of existing programs within the Department and other Federal agencies to address these energy and water related issues

(b) Program Elements. - The program under this section shall include-

(1) Arsenic treatment

(2) Desalination

(3) Planning, analysis, and modeling of energy and water supply demand

(c) CollabORATION. - In carrying out this section, the Secretary shall consult with the Administrator of the Environmental Protection Agency, the Secretary of the Interior, the Chief Engineer of the Army Corps of Engineers, the Secretary of Commerce, the Secretary of Defense, and other Federal agencies as appropriate.

(d) FACILITIES. - The Secretary may utilize all existing facilities within the Department and may design and construct additional facilities as needed to carry out the purposes of this program.

(e) AdVISORY COMMITTEE. - The Secretary shall establish or utilize an advisory committee to provide independent advice and review of the program.

(f) REPORTS. - Not later than 2 years after the date of enactment of this Act, the Secretary shall submit to Congress a report on the assessment described in subsection (b) and recommendations for future action.

More recently, DOE's Office of Electricity Delivery and Energy Reliability (DOE-OE) issued a report entitled "Electricity Reliability Impacts of a Mandatory Cooling Tower Rule for Existing Steam Generation Units" (October 2008). ${ }^{4}$ The report was requested by the Senate Committee on Appropriations, Subcommittee on Energy and Water Development. DOE was requested "... to examine the impacts on electricity reliability of requiring existing steam generators using once-through cooling systems to replace those systems with closed-cycle cooling towers to condense and to cool the steam after its use in the generation of electricity."

The report is a two-part study including an analysis conducted by DOE's Office of Electricity Delivery and Energy Reliability and a white paper prepared by the North American Electric Reliability Corporation (NERC) ${ }^{1}$. The two-part study examines the national and regional impact to capacity margins of retrofitting cooling towers at existing once-through cooling generation facilities, and

\footnotetext{
${ }^{1}$ Previously the North American Electric Reliability Council. It transitioned to the NER C[orporation] in 2007.
} 
outline the major impacts to energy supply and efficiency as a result of energy penalties, outages, retirements and feasibility issues. Most importantly, it points out the potentially significant impact to reliability for many parts of the U.S. Specifically, DOE concludes that generation losses resulting from a mandatory cooling tower requirement would exacerbate a potential decline in electric generation reserve margins that are needed to ensure reliable delivery of electricity. Note that two of the EPRI reports discussed in Chapter 5 address similar generation loss and grid reliability issues.

Other recent U.S. Government initiatives on water issues include:

An inter-agency report published in Sept. 2007: "A Strategy for Federal Science and Technology to Support Water Availability and Quality in the United States." The Office of Science and Technology Policy (OSTP) coordinated this project, through its Subcommittee on Water Availability and Quality (SWAQ), which reports to the National Science and Technology Council's Committee on Environment and Natural Resources. Twelve Federal Agencies participated, including DOE, EPA, Interior, Agriculture, Commerce, TVA and others. This report does an excellent job of describing the water resource challenges facing the U.S. and identifying programmatic and science-based responses. Energy needs are discussed briefly in the study, which focuses primarily on broader issues centered on three "challenges:"

1. Measure and account for the nation's water

2. Develop methods that will allow expansion of fresh water supplies while using existing supplies more efficiently

3. Develop and improve predictive water management tools.

An Appendix in this inter-agency report describes the role of each Federal Agency with regard to the science and technology of water availability and quality.

Much of the work being done to meet challenges \#1 and \#3 above comes under the responsibility of the Dept. of Interior, and specifically the U.S. Geological Survey (USGS). USGS is undertaking a "Water for America" initiative, described on their website, http://water.usgs.gov/wsi. One of the systems that the USGS maintains is a mapping process that segments the U.S. into "water-resource regions." One of the "sorts" of U.S. nuclear power plants provided in Chapter 4 is by these USGS regions.

Both the U.S. Environmental Protection Agency (EPA) and the U.S. Nuclear Regulatory Commission (NRC) provide regulatory oversight over nuclear plant environmental matters, including water. In addition, delegated state water agencies provide oversight over each power plant within its jurisdiction, via the National Pollutant Discharge Elimination System (NPDES) permitting process, which operates under the EPA's authority. The respective roles of these organizations and their regulatory processes are discussed in more detail in Chapter 3.

Most of the industries impacted by water issues are heavily engaged in making sure their industry's needs are understood and addressed in scientific, technological, policy and economic circles. These include agricultural, mining, petrochemical, energy, municipal water suppliers and other stakeholders. Equally active are a variety of environmental organizations at both the regional and national level that focus either directly on water issues or indirectly via their intervention in specific stakeholder areas such 
as energy. This report focuses on industry activities on the water issue as they relate directly to electricity generation or broader energy issues that indirectly impact on electricity generation (e.g., climate change). Activities of environmental organizations are discussed in this report only to the extent that they impact directly on electricity industry and government decision making relative to the Clean Water Act (CWA; see Chapter 3).

Most of the industry research activities on water that impact electricity generation are managed by the Electric Power Research Institute (EPRI). EPRI maintains four programs in Water and Sustainability:

- Water Quality Criteria Development and Assessment

- Fish Protection at Steam Electric Power Plants

- Water Strategic Issues

- Effluent Guidelines and Water Quality Management

EPRI has published a number of reports on water issues over the last three decades, and prepared a detailed program plan in 2007, "Program on Technology Innovation: An Energy/Water Sustainability Research Program for the Electric Power Industry." ${ }^{5}$ This report is based on extensive interviews and workshops with stakeholders and is available publicly on the EPRI website. A 4-page summary of the EPRI program (Technical Brief) is included as Attachment 1. The EPRI research program relative to the CWA is discussed in more detail in Chapter 5.

Investor-owned electric utilities are also represented on water issues (primarily in the legislative area) by the Edison Electric Institute (EEI), an association of U.S. shareholder-owned electric companies throughout the U.S. EEI members serve $95 \%$ of the ultimate customers in the shareholder-owned segment of the industry, and represent approximately $70 \%$ of the U.S. electric power industry. EEI has more than 65 International electric companies as Affiliate members, and more than 170 industry suppliers and related organizations as Associate members.

All utilities that own or operate nuclear energy plants, as well as other companies involved in nuclear energy, are represented by the Nuclear Energy Institute (NEI). NEI is the policy organization of the nuclear energy and technologies industry and participates in both the national and global policy-making process. NEl's objective is to ensure the formation of policies that promote the beneficial uses of nuclear energy and technologies in the United States and around the world. NEI has nearly 350 members in 19 countries. Members' businesses span the range of commercial nuclear technologies.

NEI filed amicus briefs in the CWA cases that are discussed in Chapter 3, and recently issued a report on water issues, "Water Use, Electric Power and Nuclear Energy: A Holistic Approach to Environmental Stewardship" (June 2009). ${ }^{6}$

The Utility Water Act Group (UWAG) is an ad hoc group industry group established in 1973 supporting legally sound, science-based, and cost-effective implementation of the CWA and other relevant water quality statutes. UWAG members include approximately 218 energy generation and/or transmission companies and three energy industry trade associations. Primarily, UWAG responds to and aids in the development of the Environmental Protection Agency's rulemakings, guidance, and policy under the 
CWA. It appeals in court such rulemakings and policy when necessary. Also, it focuses on the source of regulatory action by tracking and interpreting legislative activities. UWAG coordinates with other energy regulatory groups and industry trade associations in order to integrate, not duplicate, industry efforts. UWAG relies to a large extent on the research conducted by EPRI as a source of technical information relative to impingement and entrainment impacts and fish protection technologies including closed-cycle cooling. UWAG also participates actively in the EEI Water Resources Subcommittee.

\subsection{Water Issues in the United States: Overview of Challenges}

The following is a short synopsis of key facts and concerns for the U.S. from the above-cited references:

- Water shortages and water use conflicts are on the rise. Such shortages and conflicts have been part of life in the Southwestern U.S. for decades - a situation that has influenced water projects in the western states for close to a century. However, the 2007 drought in the Southeast and similar recent regional shortages elsewhere have highlighted water resources as a national issue. The Southeast drought forced several nuclear plants in the region to reduce their output, one of them by up to 50\%. ${ }^{7}$ A similar but more "...severe drought in France in 2003 caused the loss of up to 15\% of nuclear generation capacity for five weeks and a loss of $20 \%$ of their hydro-power capacity." ${ }^{8}$

- The primary national strategy for managing surface water supplies has been the construction of dams and reservoirs, with more than 79,000 dams in the country today. However, few new large reservoirs have been built since $1980 .^{9}$

- In 1980, major reservoirs in the U.S. were full. However, since then, droughts have caused some reservoir levels to decline, particularly in the West, and water managers have had to limit water withdrawals. ${ }^{10}$

- Lake Mead, which provides water and electricity to regions surrounding Las Vegas, Nevada, is 100 feet lower than historic levels - if it dropped another 50 feet, the city would have to ration water use, and the huge hydroelectric turbines inside the Hoover Dam on the lake would provide little or no power. Scientists at the Scripps Institution of Oceanography (UC San Diego) recently declared that Lake Mead could become dry by 2021. ${ }^{11}$ Many Western Cities, including Los Angeles, Phoenix, Salt Lake City, Denver, etc. will face serious water shortages in the years ahead.

- Withdrawals already exceed precipitation in many areas across the country, as illustrated in Figure 1-3. The figure shows the ratio of total freshwater withdrawals in all counties in the U.S. divided by available precipitation (precipitation minus evapo-transpiration) shown as a percentage. The figure provides an indication of the areas where current water demands are being met with significant groundwater pumping or transport of surface water from other locales. ${ }^{12}$ 


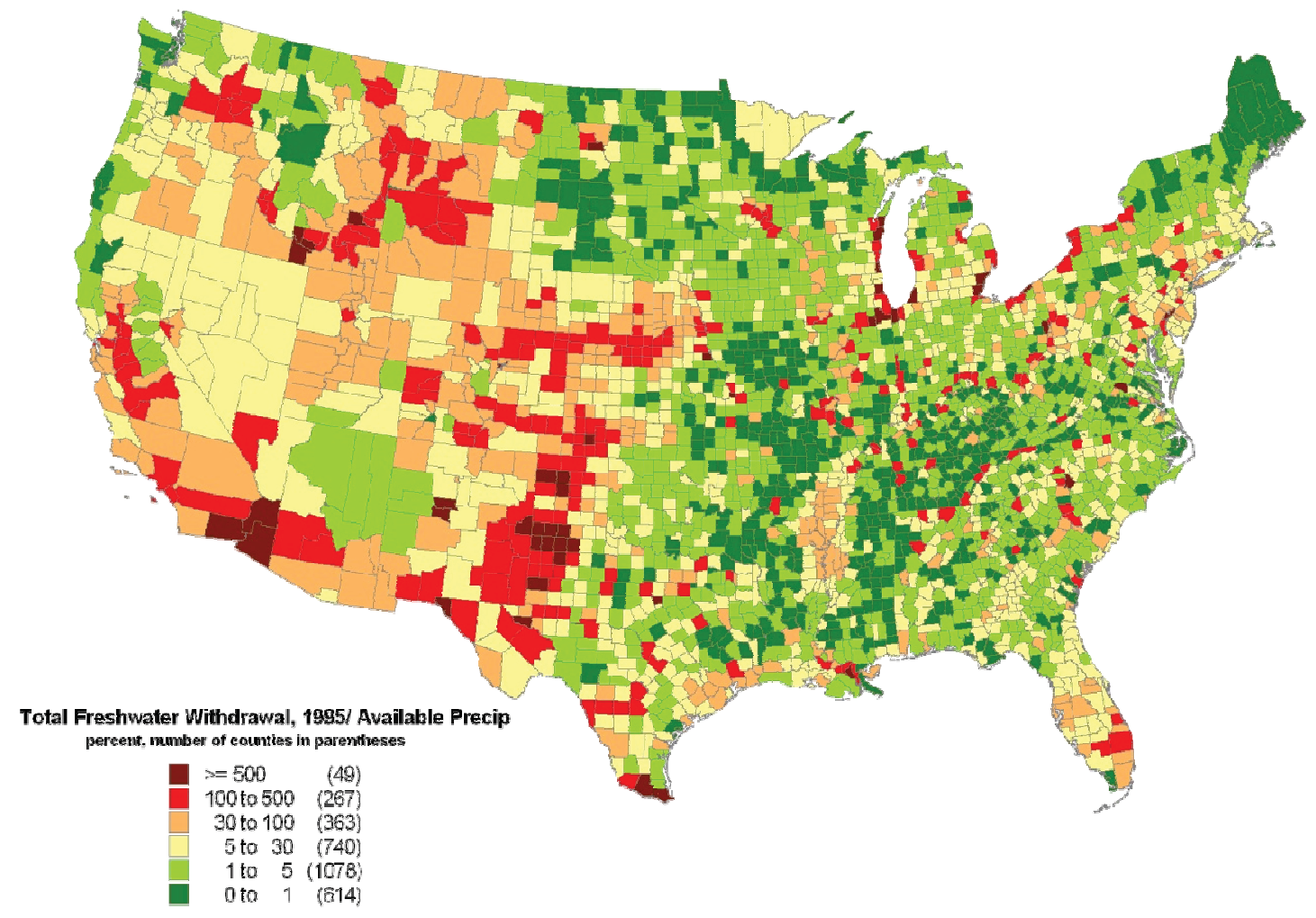

Figure 1-3. Water Shortages and Population Growth (EPRI, 2003)

Water shortage is defined as total freshwater withdrawal divided by available precipitation.

- The shortfalls are most dramatic in the Southwest, in the high plains, in California, and in Florida. Population growth in these regions between 2000 and 2025 is estimated to be 30 to $50 \%$. This additional population will place an increased demand on water and energy, given current trends in energy and water use efficiency. ${ }^{13}$

- Most state water managers expect shortages of water over the next decade, as shown in Figure 1-4 below. These include statewide, regional, and local shortages. (Note that some states that did not respond, especially California and other western states, face serious water shortages.) 

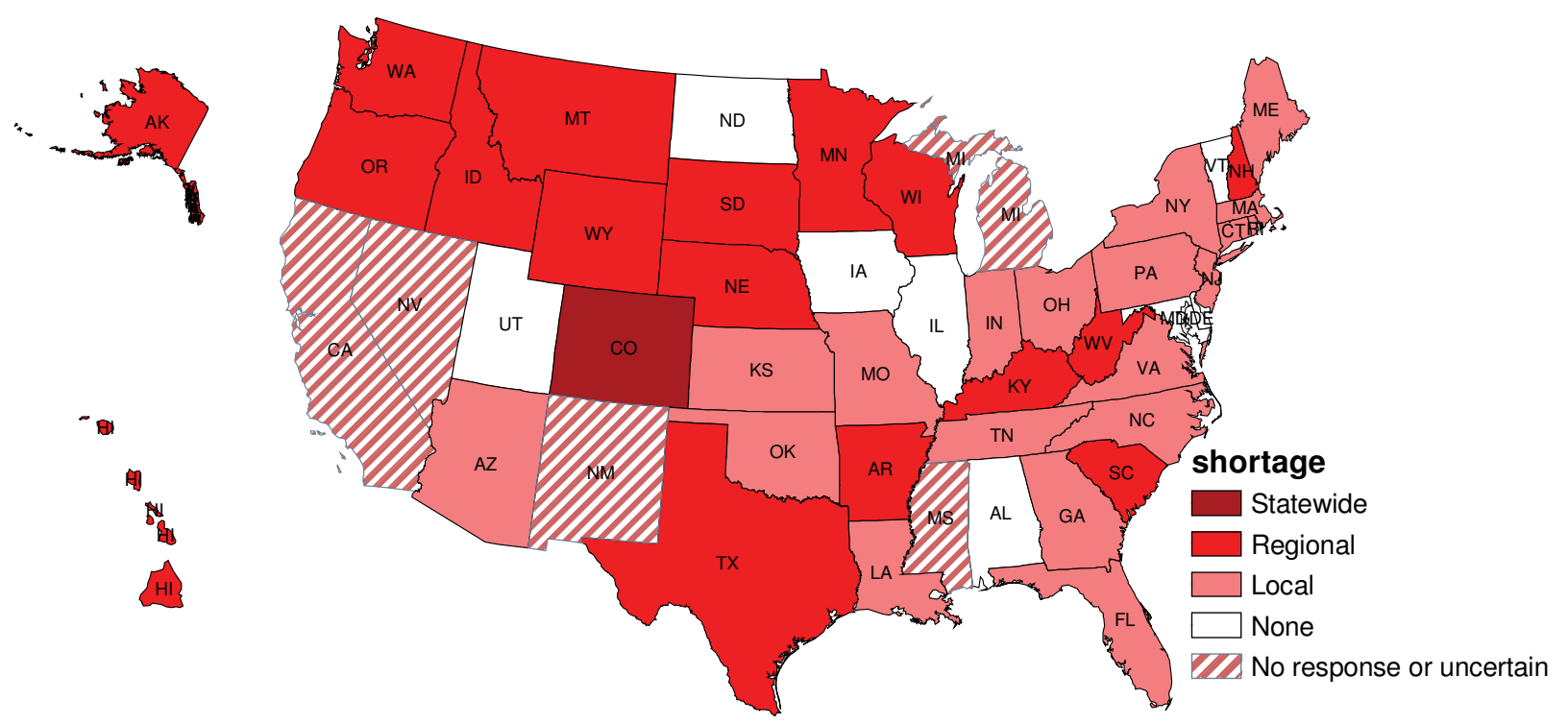

Figure 1-4: Survey of Likely Water Shortages over Next Decade under Average Conditions (GAO, 2003)

- The challenges are not limited to these regions, however. For example, EPRI data show that nearly the entire western shoreline of Lake Michigan has water demand above available precipitation. Since surface water supplies have not increased in 20 years, suppliers in many parts of the U.S. are forced to pump more groundwater to meet demand. Groundwater levels along the SW shores of Lake Michigan have declined hundreds of feet since predevelopment; and by 1980 had reached maximum withdrawals of up to 900 feet near Chicago. While subsequent relocation of withdrawals has caused groundwater levels near Chicago to rise several hundred feet, levels were declining as much as 17 feet per year in 2003 in some locations. ${ }^{14}$ See Table 1-1 for examples of other declining groundwater levels, as of 2003.

Table 1-1: Examples of Declining Groundwater Levels (DOE, 2003) ${ }^{15}$

\begin{tabular}{|l|l|}
\hline Region & Groundwater Decline \\
\hline Long Island, NY & Water table declined, stream flows reduced, salt water moving inland \\
\hline West-central Florida & $\begin{array}{l}\text { Groundwater and surface water declined, salt water intruding, sink } \\
\text { holes forming }\end{array}$ \\
\hline Baton Rouge, LA & Groundwater declined up to 200 feet \\
\hline Houston, TX & Groundwater declined up to 400 feet, land subsidence up to 10 feet \# \\
\hline Arkansas & Sparta aquifer declared "critical" \\
\hline High Plains & $\begin{array}{l}\text { Groundwater declined up to } 100 \text { feet, water supply (saturated } \\
\text { thickness) reduced over half in some areas }\end{array}$ \\
\hline Chicago- Milwaukee area & $\begin{array}{l}\text { Groundwater declined as much as } 900 \text { feet, was partially recovered, } \\
\text { but was still declining in } 2003 \text { in some locations, by as much as } 17 \\
\text { feet/yr }\end{array}$ \\
\hline
\end{tabular}




\begin{tabular}{|l|l|}
\hline Region & Groundwater Decline \\
\hline Pacific Northwest & Groundwater declined up to 100 feet \\
\hline Tucson/Phoenix, AZ & Groundwater declined of 300 to 500 feet, subsidence up to 12.5 feet \\
\hline Las Vegas, NV & Groundwater declined up to 300 feet, subsidence up to 6 feet \\
\hline Antelope Valley, CA & Groundwater declined over 300 feet, subsidence over 6 feet \\
\hline
\end{tabular}

\# Subsidence is the motion of a surface (usually, the Earth's surface) as it shifts downward relative to a datum such as sea level. The opposite of subsidence is uplift, which results in an increase in elevation.

- Almost $85 \%$ of water consumption in the U.S. is dedicated to agriculture ( $81 \%$ for irrigation and $\sim 3 \%$ for livestock). In contrast, only 3.3\% of water consumption in the U.S. is dedicated to thermoelectric plant cooling. However, if measured on the less relevant basis of water withdrawal instead of water consumption, thermo-electric plants use almost as much water as is used for irrigation. As discussed in Chapter 2, this dichotomy results from the fact that a large percentage of thermoelectric plants use once-through cooling, a process that temporarily withdraws the water, uses it to condense the steam from the turbine, and returns it to the original body of water (some 10 to 20 degrees warmer, or as specified by the NPDES permitting process), where it can be used again for other purposes (irrigation, municipal water supplies, etc.). From a thermodynamic point of view, this is the most efficient and least expensive means of cooling thermoelectric power plants, but may create environmental impacts on aquatic life. Construction of plants in more arid regions with smaller source water bodies, as well as concerns over environmental impacts of large water withdrawals, have resulted in moving away from once-through cooling, starting in the 1970s. As discussed later, most post-1970s plants use closed-cycle cooling based on evaporation. Only about ten steam-electric plants have been built with once-through cooling since $1980 .^{16}$

\section{U.S. Freshwater Consumption, 100 Bgal/day}
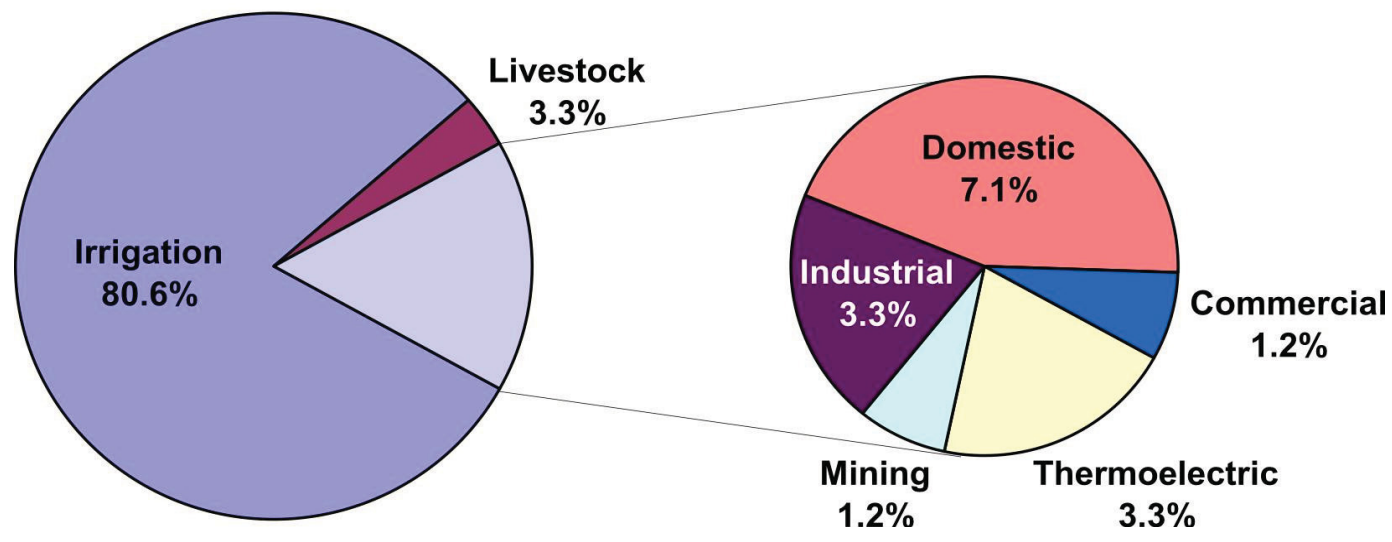

Figure 1-5: Estimated Fresh Water Consumption by Sector, 1995 (DOE Report to Congress, 2006) 
U.S. Freshwater Withdrawals, 345 Bgal/day

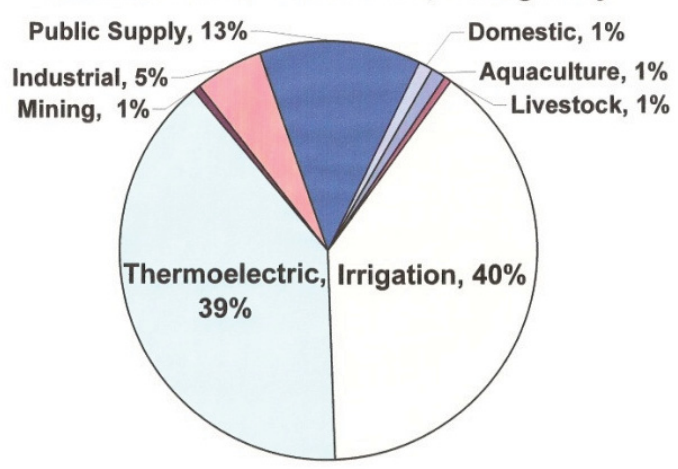

Figure II-1. Estimated Freshwater

Withdrawals by Sector, 2000

(Hutson et al., 2004)

Figure 1-6: Estimated Fresh Water Withdrawals by Sector, 2000 (DOE Report to Congress, 2006)

- Almost all means of generating electricity require water to function. Notable exceptions are wind and photovoltaic solar, which produce $1.3 \%$ and $<0.1 \%$ of U.S. electricity, respectively; and drycooled fossil energy (virtually all of which is combined cycle natural gas), which produces $0.9 \%$ of U.S. electricity. The remaining options (which generate $\sim 98 \%$ of U.S. electricity), including thermoelectric plants (coal, nuclear, conventional natural gas), hydroelectric, and other renewables (biomass, geothermal, concentrating solar) all require water for either cooling or direct use in generation. These options are discussed in more detail in Chapter 2, along with a more complete review of water consumption rates for each.

Decisions on energy and water facilities, including which technologies to use, where to site facilities, what cooling system to employ, how to address a range of environmental considerations, etc., are complex matters, and must weigh a number of competing factors which are most often site-specific in nature. Basing such decisions exclusively on cost considerations (e.g., cost to taxpayers / ratepayers, usage fees, etc.) will produce one set of outcomes. Minimizing impingement and entrainment per EPA's implementation of the Clean Water Act (CWA) without regard to other impacts will result in a different set of outcomes. Maximizing Clean Air Act (CAA) implementation with respect to cooling tower impacts on air quality (drift, particulate, etc.) will result in another set of outcomes. Minimizing land use will result in another set of outcomes. Minimizing the carbon footprint of these facilities will result in yet another set of outcomes. Any of these single-issue-driven outcomes is likely to be less than optimal for the U.S. overall, and certainly less than optimal for specific regions. Depending on the complex overlay of federal, state and local legal and policy requirements, siting power plants and determining which technologies to employ depends (or should depend) on an optimization of economics, natural resource and other environmental issues and site-specific considerations.

A key example of how competing national goals related to water usage can lead to less-than-optimum outcomes is the current drive to eliminate presumed environmental impacts from thermoelectric 
generating plant intake structures on aquatic species by mandating cooling towers, irrespective of adverse consequences of this policy to the environment in other areas (or to broader issues of national energy security and reliability). Cooling towers lead to increased air emissions, increased land use, reduced electric grid reliability, and higher electricity costs to consumers. In addition, cooling towers can have negative impacts on water consumption rates in regions of the country that are experiencing water use conflicts (or expect to experience them in the future). As discussed in Chapters 2, 6, 7 and 9, cooling towers consume about 2-3 times more water than once-through cooling. CWA requirements are placing major pressure on fossil and nuclear plants to shift to closed cycle cooling, but no comparable federal policy or regulation is in place to counter-balance this policy - in essence to ensure that changes to our national policies and laws do not create major new demands on water consumption.

As is the case for most nations around the world, the U.S. suffers from a fragmented approach to water management. Part of this is necessary, given the need to primarily manage water resources on a local or regional basis. But at the Federal level, more than 20 different agencies have responsibility for various aspects of water policy. ${ }^{17}$ Under this fragmented approach, integrating water policies and management across several sectors is extremely difficult, and often leads to sub-optimal or protracted decision-making. In many cases, government agencies or departments have policies or regulations that are at odds with each other, such as environmental regulations that severely restrict the re-use of water. From the perspective of thermoelectric power plants, inconsistencies can occur between EPA and state/local regulation, between EPA and NRC regulation, between EPA CWA and CAA implementation, etc. Stakeholder inputs to these agencies (from industry, various regional interests, public interest groups, etc.) are often - and understandably - parochial or single-issue focused, making it more difficult to create the right balance between competing demands as these agencies develop policy and/or regulation and make decisions within their purview. As discussed above, no federal agency is examining the conflicts and trade-offs associated with water use conflicts and the broader impacts on the nation from CWA implementation, especially in the areas of energy security, reliability, and cost to the consumer. It is important that such decisions are simultaneously reliant on best science to govern the process, and that they are focused on serving the overall national security interest, i.e., ensuring ample supplies of clean, reliable and affordable energy and water -- while at the same time remaining dedicated to ensuring a long-term view of environmental stewardship for the benefit of future generations. These would be difficult goals to achieve even if fragmented oversight of water issues was not an obstacle. Lacking clear guidance from Congress, the Courts have stepped into water issues and have generally missed the mark on use of "best science" to balance these competing interests.

Water Management is an extremely important but challenging national issue that deserves higher priority than is currently the case. Although this report is focused on the implications of water resource issues to U.S. nuclear plants, the conclusions here are generally applicable to other thermoelectric power plants. Importantly, this report attempts to place water issues in the context of the overall role of nuclear energy in the U.S. and its expansion as a key source of non-emitting energy for the future. 


\section{BACKGROUND}

This chapter provides background on the following technology and infrastructure issues:

- Relevant facts on nuclear power in the United States

- Basics on water withdrawal vs. water consumption, and on once-through condenser cooling vs. closed-cycle condenser cooling

- Option for dry cooling as a strategy to address cooling water issues

- Intake and discharge structures to supply and return water to/from water bodies

- Comparison of water usage rates among competing forms of electricity generation

- Comparison of water usage rates among other energy sources (e.g., transportation fuels)

- Electricity use for water management

\section{$\underline{2.1}$ Relevant Facts on Nuclear Power in the United States ${ }^{18}$}

Nuclear energy generates $20 \%$ of U.S. electricity, without generating air pollution or greenhouse gases while producing electricity. In fact, nuclear energy accounts for over $70 \%$ of all emission-free electricity generated in the United States. Nuclear energy is also the lowest cost producer of baseload electricity in the United States. Electricity production costs (which include fuel, operations and maintenance costs) are listed below for 2009:

Table 2-1: Baseload Generation Production Costs by Technology, $2009^{19}$

\begin{tabular}{|l|l|}
\hline $\begin{array}{l}\text { Baseload Generation } \\
\text { Source }\end{array}$ & $\begin{array}{l}\text { Production Costs } \\
\text { (2009 cents/kWh) }\end{array}$ \\
\hline Nuclear & 2.03 \\
\hline Coal & 2.97 \\
\hline Gas & 5.00 \\
\hline Petroleum & 12.37 \\
\hline
\end{tabular}

Electricity generated from nuclear power has tremendous forward price stability, because only about one-quarter of production costs are fuel-related. Fuel accounts for $80 \%$ to $90 \%$ of the cost of electricity for the other three forms of baseload generation (coal, gas and petroleum), making their costs highly susceptible to fluctuations in fossil fuel prices. One of the advantages (and enablers) of nuclear energy's low production cost is its position as the first power to dispatch by grid operators to local and regional customers, which makes nuclear the preferred baseload power source throughout the country, and leads to nuclear energy's very high capacity factor - averaging $90.5 \%$ over the U.S. fleet in 2009 - over twice the capacity factor of all other energy sources in the U.S. (except coal, which averages $72.2 \%$ 
capacity factor). The following figure from the DOE's EIA displays data for 2007. (2008 data are similar, with slight reductions in the first four categories and slight increases in the last three.):

Figure 2-1. Average Capacity Factor by Energy Source, 2007

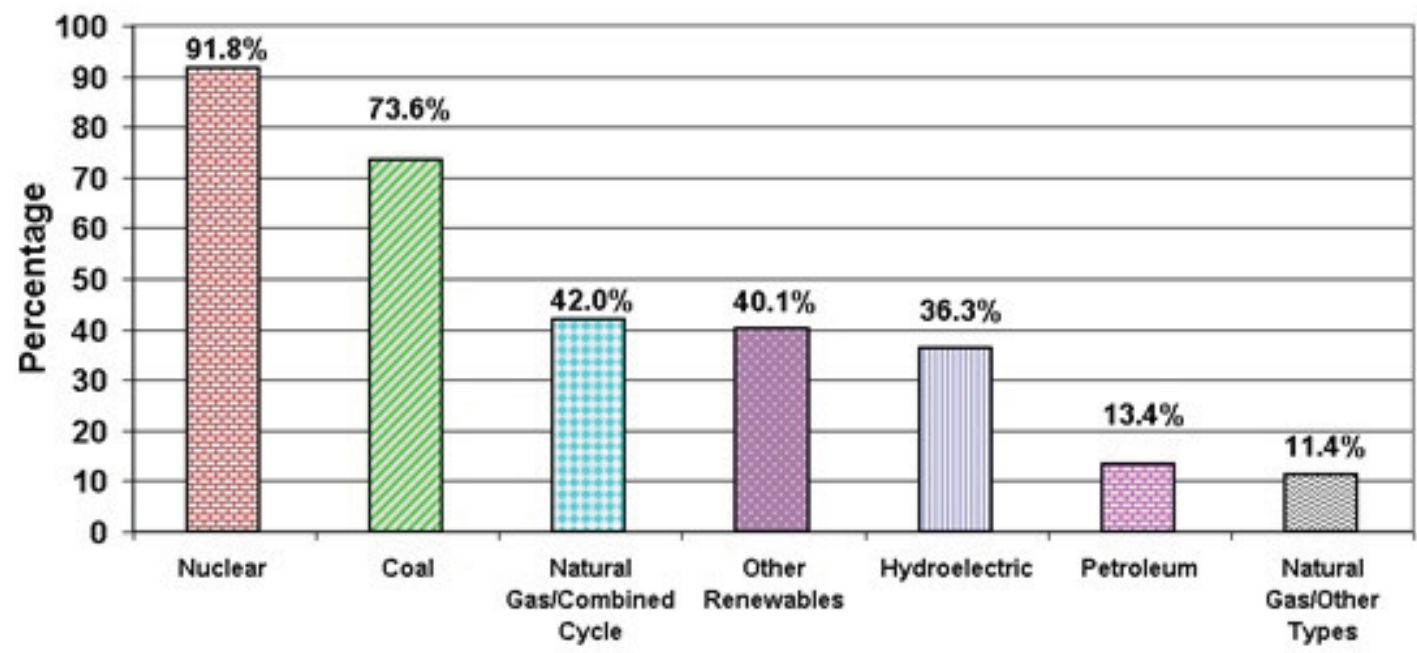

Source: Energy Information Administration, Form EIA-860, "Annual Electric Generator Report;" Form EIA-923, "Power Plant Operations Report."

Currently, 104 reactors are licensed for commercial generation of electricity by the U.S. Nuclear Regulatory Commission (NRC). These reactors operate on 65 sites in the U.S. in 31 states. Worldwide, there are about 440 reactors operating in over 30 countries, supplying about $15 \%$ of global electricity production. $60 \%$ of all world reactors operate in the United States, France, and Japan. ${ }^{20}$

Expansion in the nuclear industry is occurring in three dimensions, all of which impact water use. New plants will add demand for more cooling water. Power uprates of existing reactors require incrementally more water, which in some cases translates to a modification to a plant's water permit and/or capacity of its cooling system. License renewal of existing facilities means that arrangements for water use need to be extended further into the future, potentially in the face of competing demands for that water.

The nuclear power industry continues to make progress toward the construction of new nuclear power plants in the U.S. To date, companies have submitted 16 license applications to the NRC for 25 new reactors. Thirteen of these applications, representing 22 new reactors, are currently under active review. ${ }^{21}$ Of these, approximately $2 / 3$ are on existing sites and $1 / 3$ on new sites. Because of higher capital costs and perceived project risks within the financial community, the nuclear industry has argued that loan guarantees are important to successful deployment. Congress authorized DOE to grant $\$ 18.5$ billion in loan guarantees in Dec. 2007, and the DOE received ten nuclear power project loan guarantee applications in Dec. 2008, representing $\$ 93.2$ billion in loan volume, far exceeding the authorized funding level. The President's FY2011 budget proposes an additional \$36 billion in funding for nuclear reactor projects, which would bring the total available funding to $\$ 54.5$ billion. Since nuclear power 
plants are capital-intensive projects, these loan guarantees are essential to providing financing on a nonrecourse basis. This early financing, which lowers interest during construction, combined with nuclear energy's lower operating costs, provides electricity consumers with the lowest practicable electricity prices once the plant goes into operation. (See more on new plants in Chapters 8 and 9.)

Since 2000, the NRC has authorized 82 power uprates, yielding a cumulative capacity increase of 3760 MWe. The NRC is currently reviewing 16 applications for uprates, totaling about $1145 \mathrm{MWe}$ of capacity. Over the next five years, the NRC anticipates that companies will apply for power uprates that could represent an additional 2419 MWe of new capacity. ${ }^{22}$ The cumulative effect of these additions will average out to almost $70 \mathrm{MWe}$ per reactor, or about a $7 \%$ increase on average in output for each unit. This in turn is roughly equivalent to a $7 \%$ increase in water usage (or somewhat less, if some plants have the flexibility to adjust cooling water discharge temperatures slightly upward).

Starting in 2000, the NRC began to approve 20-year renewals of nuclear power plants' 40 -year licenses, allowing those plants to operate for a total of 60 years. Since then, NRC has approved license renewals for 59 nuclear reactors, and has under active review requests for another 19 applications for renewal. Owners have formally announced intent to file application for renewal for an additional $~ 24$ reactors, leaving only 2 or 3 U.S. reactors that have not yet announced their intent to file. Further, industry and DOE have initiated efforts to define the necessary R\&D to support a further life extension beyond 60 years for U.S. reactors (e.g., to 80 years or more). DOE and industry are working closely with NRC to ensure these efforts meet NRC requirements. If successful, these efforts would result in plant lives of at least 50-60 years beyond the average age of today's plants. Although utilities can reasonably predict regional power demands and associated cooling water needs, it is difficult for any nuclear plant owner to predict today what the competing demands for water will be at a specific site that far into the future.

See Attachment 2, "Status and Outlook for Nuclear Energy in the United States" for an excellent, up-todate summary of the industry's current performance and prospects for expansion, prepared by NEI.

2.2 Basics on Water Withdrawal vs. Water Consumption, and on Once-Through Condenser Cooling vs. Closed-Cycle Condenser Cooling

$98 \%$ of all electricity generated in the U.S. requires water for cooling or motive force as part of the process. All nuclear plants, virtually all coal plants, and some gas-fired plants use steam turbines to generate electricity. Water from a nearby river, lake, reservoir, ocean or estuary is used to cool and condense the turbine exhaust steam at these plants. All nuclear plants use water for cooling; none use dry cooling. In contrast, a small percentage of fossil plants rely on dry cooling, ${ }^{2}$ most of them gas-fired. ${ }^{23}$ The following quote comes from a 2007 EPRI Journal article, "Running Dry at the Power Plant" (see Attachment 3), which contains some excellent background on once-through vs. closed-cycle cooling." ${ }^{24}$

\footnotetext{
${ }^{2}$ Less than $1 \%$ of thermoelectric plants use dry cooling ( $\sim 0.2 \%$ of coal plants and $\sim 60 \%$ of combined cycle natural gas plants use dry cooling).
} 
"Until the early 1970s, most power plants were located next to a sizeable body of water or a major river to ensure adequate water for cooling. These plants used once-through cooling, a process that simply borrows the water, uses it to condense the steam from the turbine, and then returns it to the original water body some $10^{\circ}$ to $20^{\circ} \mathrm{F}$ warmer. While highly efficient for cooling, the process has the potential for a twofold impact on aquatic life: fish entrainment and impingement at the front end of the process, and thermal discharge at the back end. [See Chapter 3 for definitions of these impacts.] Newer units have typically employed evaporative cooling towers in a process known as wet cooling, which withdraws less than $5 \%$ of the water needed for once-through cooling. As a result, fish entrainment is minimized and thermal discharge is significantly reduced. There are, however, potentially significant local and environmental tradeoffs with cooling towers, including discharge of waterborne pollutants used to control scaling and fouling, release of particulates in air emissions, salt drift, noise and aesthetic issues." The Journal article goes on to say that over 30\% (by capacity) of today's fleet of thermoelectric power plants still utilize the once-through process. This statistic includes both nuclear and fossil units. For nuclear plants, that percentage is about $60 \%$, as explained in Chapter 4. Importantly, closed-cycle systems are more expensive than once-through systems (especially if retrofitted on an existing oncethrough system in contrast to being included in the initial design). Further, closed-cycle systems reduce plant efficiency and output, by 2-5\% or higher, depending on climate, water temperature and other factors. Even for facilities with only a $2 \%$ annual reduction, there may be a $5 \%$ reduction on hot summer days when the power is in highest demand. This penalty is at the lower end of this range for new plants designed with cooling systems optimized for closed-cycle cooling. The penalty can be $5 \%$ or higher if retrofitted on current plants (see Section 6.2). Chapter 5 describes five reports being prepared by EPRI that examine the costs, efficiency penalties and other implications of retrofitting closed-cycle cooling on existing plants with once-through cooling. It is important to recognize that such retrofitting has never been done on a U.S. nuclear power plant.

When water is used to cool a thermoelectric power plant operating in a once-through cooling mode, the term used to describe this type of water usage is "withdrawal," which connotes the "borrow and return" process between the source water body and the plant that makes the water available for other uses such as irrigation or municipal water supply. When water is used to cool a thermoelectric power plant in a closed-cycle cooling mode, the term used to describe this type of water usage is "consumption," which connotes the near complete loss of that water (70\% to $90 \%$ loss), through evaporation and drift, such that it is no longer available for other purposes. The imprecise terms "use" or "usage" are often used to describe both types of cooling. Because these latter terms can be confusing or misleading, they are avoided when practical in this report. As discussed later, the question "how much water does electricity generation "use'?" has two very different answers, because of these two different kinds of cooling. If "usage" is measured by total industry "withdrawal," then the combined flow-rate for all U.S. thermoelectric power plants is nearly $40 \%$ of freshwater withdrawals in the U.S. -- almost as much as for agriculture (see Figure 1-6). But this is misleading, since most of the water withdrawn to cool these plants can be used again. If "usage" is measured by total industry "consumption," then the actual flowrate is only $3.3 \%$ of U.S. freshwater consumption -- much less than municipal water needs, and very much less than agriculture (see Figure 1-5). 
The EPRI Journal article contains descriptions of how once-through cooling, closed-cycle cooling (wet cooling towers), dry cooling (heat rejected directly to the atmosphere), and hybrid cooling operate, along with simplified graphics for each. In summary, once-through cooling withdraws water from its source, pumps it through thousands of small diameter tubes in the condenser where turbine exhaust steam flows over the outside of the tubes and is condensed by the cooler tubes. The resultant warmer circulating water is then returned to the body of water from which it was withdrawn. Physical separation is maintained between the intake structure and the discharge structure where the water is withdrawn and returned, so as to avoid allowing the warmer water to be recycled again. ${ }^{3}$

In closed-cycle cooling, the warm water exiting the condenser is pumped to a cooling tower, instead of back to the source water body. Wet cooling towers contain "fill" materials that break up the flow of warm circulating water (from the condenser) into small water droplets, or that spread the warm water out into a thin film to maximize its surface area, which is then cooled by air inside the tower. A portion of this cooling water is evaporated into the atmosphere and exits the cooling tower in a "plume" of moist air that often looks like steam. The remaining circulating water (now cooled by evaporation) falls to a basin at the base of the tower. Air is moved rapidly over these water droplets or films to efficiently remove latent heat, by using either natural convection (in a natural draft cooling tower), or by using fans (in a mechanical draft cooling tower). The former tower design is typically very tall (e.g., >500 feet), since this elevation is necessary to create the natural draft air flow. Mechanical towers are typically much shorter (e.g., 60 feet). Since cooling tower operation creates a loss of circulating water because of evaporation, makeup water is withdrawn from the source water body. Also, because evaporation concentrates the solids and other impurities in the water (salt, sediment, etc.) a small reject flow is maintained (typically returned back to the source water body), called "blowdown." (Makeup and blowdown flows are typically intermittent.) The quality of makeup water dictates the rate of blowdown (or inversely, the cycles of concentration), with greater blowdown (or fewer concentration cycles) required for makeup water with higher total dissolved solids (TDS). Fewer cycles in turn require more blowdown (and hence more withdrawal), but not more evaporation (and hence not more consumption). Note that if the plant is a zero liquid discharge facility (e.g., Palo Verde), then an increase in blowdown rate does increase consumptive use.

\footnotetext{
${ }^{3}$ During the winter in cold climates, some of the warmer discharge water is diverted intentionally to the intake structure to prevent freezing in the intake system.
} 


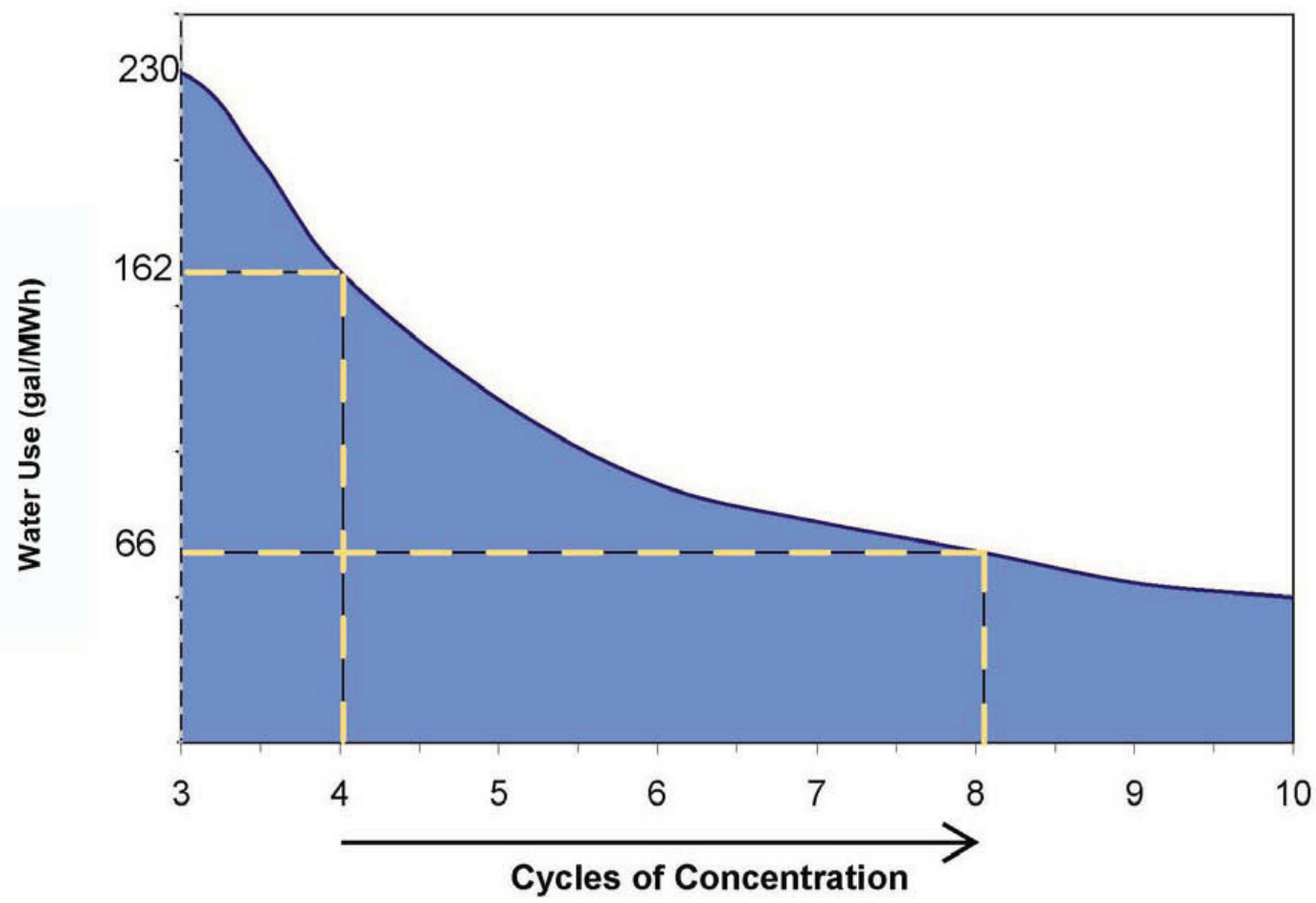

Figure 2-2: Typical Water Losses from Cooling Towers, at Varying Cycles of Concentration, EPRI ${ }^{25}$

The EPRI Journal article also contains a description of air-cooled condensers and dry cooling, which are not currently used at nuclear plants for many reasons. Dry cooling systems cost about 3 to 5 times more than wet cooling systems, and experience extreme performance penalties during the hottest days of the year ( 20-25\%). Unfortunately, these hottest days generally correspond to the greatest electric demand days. (Penalties relative to wet closed-cycle cooling are much less in cold climates, e.g., 2\%.)

Also discussed in the article are hybrid cooling technologies that use a mix of evaporative and air cooling. Hybrid systems can be used to substantially reduce the makeup water consumed in wet cooling without incurring the large performance penalties of dry cooling. Hybrid systems can also be designed for maximum water conservation, making them essentially a dry system, with just enough wet-cooling capability to prevent significant deterioration in power plant efficiency during the hottest days of the year. For nuclear plants, a few new plant designs intend to incorporate a small amount of dry cooling, sufficient to eliminate the visible plume exiting the tower, or to reduce water consumption rates. No new nuclear power plants are being sited in a location with such limited water resources as to require primary reliance on a dry cooling system (see section 2.3 for more details on dry cooling).

A few nuclear power plants have employed another type of closed-cycle cooling that reduces the evaporative losses associated with cooling towers - the cooling pond. Cooling ponds require a significant amount of land, and may not be feasible in many topographical situations or in areas where groundwater could be affected. Although typically more expensive up-front (constructing a man-make pond or lake is typically more expensive than cooling towers), the cooling pond has the advantage of 
transferring a larger percentage of waste heat to the atmosphere via convection or slower evaporation due to lower differential temperatures, reducing the rate of evaporation and thus the rate of consumptive water loss relative to cooling towers. Such systems still maintain full once-through flow through the condenser, but because these cooling ponds are dedicated to plant cooling missions, their environmental impacts are typically much less. In fact, some of these plants sited on cooling ponds are exempt from aquatic life and thermal discharge regulations (See Chapter 4).

\subsection{Option for Dry-Cooling as a Strategy to Address Cooling Water Issues}

One of the technology options to resolve CWA issues is to use air cooling (i.e., "dry" cooling) instead of water cooling for thermoelectric power plants. Since dry cooling uses little or no water, it virtually eliminates concerns for impingement and entrainment of fish. However, as noted above, no nuclear plants use air cooling. There are a number of reasons why air cooling would be a poor choice for nuclear plants, many of which are also negatives for large fossil plants. It is important to note that the EPA rejected the option to require dry cooling technology in both its Phase I rulemaking for new facilities (2001) and its Phase II rulemaking for existing facilities. EPA's reasons are included in the following list of negatives:

- Dry cooling systems are extremely inefficient in comparison to water cooling, and require large amounts of open land directly adjacent to the reactor to install. ${ }^{4}$ As a retrofit on current plants, many existing sites could not physically accommodate dry cooling.

- Because of their inefficiency, dry cooling systems exact a significant energy penalty, typically $2 \%$ to $4 \%$, but as high as $20 \%$ on an intermittent basis, relative to wet cooling systems. ${ }^{26}$ The higher efficiency penalties occur on the hottest days of the year, when electricity demand is the highest, power prices are the highest, and when replacement power may not be readily available. For a base-loaded nuclear plant, such large and unpredictable efficiency penalties are of great concern to grid stability. If widespread use of dry cooling were mandated, brownouts or blackouts would become likely during summer months.

- In addition to nuclear plant reliability and grid stability problems caused by dry cooling on hot days, these same reliability problems can also be caused by wind gusts, which cause transients in the heat removal rate from air-cooled condensers, sufficient to initiate a reactor shutdown.

- Operating a plant originally designed for once-through cooling with retrofitted dry cooling towers would create unacceptable turbine backpressures on hot days, beyond the design limits of the turbine. As a result, retrofitting once-through plants with dry cooling would necessitate replacement of the turbine with one designed to operate at higher backpressures, as well as rerouting of large bore steam piping and replacing other major cooling system components.

These modifications are cost-prohibitive, and were rejected by EPA as an option to comply with the CWA. So this option is not discussed further in this report.

\footnotetext{
${ }^{4}$ Calculations performed for desert regions (e.g., Arizona) indicate the energy penalty could be $30 \%$ or greater. One plant calculated a land requirement for dry cooling at its site of the equivalent of about ten football fields.
} 
- Dry cooling is very expensive - about 3 to 5 times higher capital costs than closed-cycle cooling. Dry cooling brings with it other environmental issues, including air pollution, noise, etc.

Some new natural gas-fired plants, most notably the Mystic generating station in Boston Harbor, have been designed for dry cooling. Dry cooling was selected for Mystic as a means to avoid concerns over possible impacts on aquatic life. (See EPRI Journal article, Att. 3, for details.)

New plant Combined License (COL) applications evaluate all options for heat dissipation. In theory, dry cooling is relatively feasible as an option for new generating plants of all kinds, in relation to its application as a retrofit on existing facilities. In the nuclear area, some small advanced reactor concepts being developed today are considering dry cooling as an option for selected market applications. However, none of the planned deployments of standardized ALWRs will use dry cooling. All new plant COLAs submitted to date have rejected dry cooling as infeasible for the site or unacceptable because of lost electrical generating efficiency and significantly higher capital and operating costs. It is likely that new nuclear plant applications for the foreseeable future will continue to favor sites that allow for sufficiently reliable and long-term assured water resources, thereby avoiding the reliability, efficiency and cost penalties associated with dry cooling.

The EPRI Journal article describes three types of dry cooling: "direct dry cooling," "indirect dry cooling," and "hybrid cooling." Direct dry cooling uses air-cooled condensers (ACCS), which function much like a car radiator - removing heat with high air flow passed over finned tubes which contain the exhaust steam from the turbine. For most nuclear units, the application of dry cooling would likely be in the form of "indirect dry cooling" (see EPRI Journal article and paragraph below) for reasons of safety and containment. Indirect dry cooling condenses steam from the turbine in a conventional shell-and-tube steam condenser, after which the hot cooling water is then cooled, prior to recirculation, in an aircooled heat exchanger (ACHE). This process is even less efficient and more costly than direct air cooling.

For the near term, the only application of dry cooling to nuclear units is expected to be in the form of hybrid cooling, which uses a combination of wet and dry cooling to gain the advantages of both and to offset the disadvantages of each. However, there may come a time in the future, if water shortages become acute and potential sites with adequate water resources are no longer available in certain regions of the country, that nuclear power plants will be forced to consider non-traditional water sources (if available), or even selective or limited use of dry cooling. At that point (likely many years or decades into the future), advanced reactor designs that are more capable of using dry cooling (e.g., High Temperature Gas Reactors, or HTGRs), would be considered. See section 8.4 for dry cooling considerations in the case of high temperature reactors and/or small innovative reactors.

All of the above problems with dry cooling apply to large base-loaded fossil plants as well. However, there are a number of unique reasons why dry cooling (especially "direct dry cooling" that uses aircooled condensers) is specifically problematic for large nuclear plants, relative to nuclear safety and licensing. There are a number of transient scenarios for which all nuclear plants must be able to demonstrate ample safety margins, which would not evolve acceptably with total reliance on dry cooling. Transients such as a loss of offsite power benefit from post trip heat removal to the condenser 
to remove reactor "decay heat." Dry cooling would inhibit the rate of this heat removal and could lead to higher temperature or pressure transients in the reactor as a result. Another scenario of concern is a hypothetical leak in ACC finned tubes, which would allow direct escape of reactor steam to the environment. Reactor steam is only slightly radioactive in BWRs, with most of the radiation coming from N-16 decay with a very short half-life (seven seconds). In PWRs, if direct dry cooling is used, a hypothetical primary to secondary leak could release radioactivity into the secondary circuit, allowing small amounts of radioactivity in the turbine exhaust steam. (This is not a concern if indirect dry cooling is used.) In both BWRs and PWRs, releases to the atmosphere via a hypothetical leak in an ACC finned tube would lack the filtering capability of a water-cooled condenser. These releases would be small, and insignificant from a public health and safety perspective. However, they could be significant in licensing calculations and safety analyses of hypothetical accident scenarios, and might be significant enough to show up in a probabilistic risk analysis as a negative for dry cooling. For these reasons, it is unlikely that a large nuclear plant would rely exclusively on dry cooling. However, the limited use of dry cooling to augment a cooling system that relies primarily on wet cooling is technically feasible for a large nuclear plant. The capability to isolate the dry cooling system and rely exclusively on wet cooling after a plant trip or transient addresses potential safety concerns. Also, some new plants are considering the addition of a small amount of indirect dry cooling to enable a "plume abatement" capability in a mechanical-draft cooling tower. The small amount of dry cooling needed to provide this function is not a safety concern.

Another limited use of dry cooling that can be included in a design without introducing safety issues is a limited use of dry cooling to compensate for either water supply limitations or discharge temperature limitations during drought conditions or summer heat waves. For example, Dominion's new Unit 3 at North Anna will have a closed-cycle, combination dry and wet (hybrid) cooling tower system, comprised of a wet mechanical tower with plume abatement, with make-up water supplied from Lake Anna, and a separate dry tower that can be brought on-line in specific circumstances. The make-up water to the wet tower will replace water lost from the operation of the wet tower, including losses from evaporation, blowdown, and drift. The hybrid cooling tower system will have two modes of operation, Maximum Water Conservation (MWC) and Energy Conservation (EC). In the MWC mode, about $1 / 3$ of the heat is rejected from the plant via dry cooling. In the EC mode, the dry cooling fans are turned off, and $100 \%$ of the heat is rejected in the wet tower (normal closed-cycle cooling). A variation of the hybrid tower would use a dry section above the wet tower section where cooler outside air is drawn in through ducts while the warm moist air from the wet section exhaust passes over the outside of the ducts. Water from the wet section exhaust condenses on the cooler dry section duct surfaces and falls back into the process stream before leaving the cooling tower, thereby reducing the water loss due to evaporation. ${ }^{27}$

Most nuclear power plants maintain a separate, independent heat rejection system for safety-grade cooling systems that cool emergency diesel generators, etc. These "essential service water" systems typically reject heat to the environment using once-through-cooled heat exchangers. The flow rates in these once-through systems are very small compared to the main turbine cooling system, and thus do not present an aquatic life protection concern. For operating nuclear plants that use once-through cooling for these systems, it is important that they are evaluated separately from a safety perspective, and that they remain once-through-cooled unless overriding concerns dictate otherwise. 


\section{2-4 Intake and Discharge Structures to Supply and Return Water to/from Water Bodies}

All thermoelectric plants have screen systems to prevent debris from entering the condenser. These screen systems can be stationary or traveling, and are typically located the intake, or within an intake canal, or just prior to circulating water pump suction on an intake bay. A basic screen system does not protect fish from being captured. Rather, the primary purpose of a basic screen system (typically $3 / 8^{\prime \prime}$ mesh) is to capture debris (trash, vegetation, etc.), so it doesn't enter the cooling system. However, in order to minimize some of, or one kind of the potential environmental impacts of once-through cooling, some plants (e.g., in ocean, estuary and tidal river environments) have installed elaborate intake and/or discharge structures, traveling screens to capture and return fish and other aquatic life, and a number of other measures to protect aquatic life. Some of these features were part of the original design at a few plants, others were added later to improve environmental performance. Plants with closed-cycle cooling typically employ basic screen systems. Since the makeup water requirements and blowdown flow-rates for closed-cycle systems are typically only $5 \%$ to $10 \%$ that of once-through systems, these intake systems are smaller; and few closed-cycle systems employ fish protection features.

Intake and discharge structures are designed specifically for the site and its source water body. Intake structures are often located within the water body at a point that minimizes the probability of drawing debris or aquatic life into the plant's intake pipe or canal. At some sites, this means locating the intake at a sizable distance offshore and/or in deeper water. Some sites use structural devices at the intake to prevent larger fish, marine mammals (e.g., seals, dolphins), or reptiles (e.g., sea turtles) from entering the intake structure.

Some intake structures use velocity caps to create a high horizontal velocity that fish can detect and avoid. Some screen systems incorporate a capture and return capability to reduce impingement mortality. Depending on the susceptibility of the site to entrainment of smaller organisms, various types of smaller mesh screens are used at a few sites to minimize entrainment. The particular configuration and mix of preventive measures varies significantly from site to site; and design features that protect aquatic life at one site may prove useless at another, because of the types of species present, water body dynamics, the water flows and temperatures encountered, etc.

Primary focus today on intake structure technologies is on means to reduce impingement mortality and entrainment of aquatic species. These two terms are discussed in more detail in Chapter 3 . For purposes of summarizing intake structure technologies, the following simplified definitions are provided:

- Impingement mortality results when fish and other aquatic life are trapped on equipment at the entrance to the cooling water intake structure.

- Entrainment results when aquatic organisms, eggs, and larvae are taken into the cooling system, passed through the condenser, and then discharged back into the source water body.

The objective of EPA requirements regarding technologies to reduce impingement is to reduce mortality of impingeable-size organisms relative to what would be impinged on standard $3 / 8$ inch screens used 
today to prevent debris from entering and clogging cooling system components. The objective of EPA requirements regarding technologies to reduce entrainment is to reduce the percentage of aquatic life that could be entrained in cooling systems (e.g., through the use of closed cycle cooling or alternatives such as fine mesh or wedgewire screens), based on the conservative assumption that all eggs, larvae, and other small life forms that can pass through such screens would be killed (e.g., by the $10^{\circ}$ to $20^{\circ}$ temperature rise).

The following table displays the technologies most commonly viewed as best technology available (BTA) candidates for nuclear power plants, including closed cycle cooling and alternatives to closed-cycle cooling. Note that technology alternatives to closed cycle cooling have advanced significantly since the 1970s and 1980s, when the much lower intake structure flow rates associated with closed cycle cooling were generally viewed as the best means of protecting aquatic species. Since then, most of the technologies listed in the following table have been improved through research, demonstration projects and a limited number of operational deployments. These demonstrations, although limited in number, have shown promising species protection results - sometimes roughly equivalent to the performance of cooling towers. These alternatives, or combinations of these alternatives, are effectively "catching up" with cooling towers in terms of environmental performance (as "BTAs,") with major cost and reliability benefits in comparison to cooling towers, and without the downside problems associated with towers. Most alternatives are poised for expanded demonstration in a wider range of water body and species applications. The diversity and adaptability of these alternative technologies should help thermoelectric power plants deal effectively with a wide range of site-specific conditions. To date, most utilities have postponed major investments in cooling tower retrofits or these alternatives to closed cycle cooling, because of uncertainty over the final § 316(b), Phase II rule requirements (see Chapter 3).

This summary of technology options has been provided by EPRI. 
Table 2-2: Alternative Intake Structure Technologies for Minimizing Impacts on Aquatic Life

\section{Behavioral Barriers}

Behavioral Barriers are generally only effective for reducing mortality of impingeable sized organisms. They are based on deterring fish from interacting with the cooling water intake structure through use of stimuli that evoke an avoidance response from the organism. Examples include use of sound, light, air bubble curtains or velocity. Some behavioral barriers such as velocity caps have been found to be highly effective, and studies on the west coast have demonstrated impingement reductions well in excess of $80 \%$. A significant limitation of this option is that effectiveness can be limited to some species with no response from others. For example use of sound has been demonstrated to be very effective for herring species with no or limited effectiveness for other species.

\section{Exclusion Devices}

Exclusion devices are designed to provide a physical barrier which is used in combination with a low through barrier velocity. These technologies tend to be highly effective from a performance standpoint, and depending on the size of the screening barrier, can be designed to reduce impingement or both impingement and entrainment. A barrier net is an example of an impingement reduction exclusion device. The technology has been shown to be effective at a relatively low cost. Sizing the net to achieve a through net velocity that does not exceed $0.5 \mathrm{fps}$ virtually eliminates impingement and also can provide facility operational benefits by preventing debris such as leaves from clogging the intake. This technology tends to be labor intensive, since the net must be changed manually to control fouling and debris to maintain the low through screen velocity. The entrainment reduction version of a barrier net is the aquatic filter barrier (AFB). The AFB uses a much finer mesh size (i.e. as fine as $0.5 \mathrm{~mm}$ ) and the overall net size is designed to reduce the through net velocity to as low as $0.25 \mathrm{fps}$. An air burst system is used to remove debris and fouling organisms. There are limitations on where these options can be used. Since these technologies extend out into the water body, they may not be allowed if the intake is in a navigation channel. AFBs, due to the small mesh size, might be required to be over a mile long and therefore their use tends to be limited to intakes adjacent to deeper water to shorten the length. Also they are not feasible for use in open oceans due to destruction during storm events. Biofouling is also a concern in marine environments. Additionally, some current is necessary for an AFB to carry away debris after the airburst or mechanically cleaning (not present in all water bodies). Wedgewire screens are another example of an exclusion device and can be designed with a wide-slot width $(9.5 \mathrm{~mm})$ for impingement reduction, or a narrow-slot width (as small as $0.5 \mathrm{~mm}$, depending on water velocity) for entrainment reduction. They are designed for use with a through-screen velocity not to exceed $0.5 \mathrm{fps}$ for impingement and even lower for entrainment reduction. While also highly effective, they tend to require less maintenance than barrier nets or the AFB. However, they are not feasible at all sites due to issues that include navigation obstruction and fouling, especially in the absence of ambient water current to carry away debris removed through mechanical or airburst cleaning systems.

\section{Collection and Transfer Systems}

These technologies are designed to collect organisms off the screens and transport them back to the water body in a manner that minimizes mortality. There are a number of manufacturers and designs. Screens can be designed with a $3 / 8$ inch mesh for reducing mortality of impingeable sized fish or a smaller mesh size (i.e. as small as $0.5 \mathrm{~mm}$ ) to reduce mortality of both impingeable and entrainable sized organisms. Screens must be operating continuously and use a low pressure wash to remove organisms 
off the screens to be effective. There are a number of facilities in the U.S that currently use such systems, including the Salem and Brunswick Nuclear Stations. Performance of this technology is variable depending on species and life stage. Some species and/or life stages are too fragile to tolerate the collection and transport associated with this technology. However, EPRI research has shown that for larvae $9 \mathrm{~mm}$ and larger, high survival rates can be achieved for many species based on laboratory studies. Field studies at facilities using the technology also have shown variable levels of performance. Another issue that can affect performance of this option is the transport distance from the screens to a suitable discharge location - one that minimizes risk of further interaction with the intake and that has suitable water quality to maximize survival.

\section{Diversion Systems}

Diversion systems are generally only effective for reducing mortality to impingeable sized organisms or larger entrainable life stages. Examples include use of louvers or modular inclined screens (MIS). For louvers, the mode of operation is similar to that of behavioral barriers in that it is based on diverting fish away from the intake. This is accomplished through use of angled bars to create a current that guides fish away from the intake. As with behavioral barriers, not all species respond and therefore effectiveness is species specific depending on the species present. The MIS uses a combination of angled screens to concentrate fish near a fish friendly pump and then to transport them back to the source water body away from the intake. The effectiveness of the MIS depends on the distance needed to transport organisms to a location of suitable water quality that minimizes risk of further interaction with the intake.

\section{Change in Intake Location}

For some facilities it may be possible to relocate the cooling water intake structure to a location that results in a significant reduction in impingement and/or entrainment. Relocation generally involves moving an intake further offshore, which could involve a change in depth. A number of facilities located on the Great Lakes have demonstrated significant impingement and/or entrainment reductions using the remanded Phase II Rule calculation baseline which assumed a shoreline intake with cooling water withdrawal from at or near the surface. Opportunities for use of this option tend to be limited due to two key factors. One is cost, since for some facilities the relocation distance may be cost prohibitive. The second factor is that for most water bodies there is no alternative location that would result in a significant reduction, or it simply results in a trade off of impingement and/or entrainment of one set of species for another.

\section{Flow Reduction}

EPA, in the remanded Phase II Rule, determined that a reduction in flow would result in a proportional reduction in entrainment and a substantial reduction in impingement. There are two major approaches for flow reduction. The first is use of closed-cycle cooling discussed extensively elsewhere in this report. The second is through reducing cooling water pump operation by either reducing the number of cooling water pumps in use or installation of variable speed drives to allow a finer level of flow control. Reducing cooling water pump operation provides a dual benefit in that it reduces the amount of cooling water withdrawn as well as the intake velocity. The major issue with this option is the direct relationship between flow and ability to generate electric power. Flow reduction is rarely a viable alternative for baseloaded nuclear units. However, for many fossil units - in particular, facilities that operate at reduced loads at night or on a seasonal basis by reducing flow during off-peak periods operators can achieve reductions in impingement and entrainment without adversely affecting generation. However, even for fossil units, the ability to reduce flow is very site specific and depends on densities of organisms in the vicinity of the intake at the times when flow can be reduced. 
Discharge structures are also site-unique. They are typically designed in ways that reduce potential adverse thermal effects. Although some aquatic species thrive on the warmer waters at a thermoelectric power plant discharge, excessive temperatures or rapid changes in temperature can kill fish and aquatic species, as can discharge water that is low in oxygen. A few discharge structures are designed to reduce specific impacts on aquatic life, as discussed below. More broadly, the plant's cooling system is designed and operated to keep discharge temperatures below threshold levels set by permitting authorities to ensure no adverse impact to aquatic life. Temperature can be dissipated in the receiving water in various ways, depending on volume and flow. CWA § 316(a) contains a variance provision for heat. Under $\S 316(a)$, facilities can get a variance from otherwise applicable thermal water quality standards if they can demonstrate that there is a balanced population of fish and aquatic life in and on the water body. Most of these demonstrations have been successful.

Specific design features are used at a few sites to assist in mixing, such as high velocity surface flumes to achieve rapid mixing with the source water body, pre-cooling or mixing in a long discharge canal, restricted embayments or holding ponds prior to discharge to the main water body, aerating structures, flow diffusers (including deep water diffusers), etc. Again, the particular configuration and mix of preventive measures varies significantly from site to site.

The preventive measures for intake structures are reviewed by EPA and state/local water authorities and have been determined to be the "best technology available" for that site. Details on EPA regulation and state/local permitting are covered in Chapter 3. 


\subsection{Comparison of Water Usage Rates among Competing Forms of Electricity Generation}

The following table is taken from EPRI's Water and Sustainability Research Plan, $2002^{28}$

Table 2-3

Cooling Water Withdrawal and Consumption (Evaporation to the Atmosphere) Rates for Common Thermal Power Plant and Cooling System Types

\begin{tabular}{|l|c|c|}
\hline Plant and Cooling System Type & $\begin{array}{l}\text { Water Withdrawal } \\
\text { (gal/MWh }\end{array}$ & $\begin{array}{l}\text { Typical Water } \\
\text { Consumption } \\
\text { (gal/MWh) }\end{array}$ \\
\hline $\begin{array}{l}\text { Fossil/biomass/waste-fueled steam, } \\
\text { once-through cooling }\end{array}$ & 20,000 to 50,000 & $\sim 300$ \\
\hline $\begin{array}{l}\text { Fossil/biomass/waste-fueled steam, } \\
\text { pond cooling }\end{array}$ & 300 to 600 & $300-480$ \\
\hline $\begin{array}{l}\text { Fossil/biomass/waste-fueled steam, } \\
\text { cooling towers }\end{array}$ & 500 to 600 & $\sim 480$ \\
\hline $\begin{array}{l}\text { Nuclear steam, once-through } \\
\text { cooling }\end{array}$ & 25,000 to 60,000 & $\sim 400$ \\
\hline Nuclear steam, pond cooling & 500 to 1100 & $400-720$ \\
\hline Nuclear steam, cooling towers & 800 to 1100 & $\sim 720$ \\
\hline $\begin{array}{l}\text { Natural gas/oil combined-cycle, } \\
\text { once-through cooling }\end{array}$ & 7500 to 20,000 & $\sim 100$ \\
\hline $\begin{array}{l}\text { Natural gas/oil combined-cycle, } \\
\text { cooling towers }\end{array}$ & $\sim 230$ & $\sim 180$ \\
\hline $\begin{array}{l}\text { Natural gas/oil combined-cycle, dry } \\
\text { cooling }\end{array}$ & $\sim 200$ \\
\hline $\begin{array}{l}\text { Coal/petroleum residuum-fueled } \\
\text { combined-cycle, cooling towers }\end{array}$ & $\sim 0$ & $\sim 0$ \\
\hline includes gasification process water & $\sim 380 *$ & $\sim 20$ \\
\hline
\end{tabular}

Note that cooling requirements for nuclear energy plants are slightly higher than coal and much higher than gas, in both the withdrawal and consumption categories.

The DOE Report to Congress includes detailed data on water use, as does the World Energy Council study discussed in Chapter 1 ("Thirsty Energy"). Both sources rely on EPRI data, along with other sources, to provide more extensive coverage of energy options, including some renewables.

The Table below is reproduced from the DOE Report to Congress as it appears in the report. It contains an error in the coal and nuclear data, which is highlighted and corrected per the "strikethroughs" below. 
Table 2-4: Water Intensity for Various Power Generation Technologies (EPRI, 2002a; CEC, 2002; CEC, 2006; Grande, 2005; Leitner, 2002; Cohen et al., 1999) ${ }^{29}$

\begin{tabular}{|c|c|c|c|c|c|}
\hline \multirow{3}{*}{$\begin{array}{c}\text { Plant-type } \\
\text { Steam }\end{array}$} & \multirow{3}{*}{ Process } & \multicolumn{4}{|c|}{ Water Intensity (Gal/MWhe) } \\
\hline & & \multicolumn{2}{|c|}{ Steam Condensing } & \multicolumn{2}{|c|}{ Other Use } \\
\hline & & Withdrawal & Consumption & Withdrawal & Consumption \\
\hline \multirow[t]{2}{*}{ Coal } & Mining & & & & $5-74$ \\
\hline & Slurry & & & $110-230$ & $30-70$ \\
\hline \multirow{4}{*}{$\begin{array}{c}\text { Fossil/ } \\
\text { biomass/ } \\
\text { waste }\end{array}$} & OL Cooling & $20,000-50,000$ & $\sim 300$ & \multirow{4}{*}{\multicolumn{2}{|c|}{$\sim 30 * *$}} \\
\hline & CL Pond & $300-600$ & $300-480$ & & \\
\hline & CL Tower & $500-600$ & $\sim 480$ & & \\
\hline & Dry & 0 & 0 & & \\
\hline Nuclear & $\begin{array}{l}\text { Mining and } \\
\text { Processing }\end{array}$ & & & & $45-150$ \\
\hline Nuclear & OL Cooling & $25,000-60,000$ & $\sim 400$ & \multirow{4}{*}{\multicolumn{2}{|c|}{$\sim 30$}} \\
\hline Nuclear & $\mathrm{CL}$ Pond & $500-1,100$ & $400-720$ & & \\
\hline Nuclear & CL Pond Tower & $800-1,100$ & $\sim 720$ & & \\
\hline Nuclear & Dry & 0 & 0 & & \\
\hline $\begin{array}{l}\text { Geothermal } \\
\text { Steam }\end{array}$ & CL Tower & $\sim 2000$ & $\sim 1400$ & \multicolumn{2}{|c|}{ Not available } \\
\hline Solar trough & CL Tower & $760-920$ & $760-920$ & \multicolumn{2}{|c|}{$8 * *$} \\
\hline Solar tower & CL Tower & $\sim 750$ & $\sim 750$ & \multicolumn{2}{|c|}{$8 * *$} \\
\hline Other & ----------- & --------- & --------- & \multicolumn{2}{|c|}{-------- } \\
\hline Natural Gas & Supply & & & & $\sim 11$ \\
\hline \multirow[t]{3}{*}{ Natural Gas CC } & OL Cooling & $7,500-20,000$ & 100 & \multirow{3}{*}{\multicolumn{2}{|c|}{$7-10 * *$}} \\
\hline & CL Tower & $\sim 230$ & $\sim 180$ & & \\
\hline & Dry & 0 & 0 & & \\
\hline Coal IGCC & CL Tower & $\sim 250$ & $\sim 200$ & \multicolumn{2}{|c|}{$7-10+130$ (process water) } \\
\hline Hydroelectric & Evaporation & & & & 4500 (avg.) \\
\hline
\end{tabular}

$\mathrm{OL}=$ Open loop cooling, $\mathrm{CL}=$ Closed Loop Cooling, $\mathrm{CC}=$ Combined Cycle

*IGCC = Integrated Gasification Combined-Cycle, includes gasification process water

Other Use includes water for other cooling loads such as gas turbines, equipment washing, emission treatment, restrooms, etc.

** References did not specify whether values are for withdrawal or consumption.

Note that the words "CL Tower" and "CL Pond" and their associated data are highlighted above. These data entries came directly from the EPRI report, with the order of the words in the process column reversed, but the order of the data itself not reversed. The effect of this error was to assign a higher rate of water usage (both in the Withdrawal column and the Consumption column) to CL Ponds than to $\mathrm{CL}$ Towers. The correct data are displayed in the previous table by EPRI, and show that CL Ponds consume less water - not more - than CL Towers. This makes sense, since CL ponds transfer a larger percentage of heat to the atmosphere by radiative heat transfer or slow evaporation with lower differential temperatures, while virtually all of the heat transfer from a CL tower occurs by rapid evaporation (with its associated higher moisture content and higher rate of water loss). 
Finally, note that even though virtually no water is consumed by once-through cooling during the cooling process, a non-trivial value is assigned to this process. This is because the warmer discharge water eventually leads to an incrementally higher evaporative loss rate from the water body over time than would have occurred if the water body had not been warmed. In contrast to water consumption rates for closed-cycle cooling, this once-through consumption rate is very hard to estimate, as is the case for hydropower. Historically, these estimates of once-through cooling consumption rates have been based on complex computer models that consider temperature, humidity, wind speed and other factors. Water consumption rates from closed-cycle cooling, on the other hand, can be calculated rather accurately from makeup and blowdown data.

Preliminary data collected in the preparation of this report suggest that the water consumption rates displayed above may need updating. As discussed in Section 7.3, the water consumption rates for oncethrough cooling are probably lower than listed above, and the water consumption rates for closed-cycle cooling are probably higher than listed above. The end result is likely a factor of two or three times greater water consumption rates for closed-cycle cooling over once-through cooling.

The corresponding WEF figure below displays values for water use during the raw materials phase of energy production more prominently, and adds rows for wind and other renewable energy sources.

RAW MATERIALS

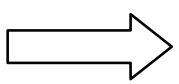

Thermoelectric Fuels

Coal: 5-70 gallons per MWh

Oil: wide variance

Natural Gas: wide variance

Uranium (nuclear):

45-150 gallons per MWh

\begin{tabular}{|c|}
\hline Hydroelectric \\
\hline Geothermal \\
\hline Solar \\
\hline Wind \\
\hline
\end{tabular}

TRANSFORMATION

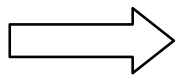

Thermoelectric

Generation with closedloop cooling:

190-720 gallons/MWh

Evaporative Loss: 4500 gallons per MWh 1400 gallons per MWh

Concentrating Solar: 750-820 gallons per MWh

Photovoltaic: minimal

Wind:

minimal
DELIVERY TO CUSTOMER

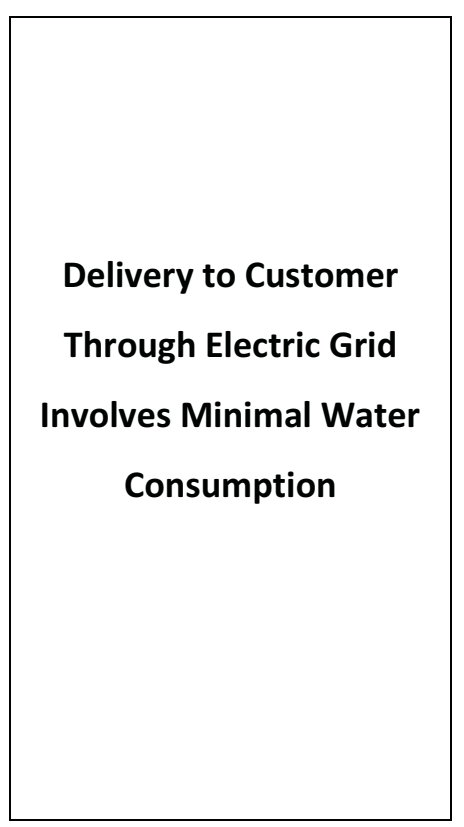

Figure 2-3: "Electricity Industry Value Chain - Water Consumption" (WEF, 2008) 
Finally, note that hydroelectric is the largest "user" of water among the options displayed. This is because of the high evaporation rate from reservoirs, with their large surface area. This evaporative loss is not a direct and sole consequence of hydroelectric power generation, and is viewed by water experts as not directly attributable to electricity generation in a manner comparable to other technologies. Evaporation is one impact associated with the beneficial uses of reservoirs (water storage, flood control, municipal water supply, irrigation, recreation, electricity generation, etc.).

Water consumption by nuclear power plants is significant, but only slightly higher than water consumption by coal plants. Nuclear plants operate at a relatively lower steam temperature and pressure, and thus lower cycle efficiency, which in turn requires higher cooling water flow-rates. Coal plants, with higher efficiency, can be cooled with slightly less water on a gal/MWhe $\mathrm{Masis}_{\mathrm{e}}$

It is important to recognize that as coal plant technology evolves to address climate change objectives, its demand for water will increase. The following table by NETL shows that water consumption by subcritical and supercritical pulverized coal plants will exceed water consumption by nuclear when $\mathrm{CO} 2$ Capture is added. Water consumption by Integrated Gasification Combined Cycle (IGCC) and Natural Gas Combined Cycle (NGCC) will remain below nuclear's consumption rate where closed-cycle cooling is used, even with $\mathrm{CO} 2$ Capture added to the process.

Table 2-5. Water consumption and cooling duty factors for thermoelectric power plants ${ }^{30}$

\begin{tabular}{|l|c|c|c|} 
& $\begin{array}{c}\text { Without } \mathbf{C O}_{2} \\
\text { Capture }\end{array}$ & $\begin{array}{c}\text { With } \mathbf{C O}_{2} \\
\text { Capture }\end{array}$ & $\begin{array}{c}\% \text { change with } \\
\mathbf{C O}_{2} \text { capture }\end{array}$ \\
\hline \multicolumn{2}{|c|}{ Water Consumption Factors (gallons } & per MWh net power) \\
\hline Nuclear & 720 & -- & \\
\hline Subcritical PC & 520 & 990 & $+90 \%$ \\
\hline Supercritical PC & 450 & 840 & $+90 \%$ \\
\hline IGCC, slurry-fed & 310 & 450 & $+50 \%$ \\
\hline NGCC & 190 & 340 & $+80 \%$ \\
\hline \multicolumn{1}{|c|}{ Cooling duty factors (MMBtu per MWh net power) } & \\
\hline Subcritical PC & 4.7 & 11 & $+130 \%$ \\
\hline Supercritical PC & 4.1 & 9.3 & $+130 \%$ \\
\hline IGCC, slurry-fed & 3.0 & 3.7 & $+20 \%$ \\
\hline NGCC & 2.0 & 4.2 & $+110 \%$ \\
\hline
\end{tabular}

${ }^{*}$ Based on a cooling water system utilizing wet recirculating cooling towers

The above table assumes closed-cycle cooling as the baseline for comparison. Based on these data from NETL, water consumption by an IGCC plant with $\mathrm{CO} 2$ Capture and closed-cycle cooling and water consumption by a nuclear plant operating on once-through cooling would be about the same. Nevertheless, IGCC is an attractive option for future power generation that consumes relatively less water than older fossil technologies. The following quote by James Rogers, Chairman, President and CEO of Duke Energy and strong proponent of nuclear and renewable energy, appears in the WEF report on "Thirsty Energy:" 
"One promising technology is integrated gasification combined-cycle (IGCC) advanced power systems. IGCC is a technology that efficiently converts coal to a synthetic gas that can be used in a gas turbine for power production. Roughly two-thirds of the power generated in an IGCC system is from the gas turbine. The excess heat from the turbine is used to produce steam in a heat recovery steam generator that produces the remaining one-third of the power. Since the gas turbine doesn't require condenser cooling water, IGCC plants require appreciably less water - up to $40 \%$ less - on a gallons per kilowatthour output basis."

As water usage grows as a strategic issue, the fact that nuclear energy consumes relatively more water than many other forms of electricity generation may be highlighted by proponents of energy alternatives to nuclear, possibly without presenting all the facts needed to address water issues holistically. This holistic approach as it relates to nuclear energy should consider its environmental advantages in areas such as nuclear's clean air profile, its small footprint in terms of land usage (in relation to renewable energy options), and its capacity to substitute plentiful nuclear fuel for limited supplies of coal and natural gas that would otherwise be consumed for electricity generation. The WEF Report "Thirsty Water" addresses this concept of holistic treatment of energy and water issues as follows:

\begin{abstract}
Water and Energy Issues Cannot Be Viewed in Isolation ${ }^{31}$
Water and energy are inextricably linked with other global issues, including climate change and energy security. A holistic approach to energy and water management considers all of these issues and looks for creative solutions that optimize all of these parameters. Some energy technologies with low $\mathrm{CO} 2$ emissions are large users of water, and technologies that may enhance energy security may be harmful from a water security standpoint. Thus, an optimized solution may involve tradeoffs among the various factors. In his perspective, Water and Energy: New Thinking, Peter Gleick sums up the energy water relationship in this way, "Decision-makers and corporations should better integrate energy issues into water policy and water issues into energy policy. Failure to link these issues will inevitably lead to disruptions in the supply of both water and power, while thoughtful, integrated policies will provide important advantages."
\end{abstract}

\title{
No Technology Is Inherently Good or Bad ${ }^{32}$
}

A corollary to the principle that water issues are local is that no technology is inherently good or bad. Even technologies that are very energy or water intensive have their place. The appropriateness of a technology depends on the local situation and the resources available. For example, desalination is an energy intensive way to provide drinking water, but in the Middle East where freshwater resources are scarce and energy resources are plentiful, desalination is likely the most sustainable way to provide drinking water. As described in the case studies, desalination plants are becoming more efficient, through co-production of electricity or use of renewable energy resources. Similarly, water-intensive technologies such as nuclear power and biofuels may be appropriate in areas where sufficient water exists to support them.

Some advocates for energy and water issues will argue that options for the future must meet all goals simultaneously - low water use $\underline{\text { AND }}$ low $\mathrm{CO} 2$ emissions $\underline{\text { AND }}$ energy sustainability. Although wind 
power comes close to meeting most of these goals and should therefore be encouraged as an energy source to meet expanding demand for electricity, it has one large disadvantage - it is intermittent and therefore not reliable as a baseload power source. Wind energy capacity factors average $30 \%-40 \%{ }^{33}$. Therefore, even though wind doesn't consume water when it operates, the backup power sources that operate when installed wind capacity is not generating electricity (typically fossil generation) do use water. As long as the contribution by wind to total electricity generation remains small, this need for backup power is environmentally inconsequential (consequences of wind power's fossil backup on clean air and clean water are small). But as wind energy expands as a percentage of total power generation, the contributions to both water consumption and $\mathrm{CO} 2$ emissions by the fossil backups to wind power become significant. If wind power begins to approach the capacity reserve margins essential to grid stability (i.e., $\sim 15 \%$ of total generation), then the added fossil generation required to backup wind would begin to surpass the wind generation itself, approaching a condition where two megawatts of new fossil capacity would be required for each addition of one megawatt of wind capacity (based on an average wind capacity factor of 33\%). Note that this outcome could be ameliorated if cost-effective energy storage technologies (e.g., pumped storage, compressed air, high voltage storage batteries) can be developed and deployed on a very large scale.

In contrast, nuclear generation is likely to remain base-loaded as the preferred low-cost form of generation, with fossil options (with slightly higher production costs) serving as the preferred backup to intermittent renewables as they expand. Fossil plants, particularly gas-fired plants, are easier to start and stop to accommodate daily cycles in power demand, and to respond to less predictable variations in wind (and solar) generation. Further, wind is generally competitive today with nuclear energy on a production cost basis, but this is primarily a result of being heavily subsidized at the federal level (and at the state level for many states), via production tax credits, investment tax credits, etc. Without these direct financial incentives for renewable energy, wind energy would likely be more expensive than nuclear energy, even on a total cost basis.

The bottom line from these comparisons of generation options is that there is no "silver bullet" that simultaneously addresses all environmental, national energy security and cost goals for the nation. Further, to meet these goals, we will need all of the above energy resources, working together. The holistic approach that is strongly recommended by the organizations that have examined these issues (as discussed in Chapter 1: DOE Report to Congress, the WEF studies, the interagency study sponsored OSTP under the guidance of the SWAQ, etc.) seeks to address all these issues in balance, and avoid any single issue dominating policy and decision-making at the expense of other important issues.

\subsection{Comparison of Water Usage Rates among Other Energy Sources (e.g., Transportation Fuels)}

The issue of water usage by other energy industries is covered in detail by the DOE Report to Congress, the WEF reports and other references. The primary focus of these assessments is water consumption by gas and liquid fuels, all of which require water to produce or extract raw materials and to refine products for use (primarily by the transportation sector). The key point of these analyses is that most of the new and emerging technologies being advocated to reduce U.S. reliance on foreign sources of oil and gas are in fact heavy consumers of water. This fact is going largely unnoticed, as biofuels (including 
ethanol and biodiesel) as well as oil shale or oil sands are touted as domestic solutions to overdependence on foreign oil - without discussing the impact on U.S. water resources from pursuing these options.

The following table provides data on water consumption among fuel types, including transportation fuels.

\begin{tabular}{|c|c|c|c|c|}
\hline \multirow{2}{*}{$\begin{array}{l}\text { Fuel Type } \\
\text { and } \\
\text { Process }\end{array}$} & \multirow{2}{*}{$\begin{array}{l}\text { Relationship } \\
\text { to Water } \\
\text { Quantity }\end{array}$} & \multirow{2}{*}{$\begin{array}{l}\text { Relationship } \\
\text { to Water } \\
\text { Quality }\end{array}$} & \multicolumn{2}{|c|}{ Water Consumption } \\
\hline & & & $\begin{array}{c}\text { Water consumed } \\
\text { per-unit-energy } \\
\text { [ gal / MMBTU ] }\end{array}$ & $\begin{array}{c}\text { Average gal } \\
\text { water consumed } \\
\text { per gal fuel }\end{array}$ \\
\hline $\begin{array}{l}\text { Conventional Oil \& Gas } \\
\text { - Oil Refining }\end{array}$ & \multirow{2}{*}{$\begin{array}{l}\text { Water needed to } \\
\text { extract and refine; } \\
\text { Water produced } \\
\text { from extraction }\end{array}$} & \multirow{2}{*}{$\begin{array}{l}\text { Produced water } \\
\text { generated from } \\
\text { extraction; } \\
\text { Wastewater generated } \\
\text { from processing; }\end{array}$} & $7-20$ & $\sim 1.5$ \\
\hline - NG extractioniProcessing & & & $2-3$ & $\sim 1.5$ \\
\hline $\begin{array}{l}\text { Biofuels } \\
\text { - Grain Ethanol Processing }\end{array}$ & \multirow{4}{*}{$\begin{array}{l}\text { Water needed } \\
\text { for growing } \\
\text { feedstock and for } \\
\text { fuel processing; }\end{array}$} & \multirow{4}{*}{$\begin{array}{l}\text { Wastewater generated } \\
\text { from processing; } \\
\text { Agricultural irrigation } \\
\text { runoff and infiltration } \\
\text { contaminated with } \\
\text { fertilizer, herbicide, and } \\
\text { pesticide compounds }\end{array}$} & $12-160$ & $\approx 4$ \\
\hline - Corn Irrigation for EtoH & & & $2500-31600$ & $\sim 980^{*}$ \\
\hline - Biodiesel Processing & & & $4-5$ & $\sim 1$ \\
\hline - Soy Irrigation for Biodiesel & & & $13800-60000$ & $\sim 6500^{*}$ \\
\hline $\begin{array}{l}\text { - Lignocellulosic Ethanol } \\
\text { and other synthesized } \\
\text { Biomass to Liquid (BTL) fuels }\end{array}$ & $\begin{array}{l}\text { Water for processing; } \\
\text { Energy crop impacts } \\
\text { on hydrologic flows }\end{array}$ & $\begin{array}{l}\text { Wastewater generated; } \\
\text { Water quality benefits of } \\
\text { perennial energy crops }\end{array}$ & $\begin{array}{c}24-150 \pm \S \text { (ethanol) } \\
14-90 \neq \S \text { (diesel) }\end{array}$ & $\begin{array}{l}\sim 2-6 \pm \S \\
\sim 2-6 \pm \S\end{array}$ \\
\hline $\begin{array}{l}\text { Oil Shale } \\
\text { - In situ retort }\end{array}$ & \multirow{2}{*}{$\begin{array}{l}\text { Water needed to } \\
\text { Extract / Refine }\end{array}$} & \multirow{2}{*}{$\begin{array}{l}\text { Wastewater generated; } \\
\text { In-situ impact uncertain; } \\
\text { Surface leachate runoff }\end{array}$} & $1-9 \pm$ & $\sim 2 \pm$ \\
\hline - Ex situ retort & & & $15-40 \pm$ & $\sim 3 \pm$ \\
\hline Oil Sands & $\begin{array}{l}\text { Water needed to } \\
\text { Extract / Refine }\end{array}$ & $\begin{array}{l}\text { Wastewater generated; } \\
\text { Leachate runoff }\end{array}$ & $20-50$ & $\sim 4-6$ \\
\hline $\begin{array}{l}\text { Synthetic Fuels } \\
\text { - Coal to Liquid (CTL) }\end{array}$ & \multirow{3}{*}{$\begin{array}{l}\text { Water needed for } \\
\text { synthesis andior } \\
\text { steam reforming of } \\
\text { natural gas (NG) }\end{array}$} & $\begin{array}{l}\text { Wastewater generated } \\
\text { from coal mining and } \\
\text { CTL processing }\end{array}$ & $35-70$ & $\sim 4.5-9.0$ \\
\hline - Hydrogen RE Electrolysis & & & $20-24$ & $\sim 3 i$ \\
\hline - Hydrogen (NG Reforming) & & & $40-50 t$ & $\sim 7 t$ \\
\hline $\begin{array}{l}\text { t Ranges of water use per unit } \\
\text { * Conservative estimates of wat } \\
\pm \text { Estimates based on unvalidate }\end{array}$ & onerme larmely hoced and & ta taken from the Energy-Wo & $\begin{array}{l}\text { ter Report to Congress (D } \\
\text { d on per-acre crop water }\end{array}$ & $\begin{array}{l}\text { OE, 2007) } \\
\text { demand and fuel yield } \\
\text { tock production }\end{array}$ \\
\hline
\end{tabular}

Table 2-6. Non-Conventional Transportation Fuel Connections to Water (Source: Sandia National Lab) ${ }^{34}$

Of particular note are the water consumption requirements for corn-based ethanol and soy-based biodiesel, which consume roughly $\underline{1000}$ gallons of water and $\underline{6500}$ gallons of water respectively for every one gallon of fuel produced. Also note that synthetic fuels (e.g., coal to liquids and hydrogen) consume 2-6 times more water than conventional oil and gas refining. The water consumption rates for cornbased ethanol and soy-based biodiesel are high because of their irrigation requirements. Note that, if the technology advances to allow for lignocellulosic ethanol to begin substituting for these waterintensive first generation biofuels are successful, then water consumption rates become quite low, on the order of conventional oil and gas refining. Also note that the energy requirements for these advanced transportation fuels are also quite high, which contributes to the high cost challenges that these advanced fuels must overcome. This suggests the need for a balanced energy portfolio. 


\subsection{Electricity Use for Water Management}

To complete the picture, it is important to recognize that supplying and treating water requires large amounts of electricity. According to EPRI, "Some $4 \%$ of the nation's electricity use goes towards moving and treating water/wastewater. Approximately $80 \%$ of [U.S.] municipal water processing and distribution costs are for electricity." ${ }^{35}$ The WEF study, "Thirsty Energy" notes:

"Pumping water over long distances or great elevations is very energy intensive. For example, water supplied to Southern California from the state water project travels 2,000 feet [elevation rise] over the Tehachapi Mountains, the largest lift of any water system in the world, and requires about 9,200 kWh per million gallons. The electricity used to deliver water to customers in Southern California is equal to one-third of total average household electricity use. Water travels long distances not just for residential use, but for agricultural use as well. ${ }^{36}$

The WEF Water Initiative Report notes that: "Desalination plants in San Diego and London cannot be built because the facilities would consume too much energy and the power supply is too thin." ${ }^{37}$

Summary: As with the earlier comparisons of electricity generating options, these data show that there are no "silver bullets" in either the electricity generation arena or the advanced fuels arena. They also help reinforce the need for a holistic approach to energy-water management that recognizes the interlocking principles that supplying energy requires water, and supplying water requires energy. 


\section{FEDERAL REGULATIONS ON CLEAN WATER AND RELEVANT COURT DECISIONS}

\subsection{The U.S. Environmental Protection Agency:}

The U.S. Environmental Protection Agency (EPA) leads the nation's environmental science, research, education and assessment efforts. The mission of the Environmental Protection Agency is to protect human health and the environment. Its goals ${ }^{38}$ from its most recent Strategic Plan are as follows:

Goal 1: Clean Air and Global Climate Change: Protect and improve the air so it is healthy to breathe and risks to human health and the environment are reduced. Reduce greenhouse gas intensity by enhancing partnerships with businesses and other sectors.

Goal 2: Clean and Safe Water: Ensure drinking water is safe. Restore and maintain oceans, watersheds, and their aquatic ecosystems to protect human health, support economic and recreational activities, and provide healthy habitat for fish, plants, and wildlife.

Goal 3: Land Preservation and Restoration: Preserve and restore the land by using innovative waste management practices and cleaning up contaminated properties to reduce risks posed by releases of harmful substances.

Goal 4: Healthy Communities and Ecosystems: Protect, sustain, or restore the health of people, communities, and ecosystems using integrated and comprehensive approaches and partnerships.

Goal 5: Compliance and Environmental Stewardship: Protect human health and the environment through ensuring compliance with environmental requirements, by enforcing environmental statutes, preventing pollution, and promoting environmental stewardship. Encourage innovation and provide incentives for governments, tribes, businesses, and the public that promote environmental stewardship and long term sustainable outcomes.

The EPA is organized under a Cabinet Level Administrator, a Deputy Administrator, nine Assistant Administrators, and ten Regional Administrators who lead the EPA's ten regional offices. Two of the Assistant Administrators have an important role with respect to the nation's nuclear power plants: The Assistant Administrator for Air and Radiation, and the Assistant Administrator for Water. Two key laws passed by Congress provide the primary legislative basis for the policies and programs under the Assistant Administrator for Water: The Clean Water Act (CWA) - the focus of this Chapter - and the Safe Drinking Water Act (SDWA), originally passed in 1974 and amended in 1986 and 1996.

From the EPA Website: The Clean Water Act (CWA) establishes the basic structure for regulating discharges of pollutants into the waters of the United States and regulating quality standards for surface waters. The Federal Water Pollution Control Act, enacted in 1948, was significantly reorganized and expanded in 1972 as the "Clean Water Act," with amendments enacted in 1977.

"Under the CWA, EPA has implemented pollution control programs such as setting wastewater standards for industry. We have also set water quality standards for all contaminants in surface waters. 
"The CWA made it unlawful to discharge any pollutant from a point source into navigable waters, unless a permit was obtained. EPA's National Pollutant Discharge Elimination System (NPDES) permit program controls discharges." ${ }^{39}$ (See discussion below.)

\subsection{The Clean Water Act (CWA): 1970s to Date:}

[The following summary of CWA history is limited to $\$ 316$ and its impacts on the use of once-through cooling by thermoelectric power plants. There are in fact many other issues relative to power plant waste water and pollutant discharges that are relevant to power plants generally (and specifically to fossil plants), in addition to $\S 316$. However, nuclear power plants to not use or discharge significant hazardous materials in the generation of electricity. The $\S 316(b)$ history includes significant interventions by the court system to address challenges to the regulations and EPA implementation. The text has been developed by summarizing or paraphrasing excerpts from recent court decisions and associated briefs and appeals by the parties relative to the CWA § 316(b) rules, as contested in the Second Circuit and reviewed by the Supreme Court in 2009. Most discussions of the legal issues are omitted here, even though they were central to the outcomes as described, in order to focus on the technology and water policy issues that DOE and industry will need to cope with in the coming years. This is not to suggest that legal and legislative matters such as the legal definitions of "Best Technology Available" and "wholly disproportionate," Congressional intent, conflicts among Circuit Court cases on CWA issues, etc. are not important, but rather that they are beyond the scope of this report. For further details on the legal aspects, the following websites contain all the recent filings, briefs and decisions: http://www.scotuswiki.com/index.php?title=Entergy Corp. V. EPA, and http://www.epa.gov/waterscience/316b/index.html ]

The principal law governing pollution of the nation's surface waters is the Federal Water Pollution Control Act, or Clean Water Act. It was originally enacted in 1948, but was totally revised by amendments in 1972. The two key sections of the 1972 Act that impact thermoelectric generating plant cooling water systems are as follows: ${ }^{5}$

- Section 316(a) relates to requirements for thermal discharge, which are established elsewhere in the CWA, and provides that effluent limitations associated with such discharge should generally not be more stringent than necessary to "assure the protection and propagation of a balanced indigenous population of shellfish, fish, and wildlife in and on that body of water." ${ }^{40} \S 316(a)$ itself is a variance provision, which allows facilities to apply for a variance from those regulatory requirements by making a Demonstration to support a variance for alternate effluent limitations. Most facilities don't need to use this provision, by meeting the basic standards.

- Section 316 (b) requires that the location, design, construction and capacity of cooling water intake structures reflect the best technology available for minimizing "adverse environmental impact."

\footnotetext{
${ }^{5}$ Many other sections of the CWA have a significant impact on thermoelectric plants. For example, $\S 402$ regulates discharges (e.g., chemicals) from these plants.

6 "Adverse environmental impact" has never been defined by EPA. Regional and State permitting authorities have made case-by-case decisions relative to this term, based on their delegated authority established in the CWA.
} 
More than 1,500 industrial facilities use large volumes of cooling water from lakes, rivers, estuaries or oceans to cool their plants, including steam electric power plants, pulp and paper makers, chemical manufacturers, petroleum refiners, and manufacturers of primary metals like iron and steel and aluminum. Cooling water intake structures may cause adverse environmental impact by pulling large numbers of fish and shellfish or their eggs or larval stages into a power plant's or factory's cooling system. There, the organisms may be killed or injured by heat, physical stress, or by chemicals used to clean the cooling system. Larger organisms may be killed or injured when they are trapped against screens at the front of an intake structure. ${ }^{41}$

Three relatively recent rulemaking phases address cooling water intakes (see details later):

- Phase I rule, promulgated in 2001, covers new facilities

- Phase II rule, promulgated in 2004 , covers large ( $\geq 50 \mathrm{MW}$ ) existing electric generating plants

- Phase III rule, promulgated in 2006, covers certain existing facilities (including smaller power plants) and new offshore and coastal oil and gas extraction facilities

The CWA itself contains very brief and general guidance on intake structures. Section 316(b) states, in full:

"Any standard established pursuant to section 301 or section 306 of this Act and applicable to a point source shall require that the location, design, construction, and capacity of cooling water intake structures reflect the best technology available for minimizing adverse environmental impact."

The EPA first published regulations implementing $\S 316(b)$ in 1976, which were struck down by the Fourth Circuit on procedural grounds. Absent a rule, EPA proceeded on a "best professional judgment" basis, which included consideration of costs in assessing "Best Technology Available." Shortly thereafter (1979), the First Circuit considered a challenge by environmental petitioners to EPA's approval of the location and design of a then-proposed cooling water intake structure at the Seabrook nuclear facility in New Hampshire. The First Circuit rejected the challenge, explaining: "The Administrator decided that moving the intake further offshore might further minimize the entrainment of some plankton, but only slightly, and the costs would be "wholly disproportionate to any environmental benefit." Petitioners, wisely, do not argue that the cost may not be considered, and no harm is done by noting that there would be other costs. The legislative history clearly makes cost an acceptable consideration in determining whether the intake design "reflect(s) the best technology available. ${ }^{42}$

From the late 1970s to the present, the EPA and state permitting authorities continued to regulate thermoelectric facilities under $\S 316(\mathrm{~b})$ on the basis of this decision and other precedents that allowed for cost as a consideration under a "best professional judgment" process, exercised in collaboration with state permitting authorities. During this three-decade era, EPA and state permitting authorities considered cost as a factor in their decisions, which were made on a site-by-site basis based on quantitative analyses provided by permittees and other parties. Independent analyses or reviews of cost data were often performed, without imposing a formal or quantitative cost-benefit analysis criteria or process. For example, the qualitative "wholly disproportionate" concept established in the Seabrook case above by the First Circuit, was used extensively in decision-making, without quantitative criteria. 
These state permitting authorities were given significant authority at the outset of the CWA by the creation of the National Pollutant Discharge Elimination System (NPDES). Section 402 of the CWA authorized a state level permit program "... to control water pollution by regulating point sources within their jurisdiction that discharge pollutants into "waters of the U.S." ${ }^{43}$ Small point sources such as individual homes typically do not need an NPDES permit; however, industrial, municipal, and other facilities must obtain permits if their discharges go directly to surface waters. In most cases, the NPDES permit program is administered by "authorized states." Since its introduction in 1972, the NPDES permit program is responsible for significant improvements to our Nation's water quality. ${ }^{44}$

\section{State NPDES Program Authority}

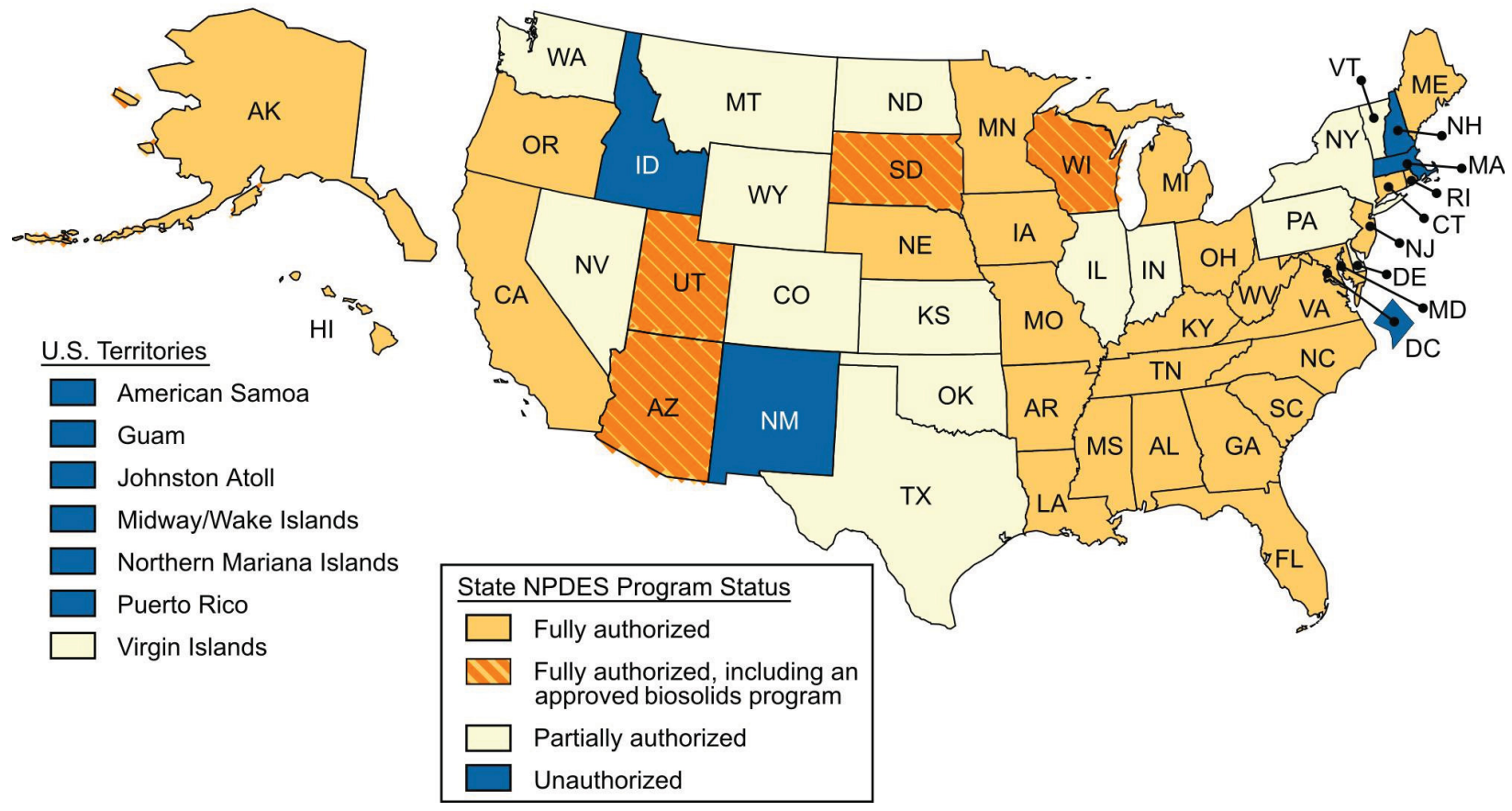

Figure 3-1: The NPDES Permitting System (EPA Website)

\footnotetext{
${ }^{7}$ As stated in a legal brief by a coalition of 18 States Attorneys General, "Under the CWA's program of cooperative federalism, state water pollution control agencies are primarily responsible for the statute's implementation. See 33 U.S.C. $§ 1251$ (b) (acknowledging that it is the states' "primary responsibility[y] . . to prevent, reduce, and eliminate pollution”). Management of the nation's natural resources depends on the leading efforts of the states. Forty-six states [see figure 3-1] operate permitting programs for point-source discharges into state waters through the National Pollution Discharge Elimination System ("NPDES"). Under this program, discharge of most regulated pollutants into the waters of the United States is illegal without a valid NPDES permit. States may also apply more stringent effluent limitations in their NPDES permits than those set by EPA. See 33 U.S.C. § 1370. States implement $\S 316$ (b) through the NPDES permitting program."
} 
A body of principles and precedents built up over the years on how to regulate thermoelectric power plants under $\S 316(\mathrm{~b})$, even though there was no formal rulemaking. This evolution of precedents, absent a formal definition of "adverse environmental impact" allowed for some consideration of the overall impacts on the source water body in making decisions on the adequacy of technology choices in the first two decades of CWA implementation. However, court challenges and decisions caused enforcement to devolve into a narrow focus on impingement mortality and entrainment of aquatic species at the intake structure of a facility as the metric of choice, with less focus on overall impacts on the source water body, or on other environmental impacts unrelated to impingement and entrainment.

Well before the $\S 316$ (b) Phase I rulemaking of 2001, there was a growing trend toward requiring closed cooling systems for new plants being built during this period, based on "best professional judgment" that favored this design approach from both a thermal discharge perspective and an intake structure (i.e., § 316(b)) perspective. It is important to note that the environmental downsides from closed cycle cooling were not fully understood or appreciated during this era. Preconstruction "best technology available" (BTA) determinations were made for many of the more recently constructed nuclear power plants on a site-specific basis, usually during the design phase. Power plants were then constructed with the approved cooling water intake structures, which determined the design of the circulating water system, the condensers, and other plant equipment. In a few cases, the preconstruction determination was made after the design was complete or even after construction start, which resulted in situations where, for example, a large intake structure was constructed for once-through cooling but cooling towers were added and accommodated in the final design.

In the mid-1990s, in order to resolve a lawsuit filed by environmental groups, the EPA entered into a consent decree, under which it agreed to promulgate nationwide regulations regarding cooling water intake structures for all industrial users. EPA proposed and promulgated a three-phased approach to the $\S 316(\mathrm{~b})$ rulemaking, as introduced above: ${ }^{8}$

- Phase I rule, promulgated in 2001, covers new facilities of all kinds including new thermoelectric generating plants

- $\quad$ Phase II rule, promulgated in 2004, covers large existing electric generating plants built before 2002 that withdraw over 50 million gallons per day of cooling water from waters of the U.S.

- Phase III rule, promulgated in 2006, covers certain existing facilities and new offshore and coastal oil and gas extraction facilities not subject to Phase II.

For the Phase I rule, EPA exercised its discretion to identify closed-cycle cooling as the Best Technology Available (BTA) for new facilities. The Phase I rule allowed for an alternative to closed-cycle cooling, but at a very high threshold. It created a two-track approach, under which Track 1 is a "fast track" approach that effectively requires closed-cycle cooling. The Track 2 option is a "demonstration track" approach that requires any combination of design measures, technologies and operating methods to reduce

\footnotetext{
${ }^{8}$ U.S. nuclear power plants are impacted by the Phase I and Phase II rules (as are fossil plants), but not the Phase III rule. (The Phase III rule implements § 316(b) on a case-by-case basis for existing facilities not covered by the Phase II rule and is currently under review in the Fifth Circuit.)
} 
adverse environmental impact to a level comparable to that which would be achieved under Track 1 . The EPA defined "comparable" as reductions of both impingement mortality and entrainment to $90 \%$ or greater of the Track 1 reduction. The Track 2 approach requires a Comprehensive Demonstration Study (CDS) that must be submitted to the permitting authority along with the NPDES application that evaluates all the options the facility intends to use. Track 2 initially allowed restoration to be used as a compliance technology. The Phase I rule was challenged but largely upheld by the Second Circuit in Riverkeeper, Inc. v. EPA (an earlier case decided in 2004 on the Phase I rulemaking, often called "Riverkeeper ("). The only part of the Phase I rule that was struck down by the Court was the provision that allowed use of restoration measures (see Section 7.3).

The final Phase II regulations were published in the Federal Register on July 9, 2004. The regulation became effective on September 7, 2004. The final rule sets standards but provides flexibility by offering several alternatives for power plants to comply. A high level summary of the final Phase II rule and its environmental benefits and costs follows, paraphrased from the EPA website: ${ }^{45}$

\section{"Summary of the Final Rule}

The final rule requires protection against these losses. For example, impingement ${ }^{9}{ }^{46}$ requirements call for the number of organisms pinned against parts of the intake structure to be reduced by 80 to 95 percent from uncontrolled levels. Entrainment ${ }^{10}$ requirements call for the number of aquatic organisms drawn into the cooling system to be reduced by 60 to 90 percent from uncontrolled levels. Large power plants have flexibility to comply and to ensure energy reliability. The rule provides several compliance alternatives, such as using existing technologies, selecting additional fish protection technologies (such as screens with fish return systems), and using restoration measures." [Restoration measures were later reversed and remanded by the Second Circuit.]

\footnotetext{
${ }^{9}$ Impingement is defined on EPA's website as a situation “....when organisms are trapped against intake screens by the force of the water being drawn through the cooling water intake structure. The velocity of the water withdrawal by the cooling water intake structure may prevent proper gill movement, remove fish scales, and cause other physical harm or death of affected organisms through exhaustion, starvation, asphyxiation, and descaling. Death from impingement ("impingement mortality") can occur immediately or subsequently as an individual succumbs to physical damage upon its return to the water body."

10 "Entrainment occurs when organisms are drawn through the cooling water intake structure into the cooling system. Organisms that become entrained are typically relatively small, aquatic organisms, including early life stages of fish and shellfish. Many of these small, fragile organisms serve as prey for larger organisms higher on the food chain which are commercially and recreationally desirable species. As entrained organisms pass through a facility's cooling system they may be subject to mechanical, thermal, and at times, chemical stress. Sources of such stress include physical impacts in the pumps and condenser tubing, pressure changes caused by diversion of the cooling water into the plant or by the hydraulic effects of the condensers, sheer stress, thermal shock in the condenser and discharge tunnel, and chemical toxic effects from antifouling agents such as chlorine. Similar to impingement mortality, death from entrainment can occur immediately or subsequently as the individual succumbs to the damage from the stresses encountered as it passed through the cooling water system once it is discharged back into the water body."
} 


\section{“Environmental Benefits and Costs}

EPA conducted rigorous scientific and economic analyses to develop this rule. The Agency worked with states, industry groups, and environmental organizations to determine, on a national basis, how best to protect the aquatic life that is critical to the environment and to commercial and recreational activities. EPA considered the costs and financial impacts to industry and its ability to produce energy in developing flexible compliance alternatives. The rule [would have minimal impact on] supply, distribution, or use of energy produced by these power plants."

"This rule protects more than 200 million pounds of aquatic organisms annually from death or injury by cooling water intake structures. The [estimated] impingement and entrainment reduction benefits range from $\$ 73$ million to $\$ 83$ million per year. These benefits are primarily from improvements to commercial and recreational fishing. There are likely to be other benefits, for example, more robust and productive aquatic ecosystems, although these are harder to quantify. EPA estimates that this rule affects about 550 facilities and costs about $\$ 400$ million per year."

A further explanation of the process undertaken by EPA and the considerations it used in developing its proposed Phase II rule follows, (with most citations removed), taken from one of Federal Government's court filings, prepared by the Solicitor General and EPA on behalf of the Federal Parties: ${ }^{47}$

"In the Phase II rule at issue here, EPA selected a combination of technologies to reflect BTA for existing large power plants. Those technologies include, among others, relocation of intakes, fine mesh passive screens, double-entry single-exit traveling screens, velocity caps, larger intakes to decrease intake velocity, and barrier nets. EPA selected those technologies based on the various options" "overall efficacy, availability, economic practicability, including economic impact and the relationship of costs with benefits, and non-water quality environmental impacts, including energy impacts."

Based on the chosen technologies, EPA established national performance standards for reducing impingement mortality (by $80 \%-95 \%$ ) and entrainment (by 60\%-90\%). EPA did not, however, require the use of any specific technology, because it wanted to "provide[] a high degree of flexibility for existing facilities to select the most effective and efficient approach and technologies for minimizing adverse environmental impact associated with their cooling water intake structures."

EPA considered treating closed-cycle recirculating cooling systems, which it had determined to be BTA for (new) Phase I facilities, as BTA for (existing) Phase II facilities. EPA rejected that alternative, however, because of its "generally high costs (due to conversions), the fact that other technologies approach the performance of this option, concerns for energy impacts due to retrofitting existing facilities, and other considerations." EPA explained that: the cost of closed-cycle recirculating cooling towers for existing Phase II facilities was many times higher than for new Phase I facilities because of the need to retrofit facilities that had not been designed to use closed-cycle towers; such cooling towers were less energy efficient than EPA's chosen alternatives; and, "[a]lthough not 
identical, the ranges of impingement and entrainment reduction are similar" under EPA's chosen option and the closed-cycle alternative.

The rule also allows a facility to request a variance resulting in a site-specific BTA determination if the facility demonstrates that its cost of complying with the national performance standards is significantly greater than the environmental benefits. EPA provided that flexibility because its "comparison of national costs to national benefits" underlying the nationwide performance standards "may not be applicable to a specific site due to variations in (1) the performance of intake technologies and (2) characteristics of the water body in which the intake(s) are sited."

The Phase II rule was challenged in the courts by environmental groups and several Northeastern states. Industry and other state organizations also challenged aspects of the rule. Petitions for review were filed in several different circuit courts. These petitions were initially consolidated in the Ninth Circuit and petitioned to be moved to the Second Circuit.

In January 2007, the Second Circuit reversed and remanded many of the key features of the Phase II regulation. In a memorandum dated March 20, 2007 to Regional Administrators, the Assistant Administrator for Water summarized the remanded provisions:

- EPA's determination of the Best Technology Available under section 316(b);

- The Rule's performance standard ranges;

- The cost-cost and cost-benefit compliance alternatives;

- The Technology Installation and Operation Plan provision;

- The restoration provisions; and

- The "independent supplier" provision.

The EPA memo went on to state: "With so many provisions of the Phase II rule affected by the decision, the rule should be considered suspended. I anticipate issuing a Federal Register notice formally suspending the Rule in the near future." EPA formally suspended the Phase II rule in July 2007.

The industry sought review of the Second Circuit decision by the Supreme Court. Their petitions for a "writ of certiorari" were led by two utilities, Entergy and PSEG, supported by a petition from the Utility Water Act Group (UWAG). The State of Nebraska, representing a coalition of 18 states throughout the country, also filed a brief supporting Supreme Court review. Opposed to the appeal were a number of environmental groups represented by Riverkeeper, and the State of Rhode Island, representing a coalition of six states in the Northeast. The Federal Government filed a brief in opposition to certiorari, saying the issues were not worthy of Supreme Court review, but indicated that the Federal Government/EPA would largely support the petitioners if certiorari were granted, because of the significance of the implications.

The primary concerns expressed by industry and the large coalition of states against the Second Circuit's decision were: 
1. Strong disagreement over the conclusion that EPA could not consider costs as part of its decision process, based on longstanding interpretation of the EPA's statutory authority and over 30 years of precedent, supported by the courts, including Courts of Appeal.

2. Strong opposition to the Second Circuit's new formulation for the only allowable exceptions for considering costs, whereby the EPA could consider cost only to determine (1) what [single] technology is affordable to the industry as a whole; or (2) whether there is a less expensive technology that is capable of achieving a virtually identical result. The Second Circuit made it virtually impossible to comply with $\S 316(\mathrm{~b})$ without converting all thermoelectric cooling systems throughout the U.S. to closed-cycle cooling technology.

3. Strong opposition to the Second Circuit's decision to prohibit the use of variances or restorative measures to achieve compliance with the regulation, which have been upheld by other Circuits.

4. Strong concern that items 2 and 3 above would have the effect of mandating a one-size-fits-all technology approach for every plant in every region of the country, irrespective of regional, state and site-specific differences that require tailored solutions.

5. Strong opposition by many states to an outcome that effectively eliminated the "cooperative federalism" relationship between EPA and state permitting authorities established in the CWA and the NPDES, under which states have the authority to apply the law, including the BTA determination, in a manner that best matches the technology options available to each state, including the practicality of these best technology options to the hydrology at each site.

The Supreme Court granted certiorari in April 2008, but limited its review to the question of EPA's authority to conduct a cost-benefit analysis. Oral arguments were made before the Supreme Court on December 2, 2008, and the court issued its decision on April 1, 2009. In a 6-3 decision, ${ }^{11}$ the Supreme Court "conclude[d] that the EPA permissibly relied on cost-benefit analysis in setting the national performance standards and in providing for cost-benefit variances from those standards as part of the Phase II regulations." ... "The judgment of the Court of Appeals is reversed and the cases are remanded for further proceedings consistent with this opinion." The Supreme Court "... express[ed] no view on the remaining bases for the Second Circuit's remand which did not depend on the permissibility of costbenefit analysis."

\section{Comment:}

It is important to recognize that the Supreme Court did not mandate the use of cost-benefit analysis by EPA in decision-making under $\S 316(\mathrm{~b})$. Rather, it said that the EPA is allowed to use cost-benefit

\footnotetext{
${ }^{11}$ The majority opinion was joined by five justices; the minority opinion by three justices. Justice Breyer concurred with the majority opinion that cost-benefit analysis should be permissible, but issued a separate opinion that would have sent the case back to EPA to further explain its switch in the language it used in spelling out its standard for conducting cost-benefit analysis ("wholly disproportionate to the environmental benefit to be gained" vs. significantly greater than the benefits ...").
} 
analysis in deciding what cooling water intake structures must be used by operating thermoelectric power plants. EPA might act on this allowed discretion and revert back to an approach that essentially mirrors its final 2004 Rule. Or it might accommodate some aspects of the Second Circuit decision, given the comment by the Supreme Court that it "...express [es] no view on the remaining bases for the Second Circuit's remand that did not depend on the permissibility of cost-benefit analysis." This uncertainty makes it difficult for states and permit holders to renew existing permits, and for industry to consider any plant modifications in relation to $\S 316(\mathrm{~b})$ matters, until more is known about revised requirements. However, R\&D on these matters is both timely and constructive. To the degree that initial actions can be taken in response to possible outcomes from the Phase II process, Chapter 9 attempts to identify the appropriate action. Further, since allowance for cost-benefit analysis is essential to a holistic approach to energy-water issues, it is essential that industry be prepared to support whatever analysis approach EPA takes, with appropriate facts and data.

Recently, EPA has announced its intent to issue a proposed revised § 316(b) rule by February 2011 and finalize it by July 2012. It will incorporate Phase III facilities as well. EPA has also indicated that the proposed rule will require closed cycle cooling as BTA on all effected facilities or a subset of facilities.

\subsection{The Role of the Nuclear Regulatory Commission}

As part of its responsibility to license nuclear facilities in the U.S., the NRC plays an important role in assessing environmental protection issues. NRC's authority and obligation under federal law to assess the environmental impacts of its decisions comes from the National Environmental Policy Act (NEPA), which specifies that a "...major Federal action significantly affecting the quality of the human environment requires a detailed statement on, among other things, the environmental impact of the proposed action and alternatives to the proposed action. The statement is to accompany the proposal through the agency review process. The Act also established in the Executive Office of the President a Council on Environmental Quality, which has issued regulations on the preparation of environmental impact statements and on public participation in the preparation of the statements." ${ }^{48}$ NRC has determined that the license renewal of an existing nuclear reactor and the licensing of a new nuclear reactor both constitute "major Federal actions." This in turn invokes the processes described below, quoted or paraphrased from the NRC website sections on "Reactor License Renewal" and "New Reactors".

License Renewal: "The NRC has established a timely license renewal process and requirements, codified in 10 CFR Part 51 [Environmental Protection Regulations for Domestic Licensing and Related Regulatory Functions] and 10 CFR Part 54 [Requirements for Renewal of Operating Licenses for Nuclear Power Plants], that are needed to assure safe plant operation for extended plant life. The timely renewal of licenses for an additional 20 years, where appropriate to renew them, may be important to ensuring an adequate energy supply for the United States during the first half of the 21st century."

New Reactors: "For new reactor facilities, the NRC reviews applications submitted by prospective licensees, and (when appropriate) issues standard design certifications, early site permits, limited 
work authorizations, construction permits, operating licenses, and combined licenses. Of the NRC's existing regulations, the following are most relevant to the design, siting, construction, and operation of new commercial nuclear power facilities:

- 10 CFR Part 51, "Environmental Protection Regulations for Domestic Licensing and Related Regulatory Functions"

- 10 CFR Part 52, "Licenses, Certifications, and Approvals for Nuclear Power Plants"

"Under the NRC's regulations in 10 CFR Part 52 and in accordance with the applicable provisions of 10 CFR Part 51, which are the NRC regulations implementing the National Environmental Policy Act (NEPA), the NRC is required to prepare an environmental impact statement (EIS) as part of its review of an early site permit (ESP) or combined license (COL) application. ... The NRC staff currently conducts its environmental reviews using NUREG-1555, "Environmental Standard Review Plan" (ESRP). However, the NRC is also considering alternatives for Enhancing the Efficiency and Effectiveness of the Environmental Review Process."

\section{NRC Review and Approval of Nuclear Plant Cooling Water Systems:}

Based on the above requirements that "major Federal actions" such as initial licensing or re-licensing of a nuclear plant be reviewed to ensure conformance to the National Environmental Policy Act, NRC reviews the cooling water systems of all nuclear plants for conformance to Federal environmental requirements, in addition to its own nuclear safety requirements. These safety and environmental reviews are done in parallel; and NRC authorization for initial operation (or continued operation during a license renewal period) is granted only after both safety and environmental requirements are met.

In the case of license renewal, an applicant must submit a detailed application under Part 54 for the plants design and operation, and a separate application under Part 51 for its compliance with NEPA. In the case of new plants, the applicant has options. Part 52 was designed for the baseline case in which an applicant applies for an "Early Site Permit" (ESP) without a commitment to a particular design or construction plan. Separately, standardized reactor designs are submitted by reactor vendors for safety review and approval by NRC via a rulemaking process ("Design Certification" or DC). An owner-operator, would then take his approved site (previously approved by NRC using the Part 52 ESP process) and a certified reactor design, and merge them into an integrated application to construct and operate that design on that site (the "Combined License", or COL). This baseline sequence allows for the least possible "regulatory approval risk" to potential owner-operators, who can establish high confidence in both the reactor design and the site it will be built on, prior to actual investment in the reactor project.

However, Part 52 gives the applicant the flexibility to combine these steps in various ways or to pursue them in parallel instead of in series, albeit with some increased regulatory risk. For example:

- Some COL applications reference designs that have not yet completed design certification

- Some COL applications incorporate the ESP review and approval as part of the COL process. 
In the first case, much of the NRC's safety review of the cooling water systems is conducted during the $\mathrm{COL}$ process, having not yet been completed as part of a previously approved certification. In the second case, the NRC's environmental review of the site, having not been previously approved, must be reviewed as part of the $\mathrm{COL}$ review and approval process. The regulatory risk associated with combining the ESP and COL steps is reduced when the application is to add new reactors to an existing reactor site that has already been approved by NRC. In all cases, the ESP and DC reviews and approvals, including public hearing and comment periods prescribed by law, must be completed before the COL is issued.

For both new plant and license renewal reviews, the NRC provides generic guidance to applicants on the required content of their site specific Environmental Reports, primarily via NUREG-1555 (Standard Review Plan) and NUREG-1555, Supplement 1: Operating License Renewal, respectively, and supporting Regulatory Guides ${ }^{12}$. In addition, NRC conducted a formal generic evaluation of environmental issues relevant to License Renewal, to narrow the scope of information that needs to be provided. This generic evaluation, NUREG-1437, "Generic Environmental Impact Statement for License Renewal of Nuclear Plants" (GEIS) was issued in 1996 (see below). NRC then issues a site-specific Supplement to this GEIS to report its findings and conclusions on each Environmental Review.

Although the Standard Review Plan provides guidance on complying with Part 51 for new plants, no comparable GEIS for ESP or COL applications has been developed. The Commission provided additional guidance to the NRC staff in 2007 on "Enhancing the Efficiency and Effectiveness of the Environmental Review Process" for new plants, but additional guidance on how to address generic environmental issues has not been developed. Hence, new plant applicants address the full scope of environmental issues in their Environmental Reports submitted as part of an ESP or COL application.

\section{Specific Results of NRC Reviews of License Renewal Applications Relative to Cooling Water Issues:}

The Environmental Review process under NEPA carried out for License Renewal addresses water issues and aquatic species protection ( $\S 316$ (b) issues) in great detail. The following detailed discussion of this process is important to understanding how NRC's approach to assessing the adequacy of environmental protection under NEPA differs from how EPA assesses equivalent issues under the CWA.

Generic Environmental Impact Statement for License Renewal (NUREG-1437): "The Generic Environmental Impact Statement (GEIS) examines the possible environmental impacts that could occur as a result of renewing any commercial nuclear power plant license and, to the extent possible, establishes the bounds and significance of these potential impacts. For each type of environmental impact, the GEIS attempts to establish generic findings covering as many plants as possible. While plant- and site-specific information is used in developing an envelope of generic findings, the NRC does not intend for the GEIS to be a compilation of individual plant environmental

${ }^{12}$ On July 31, 2009, NRC issued for public comment a proposed rule to amend its environmental protection regulations pertaining to the renewal of nuclear power plant operating licenses (10 CFR 51) and issued for comment NUREG, 1555, Supplement 1, Revision 1; Regulatory Guide (RG) 4.2, Supplement 1, Revision 1 (Preparation of Environmental Reports for Nuclear Power Plant License Renewal Applications); and the revised Generic Environmental Impact Statement (GEIS) for License Renewal of Nuclear Power Plants (NUREG-1437, Revision 1). 
impact statements. Instead, this report may be incorporated, by an applicant, into a license renewal application environmental report. The GEIS makes maximum use of environmental and safety documentation from original licensing proceedings and information from state and Federal regulatory agencies, the nuclear utility industry, the open literature, operating experience, and professional contacts. It allows the applicant to concentrate on those impacts that must be evaluated on a plant-specific basis. Information provided on the plant-specific issues will either disposition the issue as not applicable or present an analysis of the issue using site-specific information. Mitigation and alternatives to reduce adverse impacts must also be discussed. This approach, the use of a generic environmental impact statement with a plant-specific supplement, improves the efficiency of the licensing process for licensees and the NRC."

"Scoping Process: A scoping process is conducted to define the proposed action, to determine the scope of the EIS, and to identify the significant issues to be analyzed in depth. A public scoping meeting is held near the nuclear plant seeking license renewal. Based on this process and the staff's independent review, the NRC will issue a preliminary recommendation on the acceptability of a license renewal action with regard to environmental impact. A draft plant-specific supplement to the GEIS is released for public comment and a public meeting is then held to discuss the findings. After comments are addressed, the NRC publishes a final plant-specific supplement to the GEIS and provides a final recommendation regarding the license renewal application to the Commission. Transcripts of environmental scoping meetings and public meeting on the draft supplements related to license renewal are available through the NRC Public Document Room."

Under the GEIS process described above, the NRC staff identified 92 environmental issues and reached generic conclusions related to environmental impacts for 69 of these issues that apply to all plants or to plants with specific design or site characteristics. Additional plant-specific review is required for the remaining 23 issues. These plant-specific reviews are to be included in a supplement to the GEIS.

The GEIS evaluated all 92 environmental issues using the NRC's three-level standard of significanceSMALL, MODERATE, or LARGE-developed using the Council on Environmental Quality guidelines:

SMALL-Environmental effects are not detectable or are so minor that they will neither destabilize nor noticeably alter any important attribute of the resource.

MODERATE-Environmental effects are sufficient to alter noticeably, but not to destabilize, important attributes of the resource.

LARGE-Environmental effects are clearly noticeable and are sufficient to destabilize important attributes of the resource.

For 69 of the 92 issues considered in the GEIS, the GEIS analysis reached the following conclusions:

(1) The environmental impacts associated with the issue have been determined to apply either to all plants or, for some issues, to plants having a specific type of cooling system or other specified plant or site characteristics. 
(2) A single significance level (i.e., SMALL, MODERATE, or LARGE) has been assigned to the impacts (except for collective offsite radiological impacts from the fuel cycle and from high-level waste and spent fuel disposal).

(3) Mitigation of adverse impacts associated with the issue has been considered in the analysis, and it has been determined that additional plant-specific mitigation measures are not likely to be sufficiently beneficial to warrant implementation.

These 69 issues were identified in the GEIS as Category 1 issues. In the absence of new and significant information, the NRC staff relied on conclusions in the GEIS for issues designated as Category 1.

Of the 23 issues that do not meet the criteria set forth above, 21 are classified as Category 2 issues requiring analysis in a plant-specific supplement to the GEIS. (The remaining two issues, environmental justice and chronic effects of electromagnetic fields, were not categorized.)

Of the 92 issues, 40 relate to water issues (or could relate to water issues) in four broad categories:

- Surface Water Quality, Hydrology, and Use (for all plants)

- Aquatic Ecology (for plants with once-through and cooling pond heat dissipation systems)

- Ground-water Use and Quality

- Threatened or Endangered Species (for all plants)

Of the 40 issues potentially related to water, ten have been determined to potentially involve moderate or large environmental impacts at some sites and thus require site-specific evaluation. Those ten issues are presented in the following Table 3-1, extracted from the larger list of 92 issues presented in 10 CFR Part 51, Subpart A, Appendix B, Table B-1. The category on Aquatic Ecology contains the issues of relevance to $\S 316(\mathrm{~b})$ : impingement and entrainment. The third category (ground-water) has not been a problem for any license renewal applicants thus far. The fourth category includes threatened or endangered species considerations for all categories of animals and plants, and may not specifically involve aquatic species, even if this general issue is problematic for a specific site.

As of the publication date of this report, 59 individual reactor units have been reviewed and approved for license renewal. Another 21 reactors are under review, at various stages of completion. Of these 21, twelve have proceeded far enough in the review process to have received from NRC their EIS or Draft EIS for public comment. Therefore, 71 reactors (over $68 \%$ of the U.S. fleet) have either completed environmental review or are sufficiently complete to have received an initial assessment from NRC with regard to findings on the ten water-related issues listed in Table 3-1.

Of these 71, all but eight plants at six sites have been determined to have SMALL environmental impacts for all of the water-related issues listed in Table 3-1. The eight reactors that were found to create MODERATE (or SMALL to MODERATE) environmental impacts in one or more of these categories are: Pilgrim, Millstone (2\&3), Indian Point (2\&3), ${ }^{13}$ Oyster Creek, Wolf Creek, and Duane Arnold. The areas of

\footnotetext{
${ }^{13}$ NRC's draft SEIS currently lists "SMALL to LARGE" in two categories, but these are preliminary findings.
} 
concern for seven of these plants were in one or more of the "Aquatic Ecology" issues, most frequently impingement or entrainment (exception is Duane Arnold, which uses cooling towers) ${ }^{14}$. All but two of these reactors are in an ocean or estuary/tidal river environment (exceptions are Wolf Creek and Duane Arnold). (It is important to note that a finding of MODERATE on a few issues is not disqualifying for license renewal, which assesses the overall environmental impacts in all areas against alternatives, as well as all the reactor safety issues, issues related to aging of plant structures, systems and components, etc.) Four of these eight reactors have already been approved for renewal; the other four have applications that are still in progress. All eight are discussed further below.

It is important to note that each of these environmental reviews is conducted in consultation with Federal, state and local agencies, including EPA and state water permitting authorities. Note that NRC's environmental review is based on NEPA regulations and its GEIS, as discussed above. NRC's application of NEPA is in accordance with the letter and spirit of NEPA and CEQ's implementing regulations, and allows for consideration of the impacts on the source water body as a whole (in contrast to EPA criteria that do not consider evidence of no overall ecosystem impacts). Even though acceptance criteria differ among these agencies, the findings and recommendations of the NRC do reflect the input of EPA and state authorities. The end result is that 63 reactors have been judged to have SMALL environmental impacts based on the more holistic NEPA criteria, as reflected in the GEIS. This number includes 48 "Phase II" reactors with once-through cooling.

As noted earlier, Part 54, which focuses on the reactor safety aspects of license renewal, also impacts cooling water systems. License renewal requirements for power reactors are based on two key principles:

1. The current regulatory process is adequate to ensure that the licensing basis of all operating plants provides and maintains an acceptable level of safety; and

2. Each plant's licensing basis is required to be maintained during the renewal term in the same manner and to the same extent as during the original licensing term.

An applicant must identify all plant systems, structures and components that are safety-related, or whose failure could affect safety-related functions, and that are relied on to demonstrate compliance with the NRC's regulations. Further, the applicant must conduct a safety analysis of significant changes that are anticipated during the renewal period. Modifications to the intake structure, for example, would need evaluation and NRC concurrence to ensure no compromise in existing levels of safety.

\footnotetext{
${ }^{14}$ Based on a Draft NRC SEIS. NRC findings relative to Duane Arnold are preliminary, awaiting final SEIS.
} 
Table 3-1: NRC Regulation Part 51: Category 2 Environmental Issues Requiring Site Specific Analysis ${ }^{49}$

\begin{tabular}{|c|c|}
\hline Issue & Findings \\
\hline \multicolumn{2}{|c|}{ Surface Water Quality, Hydrology, and Use (for all plants) } \\
\hline $\begin{array}{l}\text { Water use conflicts } \\
\text { (plants with cooling ponds } \\
\text { or cooling towers using } \\
\text { make-up water from a } \\
\text { small river with low flow) }\end{array}$ & $\begin{array}{l}\text { SMALL OR MODERATE. The issue has been a concern at nuclear power } \\
\text { plants with cooling ponds and at plants with cooling towers. Impacts on } \\
\text { instream and riparian communities near these plants could be of } \\
\text { moderate significance in some situations. See } \S 51.53\end{array}$ \\
\hline \multicolumn{2}{|c|}{ Aquatic Ecology (for plants with once-through and cooling pond heat dissipation systems) } \\
\hline $\begin{array}{l}\text { Entrainment of fish and } \\
\text { shellfish in early life } \\
\text { stages }\end{array}$ & $\begin{array}{l}\text { SMALL, MODERATE, OR LARGE. The impacts of entrainment are small at } \\
\text { many plants but may be moderate or even large at a few plants with } \\
\text { once-through and cooling-pond cooling systems. Further, ongoing efforts } \\
\text { in the vicinity of these plants to restore fish populations may increase the } \\
\text { numbers of fish susceptible to intake effects during the license renewal } \\
\text { period, such that entrainment studies conducted in support of the original } \\
\text { license may no longer be valid. See } \S 51.53(\mathrm{c})(3)(\mathrm{ii})(\mathrm{B}) \text {. }\end{array}$ \\
\hline $\begin{array}{l}\text { Impingement of fish and } \\
\text { shellfish }\end{array}$ & $\begin{array}{l}\text { SMALL, MODERATE, OR LARGE. The impacts of impingement are small at } \\
\text { many plants but may be moderate or even large at a few plants with } \\
\text { once-through and cooling-pond cooling systems. See } \S 51.53(\mathrm{c})(3)(\mathrm{ii})(\mathrm{B}) \text {. }\end{array}$ \\
\hline Heat shock & $\begin{array}{l}\text { SMALL, MODERATE, OR LARGE. Because of continuing concerns about } \\
\text { heat shock and the possible need to modify thermal discharges in } \\
\text { response to changing environmental conditions, the impacts may be of } \\
\text { moderate or large significance at some plants. See } \S 51.53(\mathrm{c})(3)(\mathrm{ii})(\mathrm{B}) \text {. }\end{array}$ \\
\hline \multicolumn{2}{|r|}{ Ground-water Use and Quality } \\
\hline $\begin{array}{l}\text { Ground-water use } \\
\text { conflicts (potable and } \\
\text { service water, and } \\
\text { dewatering; plants that } \\
\text { use }>100 \mathrm{gpm} \text { ) }\end{array}$ & $\begin{array}{l}\text { SMALL, MODERATE, OR LARGE. Plants that use more than } 100 \mathrm{gpm} \text { may } \\
\text { cause ground-water use conflicts with nearby ground-water users. See } \S \\
51.53(\mathrm{c})(3)(\mathrm{ii})(\mathrm{C}) \text {. }\end{array}$ \\
\hline $\begin{array}{l}\text { Ground-water use } \\
\text { conflicts (plants using } \\
\text { cooling towers } \\
\text { withdrawing make-up } \\
\text { water from a small river) }\end{array}$ & $\begin{array}{l}\text { SMALL, MODERATE, OR LARGE. Water use conflicts may result from } \\
\text { surface water withdrawals from small water bodies during low flow } \\
\text { conditions which may affect aquifer recharge, especially if other ground- } \\
\text { water or upstream surface water users come on line before the time of } \\
\text { license renewal. See } \S 51.53(\mathrm{c})(3)(\mathrm{ii})(\mathrm{A}) \text {. }\end{array}$ \\
\hline $\begin{array}{l}\text { Ground-water use } \\
\text { conflicts (Ranney wells) }\end{array}$ & $\begin{array}{l}\text { SMALL, MODERATE, OR LARGE. Ranney wells can result in potential } \\
\text { ground-water depression beyond the site boundary. Impacts of large } \\
\text { ground-water withdrawal for cooling tower makeup at nuclear power } \\
\text { plants using Ranney wells must be evaluated at the time of application for } \\
\text { license renewal. See } \S 51.53(\mathrm{c})(3)(\mathrm{ii})(\mathrm{C}) \text {. }\end{array}$ \\
\hline $\begin{array}{l}\text { Ground-water quality } \\
\text { degradation (cooling } \\
\text { ponds at inland sites) }\end{array}$ & $\begin{array}{l}\text { SMALL, MODERATE, OR LARGE. Sites with closed-cycle cooling ponds may } \\
\text { degrade ground-water quality. For plants located inland, the quality of the } \\
\text { ground water in the vicinity of the ponds must be shown to be adequate } \\
\text { to allow continuation of current uses. }\end{array}$ \\
\hline \multicolumn{2}{|r|}{ Threatened or Endangered Species (for all plants) } \\
\hline $\begin{array}{l}\text { Threatened or } \\
\text { endangered species }\end{array}$ & $\begin{array}{l}\text { SMALL, MODERATE, OR LARGE. Generally, plant refurbishment and } \\
\text { continued operation are not expected to adversely affect threatened or } \\
\text { endangered species. However, consultation with appropriate agencies } \\
\text { would be needed at the time of license renewal to determine whether } \\
\text { threatened or endangered species are present and whether they would be } \\
\text { adversely affected. }\end{array}$ \\
\hline
\end{tabular}


The following summarizes the recommendations of the NRC with respect to the eight reactors applying for License Renewal that did not receive a finding of "SMALL" environmental impacts in all water related categories. Each of these summaries is paraphrased from the NRC's EIS issued as a Supplement to NUREG-1437. Each is available on the NRC website, with extensive documentation on each issue, including specifics on each species that is potentially impacted.

Millstone 2\&3: "For entrainment, the staff concludes that the potential environmental effects would be of MODERATE significance in the context of the standards set forth in the GEIS."

Wolf Creek: "A SMALL to MODERATE impact was determined for groundwater quality and the potential for water-use conflicts (plants with cooling ponds or cooling towers using makeup water from a small river with low flow). If water use conflicts occur, associated impacts in the Neosho River due to impingement and habitat reduction on aquatic organisms, including threatened and endangered species, would be SMALL to MODERATE."15

Oyster Creek: "For two Category 2 issues (entrainment of fish and shellfish in early life stages and impingement of fish and shellfish), the NRC staff determined that the existing once-through cooling system could have a MODERATE impact if species composition and abundance of aquatic organisms in Barnegat Bay have changed substantially from the 1970s and 1980s during which the last studies of the effects of OCNGS operations on bay-wide populations were conducted.

Also, the NRC staff found that impacts on federally protected sea turtles would be SMALL during the proposed renewal period. If the NRC renews the OCNGS license, the renewed license would contain requirements consistent with the Incidental Take Statement in the 2006 Biological Opinion.

Mitigation measures were considered for each Category 2 issue. Current measures to mitigate the environmental impacts of plant operation were found to be adequate in most cases, and no additional mitigation measures were deemed sufficiently beneficial to be warranted. Additional mitigation may be required by the state of New Jersey that would result in reduction of impacts related to cooling-system operation."

Pilgrim: "A MODERATE impact was determined based on entrainment of the local population of winter flounder (Pseudopleuronectes americanus) and a MODERATE impact was determined based on impingement of the Jones River population of rainbow smelt (Osmerus mordax). The staff concluded that the potential site-specific impacts of the cooling intake system due to entrainment (local winter flounder population) and impingement (Jones River rainbow smelt) would be MODERATE. For all other marine aquatic species, the staff concluded that potential impacts due to entrainment and impingement

\footnotetext{
${ }^{15}$ Wolf Creek is an example of a plant that benefits environmentally from continued once-through cooling. Wolf Creek operates on a cooling pond, Coffey County Lake, which is fed by rainwater. Additional makeup water is withdrawn during dry parts of the year from the nearby Neosho River, just downstream of a dam that created John Redmond Reservoir (another backup source of makeup water). Makeup water needs are at a minimum now because the plant is designed for once-through cooling. If cooling towers were installed, makeup water needs would become much greater to compensate for evaporation, which would adversely impact the aquatic life in the Neosho River.
} 
would be SMALL to MODERATE. Additional mitigation to minimize the impacts of entrainment and impingement may be justified. EPA Region I is currently in the process of reviewing the National Pollutant Discharge Elimination System permit renewal application for PNPS. It is expected that this evaluation would evaluate the need for and feasibility of any additional mitigation measures." [Note that a Final EIS has been issued on Pilgrim by NRC, but the license renewal process has not been completed.]

Indian Point: "The NRC staff concludes that the potential environmental effects for most of these issues are of SMALL significance in the context of the standards set forth in the GEIS with four exceptionsentrainment, impingement, heat shock from the facility's heated discharge, and impacts to aquatic endangered species. The NRC staff jointly assessed the impacts of entrainment and impingement to range from SMALL to LARGE (depending on species affected), based on NRC's analysis of representative important species. Impacts from heat shock likely range from SMALL to MODERATE depending on the conclusions of thermal studies proposed by the New York State Department of Environmental Conservation (NYSDEC). NRC staff did not find data that suggest the effect of heat shock is likely to rise to LARGE. Given the uncertainties in the data NRC staff reviewed, impacts to the endangered shortnose sturgeon could range from SMALL to LARGE. The NRC staff considered mitigation measures for each applicable Category 2 issue." [Note that a Draft EIS has been issued for comment on Indian Point by $N R C$, but the EIS has not been finalized and the license renewal process has not been completed, and until such time, the NRC staff's conclusions should be considered preliminary.]

Duane Arnold: "DAEC ... uses a cooling-tower-based heat dissipation system, and water to replace that lost to evaporation in the cooling system is withdrawn from the Cedar River (which ... meet[s] NRC's definition of a small river). NRC considered surface water use conflicts to be a Category 2 issue for two reasons:

1. Consumptive water use can adversely affect riparian vegetation and in-stream aquatic communities. Reducing the amount of water available to either the riparian zones or in-stream communities could result in impacts on threatened and endangered species, wildlife, and recreational uses of the water body.

2. Continuing operation of these facilities depends on the availability of water within the river from which they are withdrawing water. For facilities that are located on small bodies of water, the volume of available water is expected to be susceptible to droughts and to competing water uses within the basin. In cases of extreme drought, these facilities may be required to curtail operations if the volume of water available is not sufficient.

An additional effect of the withdrawal of water from a small river is that the withdrawal may have an impact on groundwater levels, which would result in groundwater use conflicts (NRC, 1996).

The design rate for water withdrawal under operating conditions is ... approximately $0.6 \%$ of the average river flow. Maximum consumptive use is ... approximately $0.46 \%$ of the average river flow. During lowflow periods, the withdrawal rate and consumptive rate are higher proportions of the river flow ... (a net consumptive rate of over $3 \%$ of [minimum] low flow). 
In summary, the withdrawal is typically less than $1 \%$ of mean river flow and the release of water from a reservoir is possible during drought. However, during a period of low river flow associated with a drought, the withdrawal rate may be significant. The Staff concludes the impact on groundwater due to the use of a small amount of river makeup water is SMALL to MODERATE. [Note that the above text comes from NRC's Draft EIS, which has been issued for comment. The EIS has not been finalized and the license renewal process has not been completed. As such, these NRC staff conclusions should be considered preliminary.]

\section{Specific Results of NRC Reviews of New Plant Applications Relative to Cooling Water Issues:}

The NRC has approved four Early Site Permits (ESPs), all on existing sites, which contain important insights on environmental protection at these sites. Further, the $22 \mathrm{COL}$ applications contain important insights on various environmental or cooling water issues, even though most these applications have not completed NRC environmental review. Four of these COL applications have proceeded far enough in the NRC review process to obtain a draft EIS for EPA and public review.

The four sites (and applicants) for which NRC has issued a final ESP are:

- Clinton (Exelon)

- Grand Gulf (Entergy)

- North Anna (Dominion)

- Vogtle (Southern Nuclear)

In addition, the NRC Staff is currently reviewing an ESP application by Exelon for its Victoria County site in Texas, and a recently submitted ESP application by PSEG for additional unit[s] at its Salem/Hope Creek site in New Jersey. Also note that COL applications have been filed for two of the four ESP sites above: North Anna and Vogtle.

Since all of these applications are for sites that will be cooled by closed-cycle cooling, the level of detail required to assess environmental impacts on aquatic life is less. These applicants have opted for closed cycle cooling primarily because EPA's Phase I Rule for new facilities makes it virtually impossible to consider once-through cooling for new nuclear power plants. All ESP applications except the Vogtle application used a "Plant Parameter Envelope" approach that bounds a number of reactor design options, providing maximum flexibility for future technology choices. The decision to construct two AP1000 reactors at the Vogtle site was included in the Vogtle application.

All six ESP applications are based on closed cycle cooling. Clinton, Grand Gulf, North Anna, Vogtle, and Salem/Hope Creek propose to use cooling towers for heat removal; Victoria County proposes to use a cooling basin (cooling pond) to reject plant heat. For two of the ESP applications, the option for hybrid (wet-dry) cooling was included: North Anna and Clinton. The North Anna cooling system design will definitely include both wet and dry towers as previously discussed; the hybrid cooling needs at Clinton are more flexible at this point, since an actual reactor design has not been selected. 
NRC reviews of these ESP applications resulted in findings that all the environmental impacts of all water-related issues were SMALL, with two exceptions. For two sites, North Anna and Clinton, "Water Use" was judged to have SMALL impacts during normal years, but to present SMALL or MODERATE impacts during drought years or critical low-water years. This finding matches the plans for these two sites to include some dry cooling capability in their plant designs to deal with this contingency.

All ESP applications, as well as the COL applications submitted to date, do a thorough job of evaluating all cooling system design options available. Few seriously considered once-through cooling as an option, primarily because of the virtual prohibition against once-through cooling in the EPA's Phase 1 Rule. All considered the option of dry cooling and rejected it for a range of reliability and economic reasons, except as required either for plume abatement (using a very small amount of dry cooling in a wet cooling tower), or to augment wet cooling during drought conditions (e.g., North Anna). All applications evaluated thoroughly the options for natural draft towers vs. mechanical draft towers, with varying results depending on the site. 


\section{CATEGORIZING U.S. NUCLEAR POWER PLANTS BASED ON THEIR COOLING WATER SYSTEMS}

The current fleet of operating nuclear power plants rely relatively more on once-through cooling than fossil plants. Many references ${ }^{50}$ estimate only $30 \%$ to $40 \%$ (by capacity) of today's fleet of thermoelectric power plants still use once-through cooling. This statistic applies to all thermo-electric plants and is dominated by fossil plant data. In contrast, well over half of the nuclear power plants in the U.S. use once-through cooling.

EPA, NRC and other organizations all use slightly different definitions and means of categorizing site water bodies and associated cooling systems for thermoelectric power plants. In order to avoid confusion and take a more functional approach to categorization, this report adopts a system of "binning" nuclear power plants (NPPs) in a larger number of more uniquely defined situations.

There are two general sources of confusion as NPPs are assigned to various cooling system groups:

- Differing definitions of cooling ponds and associated questions such as the definition of "manmade" and "navigable," and when a lake becomes a reservoir, etc.

- Various special cases and unique circumstances that don't fit standard labels.

Attachments A, B, and C are spreadsheets that provide the following NPP data for the United States:

- Attachment A: a listing of all currently operating reactors (104) and planned reactors with Combined Operating License Applications (COLAs) or Early Site Permits (ESPs) on file with NRC, organized by USGS water resource regions, along with other relevant data (operator/licensee, State, cooling water source basics, cooling system basics, condenser flow rate, reactor type/NSSS supplier, summer capacity, thermal output, and operating license issuance date). In addition to the $22 \mathrm{COL}$ applications that are under active NRC review, Attachment A also lists other new plants with only announced plans for future submittals, prior submittals with NRC review currently suspended, and Watts Bar Unit 2 construction completion.

- Attachment B: a breakdown of existing U.S. nuclear power plant sites (65), organized by cooling water "situation." Additional site information in this table includes cooling water source description, site size (acres), intake structure location and design, discharge structure location and design, etc. New plant data are also displayed, including initial data on four "greenfield" sites, which add to the 65 existing sites.

- Attachment C: a summary tabulation of the number of NPPs in each cooling water situation, organized by the groupings in Attachment $\mathrm{B}$, on both an individual reactor basis and a plant site basis. Data are also broken down by current plants and new plants in these categories.

Before presenting the binning used for cooling system categories in this report (Attachment B), the USGS water resource region breakdown used in Attachment $A$ is shown next in Figure 4-1, along with a table showing the number of reactors in each USGS region: 


\section{Figure 4-1: USGS Water Resource Regions ${ }^{51}$}

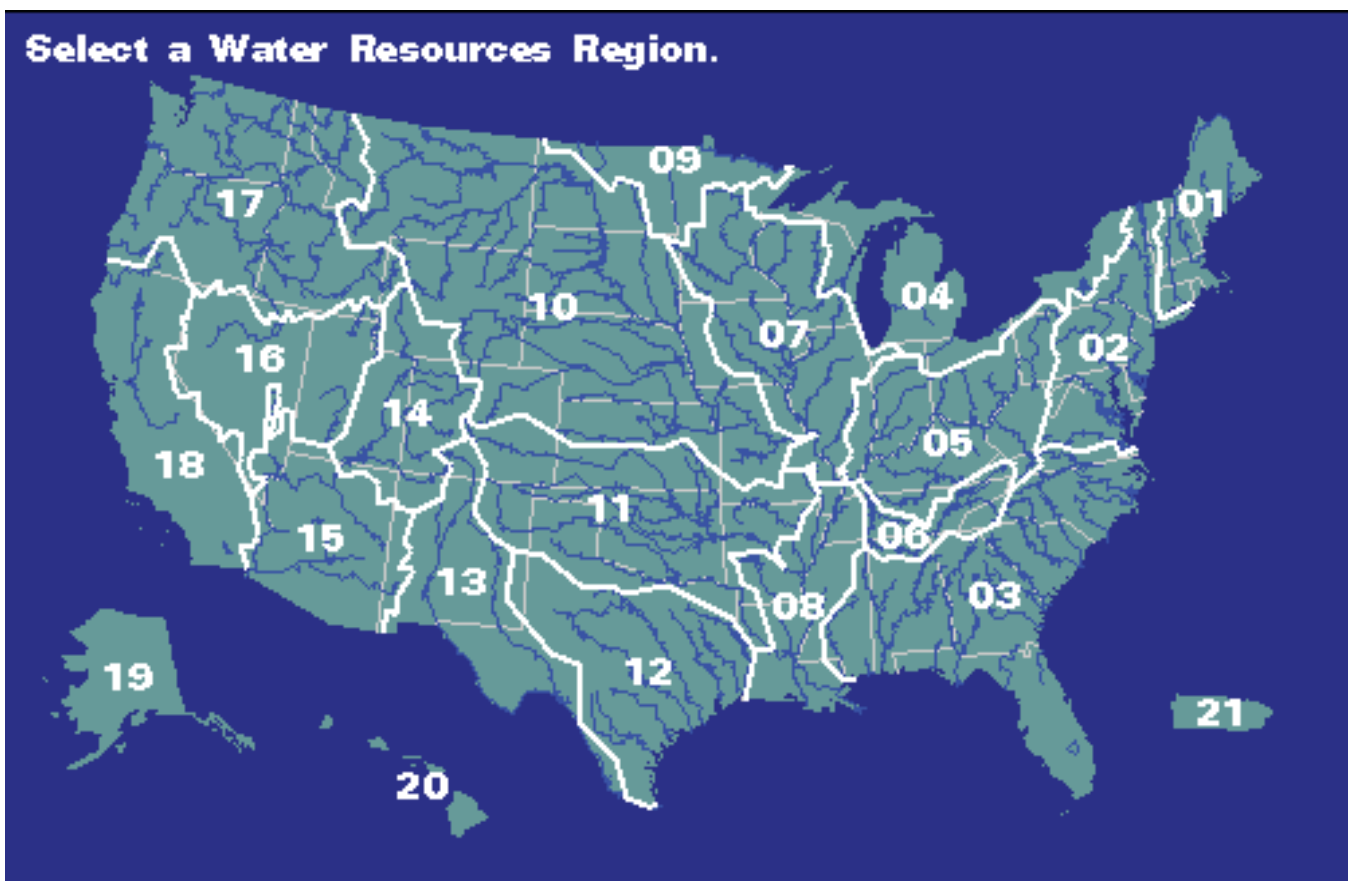

Note: The gray lines are state lines, the blue lines are major rivers, and the white lines are water-resources region boundary lines.

Table 4-1: Number of U.S. Reactors by USGS Water Resources Region

\begin{tabular}{|l|l|c|c|}
\hline Region \# & Region Name & \# Operating reactors & \# new reactors (w/COLA or ESP) \\
\hline 1 & New England & 5 & -- \\
\hline 2 & Mid-Atlantic & 19 & 3 \\
\hline 3 & South Atlantic-Gulf & 23 & 12 \\
\hline 4 & Great Lakes & 13 & 1 \\
\hline 5 & Ohio & 2 & -- \\
\hline 6 & Tennessee & 6 & $3^{*}$ (incl. Watts Bar-2) \\
\hline 7 & Upper Mississippi & 15 & -- \\
\hline 8 & Lower Mississippi & 3 & -- \\
\hline 9 & Souris-Red-Rainy & -- & -- \\
\hline 10 & Missouri & 3 & -- \\
\hline 11 & Arkansas-White-Red & 3 & -- \\
\hline 12 & Texas-Gulf & 4 & 4 \\
\hline 13 & Rio Grande & -- & -- \\
\hline 14 & Upper Colorado & -- & -- \\
\hline 15 & Lower Colorado & 3 & -- \\
\hline 16 & Great Basin & -- & -- \\
\hline 17 & Pacific Northwest & 1 & -- \\
\hline 18 & California & 4 & -- \\
\hline $19 / 20$ & Alaska/Hawaii & -- & -- \\
\hline 21 & Caribbean & -- & -- \\
\hline TOTALS & ---- & $\mathbf{1 0 4}$ & $\mathbf{2 3}$ * \\
\hline
\end{tabular}


Regarding cooling system situations, the following bins have selected for this report. The table below also includes the number of plant sites in each situation, along with various comments and clarifications. For simplicity, only current plant sites and reactors are included in the table below. New plant data are displayed, along with current plant data, in Attachments A, B and C.

Table 4-2: Number of U.S. Nuclear Plant Sites, Organized by Cooling Water Situation

\begin{tabular}{|l|l|c|c|}
\hline $\begin{array}{l}\text { Situation } \\
\text { number }\end{array}$ & Situation Description & $\begin{array}{c}\text { Number of } \\
\text { Sites }\end{array}$ & $\begin{array}{c}\text { Number of } \\
\text { Reactors }\end{array}$ \\
\hline 1 A & $\begin{array}{l}\text { Site uses wet closed cycle cooling towers at all reactor units } \\
\text { on that site (natural draft, mechanical or combination) }\end{array}$ & 22 & 32 \\
\hline 1 (+2)\#
\end{tabular}

\# Two sites with both a closed-cycle cooled unit and a once-through cooled unit are listed under the applicable once-through category. This applies to Nine Mile Point (Sit. 7) and Arkansas Nuclear One (Sit. 3), where the older unit is once-through cooled and the newer unit uses a natural-draft cooling tower. When these site data are summed on an individual reactor basis, the data are adjusted to add two reactors to the Situation $1 \mathrm{~A}$ total and subtract one each from situations 3 and 7 .

It should be recognized that the number of sites in situations 2-7 are a subset of the total number of sites in each category. For example, the six sites listed for Situation \#7 (once-through cooling on a Great Lake) are not the total number of reactor sites on the Great Lakes. Per Table 4-1 and Attachment A, there are a total of 13 reactors on ten sites on the Great Lakes. Of these ten sites, six are in Situation 7 and four are in Situation 1A. (Note that Situation $1 \mathrm{~A}$ is not broken down into cooling water body type.) 
Also note that EPA distinguishes between facilities that withdraw more than $5 \%$ of mean annual flow in a river, and facilities that withdraw less than $5 \%$ of mean annual flow. Facilities that used more than $5 \%$ of the mean annual flow tend to be on small rivers. EPA also differentiates between rivers and reservoirs based on retention time of a water particle flowing down stream. If the retention time exceeds seven days it is considered a reservoir and if it is less than seven days it is a river. The binning approach described above does not classify sites on rivers as to whether they are "large" or "small" but rather as to whether the river is free flowing at the site or held behind a dam (i.e., on a reservoir). This simplified binning process conforms closely to which plants EPA would consider to be on a river and which plants are on a reservoir.

In order to answer the question, "How many U.S. reactors are once-through-cooled and how many are closed-cycle-cooled, one needs to establish some conventions or "rules." For purposes of this report, the following "rules" are used to bin reactors into the above "situations:"

- The "closed-cycle cooled" category includes all reactors that are cooled exclusively $100 \%$ of the time by either cooling towers (Situation $1 \mathrm{~A}$ ) or a cooling pond that is exempt from $\S 316(\mathrm{~b})$ requirements (Situation 1B).

- $\quad$ Plants that are cooled by a cooling pond that has not been determined to be exempt from § 316(b) are treated as "once-through."

- Plants that have cooling towers that do not provide all cooling needs at $100 \%$ power at all times of the year (e.g., plants with "helper towers" or "seasonal towers") are treated as once-through. This includes a few plants that use towers extensively, for large portions of the year, or that have large capacity towers that can provide a majority (but not all) of the required cooling. This "rule" is based on the convention that if the plant is considered a "§ 316 (b) Phase II plant" by the EPA and/or NPDES permitting system, then it should be counted as a once-through plant. Also note that helper towers typically reduce discharge temperatures but don't reduce flow rate through the intake structure.

- Plants whose condensers are closed-cycle cooled, but that use once-through cooling for small or auxiliary site heat loads (e.g., essential service water) are retained in the "closed-cycle" category. This is a reasonable convention, since the required flow rates for these smaller systems are typically less than the makeup flow rates to a closed-cycle cooling system for the condenser.

Based on these assumptions, cooling categories for the U.S. reactor fleet can be summarized as follows:

Table 4-3: Summary of U.S. Nuclear Power Plant Cooling System Types

\begin{tabular}{|l|c|c|}
\hline \multicolumn{1}{|c|}{ Cooling Mode } & Total Reactor Count & Percentage \\
\hline Once-Through Cooling & 62 & 59.6 \\
\hline Closed-Cycle Cooling & 42 & 40.4 \\
\hline TOTALS & $\mathbf{1 0 4}$ & $\mathbf{1 0 0 . 0}$ \\
\hline
\end{tabular}




\section{Additional Notes:}

\section{Situation 1A:}

A number of sites with cooling towers are not listed in this category because their cooling towers are "helper towers," that are used primarily during summer months and are not capable of providing $100 \%$ of the cooling of the plant at full power. Rather, they augment or assist a once-through system, especially during summer months (high cooling water temperatures and/or low river flow.) Helper towers are typically used in-line with circulating water exiting the condenser to cool that water prior to discharge to the source water body, without recirculation to the intake side of the condenser. This configuration does not reduce intake flow rates, as occurs in closed-cycle cooling.

Co-located reactors Hope Creek (Sit. 1A) and Salem (Sit. 5) are listed as separate sites because of different NPDES permitting and ownership history.

\section{Situation 1B:}

Four sites with man-made cooling ponds (or equivalent) have been granted an exemption by their state permitting authority from $\S 316$ (b) requirements, at the request of the owner/operator. These four sites are: Turkey Point, South Texas, LaSalle and Braidwood. Turkey Point uses a unique system of manmade canals (instead of an open pond) that is appropriate to the hydrology and geology of Southern Florida. The other man-made cooling ponds in this situation were previously open lands (no significant rivers or creeks within the impounded pond area). After creating the embankment for the man-made pond, it was filled over time from a nearby river. ${ }^{16}$ Although full condenser flow-rate equivalent to a once-through cooling system is maintained for reactors on these sites, aquatic life is minimal (or never introduced) inside the pond, making concerns for impingement, entrainment and thermal impacts largely irrelevant. Makeup water to these sites, if needed, does come from nearby "waters of the U.S." (a river or ocean) subject to $\S 316(b)$, but makeup flow rates are equal to or less than the amount of makeup water required to support a closed-cycle cooling tower site.

\section{Situation 2:}

These sites are similar to sites in Situation 1B, but differ from situation 1B in that the permitting authority has judged that the cooling pond is "waters of the U.S.". Most of the water bodies used to cool the sites in this situation were created by damming a small river or creek at its headwaters, and filling it over a period of months or years, similar to how it was done for cooling ponds in Situation 1B. Also, the inflow to these ponds from local rain and runoff (e.g., feeder creeks) is typically too small to maintain pond level, so makeup from a nearby river that is off-stream from the cooling pond is sometimes pumped into the pond to augment natural pond inflows (same as in Situation 1B). In most

\footnotetext{
${ }^{16}$ These are general characteristics of sites that have been granted exemption from $\S 316(b)$, and may or may not have been considerations in the granting of that exemption. Sites included in Situation 1B are ones that both the utility and the permitting authority have agreed should be in that status (the sole basis for this categorization).
} 
cases, aquatic life was not preexisting in these ponds, but was often introduced artificially for the purpose of providing sports fisherman expanded access to fishing sites in the region. ${ }^{17}$

One site in this situation, North Anna, is unique, in that the cooling lake is divided into a warm side and cool side by small dams on three fingers of Lake Anna. The nuclear plant is sited on the warm side of the lake, which functions as a cooling pond per above. The makeup water source for this cooling pond is the cool side of the lake. (If this site had been constructed without separating the warm and cold segments, then the resulting standard lake-cooled configuration would have been assigned to Situation 3.)

Also note that one site in this category (Dresden) employs cooling towers during summer months.

The NRC defines a cooling pond as "a man-made impoundment that does not impede the flow of a navigable system and that is used primarily to remove waste heat from condenser water prior to recirculating the water back to the main condenser" (ORNL/NUREG/TM-226). NRC specifies in NUREG1437 that most of the sites in both Situation 1B and Situation 2 qualify as "Cooling Ponds."

One site in this category (VC Summer) operates in conjunction with a pumped storage facility on the same reservoir.

\section{Situation 3:}

These sites are on man-made lakes, but these lakes are "on-stream" with the source river and provide a range of public services and missions (e.g., recreation, municipal water supply, irrigation) - thus the label "multi-purpose reservoir." For these sites, the cooling function and the makeup water source are the same river (unlike Situations $1 \mathrm{~B}$ and 2).

Three of the sites in this category have installed Helper towers that are used during summer months (Vermont Yankee, Browns Ferry and Sequoyah). Another site, Peach Bottom, has Helper towers on site that were previously used, but are now inactive (retained operable for contingency only).

Two sites in this category operate in conjunction with a pumped storage facility on the same reservoir (Oconee, Peach Bottom).

Arkansas Nuclear One (ANO) Unit 1 uses once-through cooling on its reservoir; adjacent Unit 2 uses closed-cycle (wet) cooling, based on a natural draft tower.

Watts Bar has cooling towers that are capable of supporting $100 \%$ reactor power at all times of the year. It was originally designed and operated as a closed-cycle cooling site. (The site has two large hyperbolic towers - one operational on Unit 1, and one ready to operate when Unit 2 is ready to start operation.) Approximately ten years ago, TVA took advantage of an existing water permit it holds for a nearby nonoperating fossil plant, which receives cooling water upstream of the Watts Bar Dam. TVA utilizes water from that fossil plant and mixes it with the Watts Bar Unit 1 cooling tower basin inventory. This

\footnotetext{
17 These are general characteristics of sites that have not been granted exemption from $\S 316(\mathrm{~b})$. Sites included in Situation 2 are ones that either the utility did not request an exemption, or the permitting authority did not grant one.
} 
modification was performed to reduce condenser circulating water temperatures and improve plant efficiency. This "supplemental CCW" comprises about $1 / 3$ of total condenser circulating flow, when in operation. However, for purposes of this report, Watts Bar is considered a closed-cycle plant, since it could discontinue use of Supplemental CCW, if $\S 316(\mathrm{~b})$ requirements make its use problematic.

\section{Situation 4:}

These sites are on the open ocean or a bay off the open ocean with full open-ocean salinity levels (no fresh water dilution). Four of these seven sites are on the Atlantic, two on the Pacific, and one on the Gulf of Mexico. Most of these sites have taken extraordinary measures to minimize adverse environmental impact on marine life or provide extensive remediation programs to compensate for losses. None of them have incorporated cooling towers into their systems, largely because salt-water cooling tower operations are challenging (e.g., particulate emissions from towers, including salt drift, can impact switchyard reliability, local ecology, etc.; other challenges include corrosion issues, brine blowdown, etc.).

Note that this category of nuclear sites is the only one for which corresponding sites in an equivalent cooling water situation are not contained within Situation $1 \mathrm{~A}-$ i.e., all nuclear plants on coastal sites in the U.S. use once-through cooling - nuclear power plants have no experience with salt water cooling towers at an ocean site. This observation not only applies to the U.S. - it applies globally. All nuclear plants in other countries that are sited on the ocean also use once-through cooling. We do have limited experience with cooling towers at ocean sites for a few fossil plants (e.g., two coal units at Crystal River in Florida use natural draft cooling towers). This limited experience suggests that salt-water cooling towers are not infeasible, but present major challenges as discussed above. The State of California the home of two of these sites, has adopted a policy requiring 19 coastal power plants to begin phasing out once-through cooling systems, in order to better protect marine life. This policy has involved extensive analysis of the pros and cons of requiring cooling towers on coastal sites, and impacts two nuclear sites in California (Diablo Canyon and San Onofre). (New York and New Jersey are considering similar policies; see "Situation 5," below.) These details are discussed later in Chapters 6 and 9.

\section{Situation 5:}

These sites are located on a river-fed estuary (e.g., Chesapeake Bay) or a Tidal River (e.g., Hudson River). In either case, the site experiences both freshwater flow from up-river and saline inflow from an ocean. A tidal river site typically experiences varying salinity levels based on tides or seasonal differences driven primarily by spring runoff. Note that some of the sites in Situation $1 \mathrm{~A}$ or $1 \mathrm{~B}$ are also located in a similar aquatic environment (e.g., Turkey Point, South Texas, Hope Creek), but since makeup flow from their nearby estuary or tidal river is minimal compared to once-through cooled sites, these sites are binned based on their effective closed-cycle configuration (i.e., 1A or 1B) and their exemption from $\S 316$ (b).

Retrofitting cooling towers at Situation 5 sites would be problematic for reasons similar to Situation 4, since most of these sites experience significant salinity, especially during months when river flows are low. The Hope Creek reactor (a Situation 1A plant) uses cooling towers on an estuary, demonstrating that cooling tower operations in this environment, although challenging, are feasible. Finally, as with 
Situation 4 above, some States are taking preemptive action (prior to EPA issuing its revised draft Phase II Rule) to require cooling tower retrofitting at plants in this situation. The State of New Jersey issued a new draft NPDES permit in January 2010 for Oyster Creek that required the retrofitting of a closed cycle cooling system on that plant, with a seven-year compliance schedule. Then in March 2010, the State of New York issued a draft policy requiring closed-cycle cooling at most state power plants. New York subsequently denied the water quality certificate for the license renewal of the Indian Point plant, based in this draft policy.

\section{Situation 6:}

Two of these sites on rivers (Prairie Island, Monticello) employ cooling towers in a closed cooling cycle mode during summer months. These two sites use sluice gates to restrict intake and discharge flow from/to the Mississippi River from May through September, when high temperatures and/or low flow conditions exist on the river. (This design is different than the typical "helper tower" arrangement used at a few other sites that reduces discharge temperatures without reducing intake flow rate.) During other months, Prairie Island and Monticello operate in an open cycle/once-through mode.

\section{Situation 7:}

One of these sites, Nine Mile Point, uses once-through cooling for its older Unit 1, and closed-cycle cooling (natural draft tower) for its newer Unit 2. Note that the new draft policy issued by the State of New York also applies to three New York reactors on Lake Ontario: Ginna, Fitzpatrick and Nine Mile Point-1. 


\section{EPRI REPORTS ON § 316(b) RULE IMPACTS AND POTENTIAL FOR CLOSED-CYCLE COOLING RETROFIT}

As discussed in Section 1.2 and Attachment 1, EPRI has conducted research on a broad range of cooling water issues for over three decades, including technologies that address impingement and entrainment of fish and shellfish. These efforts have been led by EPRI's Environment Sector, with support from EPRI's Generation (fossil) Sector and EPRI's Nuclear Sector. As the $\S 316(\mathrm{~b})$ rules were being developed, EPRI conducted research on a range of technologies with promise to address these issues, some of which were considered in the EPA final Phase II rule of 2004.

When the Second Circuit issued its ruling in 2007 on Phase II, EPRI was asked by member companies to examine in closer detail the potential impacts on the utility industry from a requirement to retrofit closed-cycle cooling towers on all existing U.S. fossil and nuclear plants that came under the Phase II rule. The purpose was to develop accurate, up-to-date and objective data that EPA could use in its rulemaking process. Four reports were chartered in 2008:

1. Estimation of the cost of retrofitting existing Phase II facilities with closed-cycle cooling (Maulbetsch Consulting)

2. Determination of impacts to energy production and supply by quantification of the number of facilities/Units/MW at risk of closure and the loss of MW due to retrofitting (Veritas Economic Consulting)

3. Quantification of the adverse environmental and social impacts associated with closed-cycle cooling compared to impingement and entrainment losses (URS Corporation)

4. Identification of impacts to transmission system reliability and electric power supply based on results of the second project (Veritas Economic Consulting and PwrSolutions)

A fifth report was initiated at the end of 2009 that will assess the environmental benefits and economic costs of a potential national retrofit to closed cycle cooling systems. This final report, in combination with the first four, will provide the technical information needed for overall cost-benefit analyses.

Preliminary drafts of these reports were delivered to EPA in May 2008 to meet an EPA deadline for their proposed Rule schedule at that time. However, that time frame was not adequate to complete the research, and work continues to finalize the reports. Preliminary results indicate:

- Even though closed-cycle cooling retrofits would reduce impingement and entrainment, these benefits would be offset by other adverse environmental impacts related to cooling towers.

- Retrofitting cooling towers is not feasible at some existing plants (e.g., due to insufficient available space, air permitting restrictions).

- Plant shutdowns, in combination with the typical retrofit energy penalty associated with closedcycle cooling, could negatively impact the efficiency and reliability and stability of electricity supply in some regions of the U.S. 
- Retrofitting towers would be very expensive for all nuclear facilities and most fossil facilities. Many facilities, especially fossil peaking units would be unable to bear the costs of retrofitting and would likely be shutdown. ${ }^{18}$

As discussed in Section 1.2, the third issue on the impacts of retrofitting on reliability and stability of electricity supply has also been studied recently by DOE's Office of Electricity Delivery and Energy Reliability and by NERC, with similar conclusions. Other organizations, such as CA-ISO, NEI and EEI have come to similar conclusions. The above results generally apply to both fossil and nuclear plants. Reports $\# 1$ and \#3 above are most relevant to nuclear plants and do contain some nuclear specific data and analyses on specific issues. Preliminary results of these reports relative to nuclear plants are as follows:

- Given the high capacity factors and relatively low production costs of nuclear power plants, few if any nuclear plants are immediately susceptible to permanent shutdown as a result of a mandate to retrofit towers. This is despite the fact that retrofitting costs at nuclear plants would be significantly higher than at fossil plants.

- With a few exceptions, nuclear sites have enough physical space to support cooling tower retrofits. At some nuclear sites, retrofitting - although physically feasible - would involve massive reconstruction of the site, prohibitive costs (\$1 to \$3 billion) and excessive plant outage times (> 1 year). More details on such situations are provided in Chapter 6 .

- One of the major adverse environmental impacts of retrofitting cooling towers at nuclear plants is the loss of emission-free generation, both during the duration of the retrofit outage and following the outage as a result of down-rating the plant. Retrofit outages would require replacement power from fossil plants, along with their associated fossil emissions (including $\mathrm{CO}_{2}$ emissions) throughout the duration of the outage. These cumulative emissions would be major environmental issues, if all of the 62 "Phase II" nuclear reactors were shutdown for outage durations estimated to average about eight months per reactor. Two sites (San Onofre and Diablo Canyon in California) have determined that retrofitting would require an outage of over a year (i.e., 17 months). After retrofitting, nuclear plants originally designed to operate with oncethrough cooling would produce less energy than previously. This reduced energy production would continue for the life of the plant, reducing the rated capacity of the plant and requiring replacement power from fossil plants, with their associated environmental effects.

More insights of a qualitative nature on cooling tower retrofit costs and impacts are presented in Chapters 6 and 7. Since this report is intended to be complementary to and not duplicative of these EPRI reports, all quantitative analysis of retrofit costs and adverse impacts of closed-cycle cooling will be covered in the EPRI reports, when they are completed and published.

\footnotetext{
${ }^{18}$ While CCC retrofits at fossil facilities are categorized as "easy," "average" or "difficult," CCC retrofits at nuclear facilities are categorized by EPRI as either "difficult" or "more difficult" (i.e. there is no easy nuclear retrofit).
} 


\section{INTERVIEWS WITH NUCLEAR PLANT EXPERTS}

With the assistance of EPRI's Chief Nuclear Officer and EPRI's Nuclear Power Council, Points of Contact (POCS) were identified for each U.S. nuclear power plant for the purpose of supporting the development of this report. Most POCs are plant experts in environmental management, plant cooling water systems or both. Most POCs are located at their respective plant sites; a few are located at company headquarters. Each POC was interviewed by phone, with the following objectives for each call:

- Review status of data inputs to the EPRI reports described in Chapter 5 for each POC's plant. In cases where data inputs had not been provided or were incomplete, guidance was provided on how to complete this task.

- Urge review of the latest drafts of the EPRI reports, including cases where site-specific analysis had been performed and documented in one or more of the reports on the site in question.

- Review two specific technical issues in the EPRI reports that warranted further nuclear plant specific inputs: (1) assumed cooling tower design under the retrofit scenario, and (2) likely utility decision on the matter of condenser re-optimization under the retrofit scenario (both discussed further below).

- Review possibilities for near term and longer term actions, including R\&D, that might assist the industry in meeting compliance obligations, addressing anticipated challenges in water management, etc. Although many of these needs are site-specific, these interview questions focused on the possibility that some generic activities, including R\&D, might be identified of value to a significant number of plants.

This Chapter provides the results of these interviews, organized as follows:

1. Cooling tower designs for nuclear power plants

2. Condenser re-optimization as part of a cooling tower retrofit project at a nuclear plant

3. General comments about environmental protection and future R\&D needs

4. Specific comments, organized by cooling water situation (Situations 1-7, per Chapter 4)

\subsection{Cooling Tower Designs for Nuclear Power Plants}

The EPRI reports discussed in Chapter 5 assumed for purposes of estimating retrofit costs and impacts that all thermoelectric power plants that might be mandated to install cooling towers would comply with that requirement by installing mechanical draft cooling towers. This assumption was based in part on the fact that few hyperbolic towers have been built in the last twenty years - most cooling towers constructed have been mechanical towers. Note that the capital cost of mechanical towers is less than the capital cost of natural draft (hyperbolic) towers, but operations and maintenance costs are higher. 
That assumption is probably a good one for fossil plants, but may not be the best assumption for nuclear plants. Natural draft cooling towers, although more expensive from a capital cost perspective, are typically less expensive from a life-cycle perspective, for two reasons: their operations and maintenance costs are lower, and they avoid the extra parasitic load on the plant's electricity output needed to power the fans in mechanical draft towers. Given that nuclear plants operate at high capacity factors (i.e., $>90 \%$ ), and that their expected lifetimes (given license renewal) are likely to continue at least another $25+$ years, the payback times for the more expensive natural draft towers make them a good option.

Following are statistics on types of cooling towers selected for U.S. nuclear power plants:

- Of the 34 reactors in the U.S that use cooling towers (Situation $1 \mathrm{~A})$, twenty of them use natural draft cooling towers, 13 use mechanical draft towers, and one (Grand Gulf) uses both.

- Of the 11 reactors that are once-through cooled but use "Helper" towers, nine use mechanical towers, and two (Sequoyah 1\&2) use natural draft towers.

- Of the 26 planned reactors with COL or ESP applications before the NRC, ${ }^{19} 13$ reactors plan to use mechanical towers, nine plan to use natural draft towers, and four plan to use cooling ponds exempt from $\S 316$ (b) requirements. Two of the reactors planning to use mechanical towers also plan to use municipal effluent for makeup. In addition, Watts Bar-2, currently back under construction, already has a natural draft tower constructed.

Based on these statistics, one might expect roughly half of the U.S. nuclear plants that currently use once-through cooling to opt for mechanical draft and roughly half to opt for natural draft towers, if towers were mandated for compliance under $\S 316(b)$. However, interviews completed to date suggest that most nuclear utilities would opt for mechanical draft towers, if towers were imposed. Some utilities have not yet conducted an assessment of which design they would use, given the unsettled nature of $\S 316$ (b) compliance. For those that have considered the options, roughly $80 \%$ would opt for mechanical towers (only $20 \%$ for natural draft towers), for one or more of the following reasons:

- Already have mechanical towers on site (either "helper" towers or ones used on another unit)

- Site aesthetics ("viewscape") limitations would likely preclude use of the much taller natural draft hyperbolic towers (i.e., utility is anticipating local community preferences)

- Local zoning laws preclude structures as high as natural draft towers

- Seismic design requirements preclude natural draft towers (e.g., California sites)

Given the above, the EPRI assumption that all retrofitted towers would be of the mechanical draft type is confirmed as a good general assumption, for EPRI's purposes of general cost estimating of the impacts of closed-cycle cooling tower retrofits at U.S. plants.

\footnotetext{
${ }^{19}$ Includes data from three units that have filed COL applications but have subsequently deferred construction, since these filings are still useful in assessing utility choices for preferred cooling tower technology.
} 


\subsection{Condenser Re-Optimization as Part of Cooling Tower Retrofit Projects}

The "Balance of Plant" (BOP) or non-nuclear portion of a nuclear plant is designed to match the cooling water source that it will draw from and the cooling strategy (i.e., once-through or closed-cycle) that it will employ. These decisions dictate the design of the steam condenser, the condensate system, the circulating water system, and other supporting systems and structures. See EPRI's Journal Article (Attachment C) for a short description and graphics of how these systems and components work.

If a plant will use once-through cooling, the BOP piping systems have to be larger, designed to be able to accommodate the large flow rates at low pressure drops. The condenser would also be designed for high flow-rates and a relatively small temperature gradient ("delta- ${ }^{\prime \prime}$ ) between its inlet and outlet. These combinations are optimal for once-through cooling system efficiency, and have the environmental protection advantage of discharging heated water back to the source water body at a cooler temperature than would be the case for cooling towers. However, this higher flow-rate has the disadvantage of potentially heightening the impingement and entrainment rates at the intake structure.

If a plant will use closed-cycle cooling, the cooling water piping systems don't need to be as large, but they often need to be designed for higher discharge pressures (particularly for the circulating water piping). The condenser is designed for lower flow but higher delta-T, since the most efficient cooling tower operation is obtained by delivering hotter water at lower flow-rates to the tower, thereby maximizing its evaporative process and minimizing tower size. Optimizing the BOP to match closedcycle cooling in turn allows for a smaller cooling tower design than would be the case if cooling towers were added to a plant originally designed for once-through cooling. This in turn reduces the parasitic power loads associated with cooling towers (mechanical fans, more pumps or higher head pumps, etc.), thereby minimizing these efficiency losses. Condensers that are optimized for closed-cycle cooling are typically "double-pass," which means that circulating water makes two passes through the condenser as it picks up latent heat from the surrounding steam, instead of a single pass, which is typical of condensers in once-through cooling systems.

These BOP systems are a fundamental part of the plant design and not easily changed. For example, the condenser is typically integrated within the structural support (pedestal) for the steam turbines mounted above it, and is not easily modified. Likewise, piping systems are an integral part of the condenser's design and are often inaccessible for major modifications. In addition, the large-bore circulating water lines are typically oriented differently for once-through and closed-cycle cooling systems. For once-through (single pass) condensers, the inlet and outlet water boxes and circulating water lines are on opposite sides of the condensers. For closed loop cooling (two pass) the inlet and outlet water boxes and circulating water lines are on the same side of the condenser. To retrofit from a one pass to a two pass condenser would require extensive revisions to the condenser water boxes, circulating water lines and likely the turbine pedestal. These structures are often located below-grade, which further increases the complexity and cost of such a retrofit. It is much easier to design and build the BOP to the plant's design parameters and intended cooling mode than to change it later. 
Plant owners might be tempted, if cooling towers were mandated as a retrofit to plants designed with once-through cooling, to simply add the towers and leave the BOP at sub-optimal conditions for the new cooling system. This approach would typically have lower capital costs than doing the optimized retrofit, but would significantly reduce the amount of electricity generation. For plants with low availability (e.g., fossil peaking units) or older fossil plants that might not operate much longer, this shortcut might be a cost-effective business decision. However for nuclear power plants, all of which operate at high capacity factors and are planned to operate for many more decades, this shortcut is very undesirable. Phone interviews suggest that most U.S. nuclear plants would seriously consider the option to re-optimize their condensers and supporting systems, if cooling towers were mandated. (A few nuclear plants would likely find that re-optimization is not physically possible, despite its advantages, due to inaccessible piping, undersized condenser, structural interferences, etc. Some of these potential complications were identified during phone interviews.)

This is an important finding, since the current draft of EPRI report \#1 assumes this extra step would not be taken in its baseline assumptions for estimating the costs of cooling tower retrofits. Given the preference voiced by interviewees to optimize the condenser at many or most nuclear plants as part of an assumed retrofitting project, EPRI report \#1 may be seriously under-estimating the cost of the retrofit at nuclear plants, and may not be accounting for all of the added costs associated with the longer duration of a more complex retrofitting outage.

Note that the shortcut of adding towers without re-optimizing the system can typically be accomplished with a shorter outage than for the re-optimization case, since the towers can be constructed while the unit is operating. (Exceptions to a shorter (i.e., 2-3 month) "tie-in" outage in a hypothetical "nonoptimization" case would include situations where interference with existing operational infrastructure requires extended system down-time.) The "tie-in" parts of any retrofit project would always require the plant to be shut down for the work.

In the re-optimization case, a much longer outage would almost always be needed, since all the work on the condenser, condensate system, and circulating water system must be done with the plant off-line. EPRI Report \#1 (DRAFT) assumes such an outage on a nuclear plant would take approximately eight months, on average. Interviews with many POCs validate this assumption, with the caveat (as above for the cooling tower design question) that most utilities have not studied this retrofitting project in detail. Those that have already performed a site-specific cost estimate for cooling tower retrofits have typically, as part of that effort, evaluated the need to re-optimize their condenser, estimated the outage duration required, etc. Those site-specific studies, where available, are being factored into the EPRI reports. Interviews with POCs confirm that a cooling tower retrofit of a nuclear plant would be an extremely difficult project, and that an outage of roughly eight months or more is a reasonable assumption. For some nuclear plants, such an outage would take over one year - approaching two years in a few cases. 


\subsection{General Comments about Environmental Protection and Future R\&D Needs}

Although each U.S. reactor faces a unique set of challenges and options for addressing environmental issues, the following general comments emerged as sufficiently generic to be highlighted here. To avoid duplication, this text focuses on key points and avoids repeating utility inputs documented elsewhere.

- Utility experts expressed frustration with the Second Circuit decision and its negative impacts on energy security, reliability, and the environment. The most frequently cited frustrations were the impracticality and inefficiency of mandating a one-size-fits-all approach to protecting aquatic life, and the counter-productivity of prohibiting restoration activities (e.g., wetland development, fish hatcheries) as an option for mitigating entrainment and impingement of aquatic biota.

- Many utilities maintain excellent environmental protection and ecology programs aimed at endangered species protection, wetlands development, reef development at coastal sites, shoreline preservation, etc. Major ongoing investments are made each year in such activities. Unfortunately, the Second Circuit decision has disallowed these activities.

- Many utilities felt they had achieved good to excellent performance from measures to date to prevent impingement of fish, as well as good to excellent performance from measures to exclude special or endangered species (or return them unharmed to the source water body), including marine mammals, sea turtles, and some locally popular game fish. Preventing entrainment of larvae is a much more difficult challenge. A few utilities have already invested major resources in these efforts, with varying results. Further investments are anticipated. Given that numerous peer-reviewed scientific analyses that have shown no adverse impacts on the overall aquatic environment in the source water body, many utility experts believe preventive measures may be approaching a point of diminishing returns, when performance is measured holistically.

- Some utility experts provided vivid examples of how imposing cooling towers at their site would have worse adverse consequences on aquatic life than maintaining their once-through cooling system with its current BTA configuration (clear cases of a "cure worse than the disease"):

- One site (Wolf Creek) noted that imposing cooling towers would increase makeup requirements to their cooling lake from a nearby small river to the point that downstream aquatic life in that river would be damaged by reduced freshwater flows. (See NRC evaluation of Wolf Creek situation at end of section 3.3.)

- Another site noted that imposing cooling towers would slowly deplete the water inventory in the plant's cooling lake, since makeup rate from the nearby river that serves as the plant's water source would not be sufficient to maintain lake level with the higher evaporative loss rates associated with cooling towers. Eventually, this condition would probably force the plant to be shut down permanently, since alternative sources of makeup water do not currently exist. 
- Many sites where retrofitting cooling towers would have negligible positive impact on overall aquatic life protection noted adverse environmental impacts from cooling towers in other areas (particulate emissions from towers, higher water consumption rates, etc.), that would make the overall environmental performance of the plant worse as a result of a cooling tower retrofit.

- Some utility experts were concerned that many stakeholders don't yet appreciate that scientific studies consistently show that fish mortality resulting from impingement and entrainment is a small percentage of total fish and larvae mortality, including natural causes. Even in cases where large numbers of fish are impinged or entrained, these numbers are small in relation to the total population of fish in the source water body. In many cases, data spanning many decades show no overall degradation of aquatic life as a result of plant operations, or even improvements in the quantity and quality of aquatic life since the plant began operating (e.g., Salem). Many states have certified that no adverse environmental impact is occurring. No utility experts interviewed were aware of any lasting impacts on the overall health of aquatic species in their source water body (beyond the immediate vicinity of the intake structure) as a result of plant cooling system operations.

- "Results-oriented" environmental monitoring of water body ecosystems has demonstrated this outcome in many cases and over many decades. However, EPA and some courts (e.g., Second Circuit) have typically discounted or ignored what industry experts consider to be the more relevant and important data: overall ecosystem performance. This has forced decision-making to be based on technology performance in the immediate vicinity of the plant - irrespective of overall source water body impacts. These near-field data are less complete or out of date, especially for impacts from entrainment.

- As a related matter, experts noted that many of the impacted species have no commercial or recreational value or are non-native species that are deemed "undesirable" by the state permitting authority. Experts also noted that many individual fish are already dead or moribund from other causes when impinged at intake structures. At many sites, the commercial and recreation species are rarely impinged in significant numbers. ${ }^{20}$ These details are not properly considered by intake structure performance standards that simply count dead fish.

- Screen technology performance is highly site specific. Nuclear plants have had varying experiences with new screen technologies. Some have worked well, others have not. New screen technologies such as fine mesh or wedgewire are expensive and difficult to maintain, but sometimes offer excellent performance, especially when debris loading is minimal, and constant water flow is present to enable effective screen cleaning. Application of these screens in stagnant or slow moving waters has been determined to be impractical at some sites, due to

\footnotetext{
${ }^{20}$ Efforts to reduce impacts on aquatic species that include saving species of no recreational or commercial value might still be important because they provide a food source (forage base) to the valued species. However, overall ecosystem data accumulated to date do not indicate that an overall degradation of valued species occurs when forage species are lost.
} 
frequent clogging. Application of these screens in tidal estuaries is generally unacceptable where debris loading creates rapid clogging and tidal action creates routine re-impingement of the debris. Clogging is not only an operational problem - it can lead to reactor shutdowns and to losses of power to the grid, which in turn can lead to grid instabilities or even blackouts. (Note: recent testing and demonstration projects aimed at addressing clogging issues are making good progress, indicating that screen technologies could soon qualify as BTA at many U.S. sites. Further testing is needed, aimed at a broader range of siting conditions.)

- Some utility experts are concerned about the consequences of imposing cooling towers with associated higher water consumption rates in regions of the country expected to face increasing competition for water resources, and regions prone to drought conditions. Plants with oncethrough cooling typically have good plans and contingency options to deal with drought, but have concerns about their ability to continue normal operations in an extended drought if they have to deal with the much higher water consumption rates associated with cooling towers.

- The WEF report discussed in Chapter 1, "Thirsty Water" provides an example of the implications of drought to electricity generation and the importance of prompt action: "The summer of 2007 brought the most severe drought the US Southeast had seen in more than a century. The extremely dry conditions affected all water users - some cities even banned certain nonessential uses of water. During the drought, the US Federal Energy Regulatory Commission convened a group of experts to understand the implications of the drought on grid reliability and to make plans to mitigate the negative effects. On a company level, Southern Company ... helped forge a dialogue among the stakeholders in its communities, including power plant operators, community leaders and those who live near plants or reservoirs, to discuss how best to balance the water resources available. Elevated temperatures and reduced flow rates in power plant intake waters made compliance with outlet water temperature limits particularly difficult. To comply with the temperature limits on its permits, Southern Company ultimately produced less power at some units and took other units offline at times while ultimately managing its pool of generation resources to ensure continued reliability. The lessons of the drought of 2007 have been well learned, however. Although 2008 was another dry year in the U.S. Southeast, the drought did not have nearly as large an impact on power generation. The 2007 drought brought a new sense of urgency around water management, bringing about changes in water storage during the winter and making 2008's dry summer much easier to manage." ${ }^{\prime 52}$

- Many nuclear sites would find it difficult, or have already found it impossible, to permit cooling towers at their site, due to limitations on particulate matter release limits stemming from the Clean Air Act. Even with the best drift elimination technologies added to towers, the amount of particulate that still escapes would exceed state or federal limits at many plants. Some plants with existing towers have had difficulty with permits for this same reason.

- Most nuclear plants maintain an independent cooling water source to their safety grade cooling systems (e.g., essential service water) - independent from the circulating water system that 
cools the condenser. Many of these safety grade cooling systems use once-through cooling, even if the plant has towers for condenser cooling. Experts stated that for operating plants, these smaller cooling systems should not be forced to use less reliable closed-cycle cooling.

- A large percentage of plant sites are in a physical situation where cooling tower retrofits would preclude building new units on that same site. Many plants have the physical space to add another reactor to their site, should electricity demand warrant consideration of new capacity. However, the space that would be required to install cooling towers, if imposed on the existing reactor(s), would make it physically impossible to also construct additional reactor(s) on that site. This in turn would potentially force a utility to build new units on greenfield sites, which could increase environmental impacts.

- Utility experts favor an R\&D program to deal with $\S 316(\mathrm{~b})$ issues that is comprehensive enough to deal with all the options that industry might need, including improved tower designs, improved screen technologies, innovative ways to discourage fish from approaching intake structures, and better documentation of the performance of technologies already in use. Specific areas of R\&D recommended by utility experts include:

- Better tower technologies with means to reduce water consumption rates and particulate matter "drift;" as well as tower technologies that reduce O\&M demands

- Technologies to address cooling tower issues in coastal regions, including salt drift and brine blowdown issues, as well as significant sediment-based drift issues at lower quality freshwater sites.

- Improved understanding of cooling tower particulates relative to such aspects as size, constituents, potential impact on the environment and human health, etc., to quantify the impacts of cooling tower particulates with respect to clean air regulation (e.g., EPA regulation of PM2.5).

- Better data on the performance of particulate matter elimination technologies of existing tower designs

- Screens that minimize debris issues and are easily cleaned; improved fish capture and return systems

- Better data to show that the EPA assumption of $100 \%$ entrainment mortality is overly conservative. Existing data from some sites show entrainment mortality is well below $100 \%$, and for some species approaches zero. The correct number is highly species and site-specific; more and better data are needed.

- New plant siting decisions will increasingly consider means to avoid $\S 316$ (b) compliance concerns altogether, by using closed-cycle cooling or by finding alternatives to "waters of the U.S." for cooling, depending on which strategy is technically and economically feasible at a particular site. Two ways to avoid "waters of the U.S." are through the use of man-made cooling 
ponds that are capable of obtaining an exemption, and the use of non-traditional cooling water sources. Unfortunately, both of these options are available and practical at only limited sites in the U.S. Non-traditional cooling water options include but not limited to:

- Saline aquifers and collector wells (undrinkable groundwater)

- Reclaimed or reprocessed water from municipal water treatment facilities ("gray water")

- "Produced" water from energy production (oil and gas wells and mine pool water in abandoned coal mines)

Excess run-off from irrigation.

Some of these waters are contaminated; others are usable by thermoelectric power plants with limited pre-treatment requirements. Most have technical, economic or environmental hurdles to overcome, most of which are site-specific. Such waters can be retained in a holding pond or cooling pond for additional flexibility and backup in the case of supply interruption. Long-term contracts for access to such waters are essential to assured and reliable supply; or provisions must be made for alternate sources.

- Utilities encouraged more R\&D on alternative water sources. All were aware of the successful operation of the cooling system at Palo Verde, which uses recycled municipal wastewater from Phoenix. Some were aware of more recent experiences, such as the use of mine pool water at Limerick to augment its normal cooling tower makeup source (Schuylkill River), plans to use municipal effluent for new units at Turkey Point, and plans to use a saline aquifer for makeup water to a proposed second unit at Callaway (now deferred). Some noted that the mining and agriculture industries are often required to process their waste water prior to release, suggesting an opportunity for assuming that responsibility as part of long term arrangements for access to this water.

- Utility experts discussed experiences and lessons learned for "what works" at their individual site, relative to all aspects of cooling system design and operations. These unique lessons learned and best practices varied widely because of site-specific differences. There seemed to be some indicators that these best practices are not getting shared around the industry as often as they perhaps should be, suggesting the need for better benchmarking opportunities focused on cooling water issues, to include both fossil and nuclear experience. EPRI has established a small Intake Blockage Interest Group that includes information sharing on this one topic, but many more areas of information and "best practices" sharing remain unaddressed (cooling tower O\&M, reservoir water management, water treatment system management, etc.).

\subsection{Specific Comments, Organized by Cooling Water Situation (Situations 1-7, Per Chapter 4)}

(Note: these comments from phone interviews apply to both current and future cooling water issues in each of the cooling water situations introduced in Chapter 4.) 
1A: Site uses closed (wet) cooling towers at all reactor units on that site (natural draft, mechanical or combination)

A significant number of plants with cooling towers were initially designed for once-through cooling, but added towers during construction based on guidance from EPA or state permitting authorities.

Many sites have experienced maintenance problems with cooling towers, and have accumulated a number of "lessons learned" regarding cooling tower design upgrades, operations under various seasonal conditions, etc. that would benefit other sites facing similar circumstances.

1B: Site uses once-through cooling on a man-made cooling pond that is not "waters of the U.S." and thus exempt from CWA $\S 316(\mathrm{~b})$ requirements.

Establishing this status has been quite beneficial, in terms of efficient and reliable operations, lower electricity costs to consumers, etc. This status was sometimes established following a period of commercial operations (as opposed to establishing exemption during construction). ${ }^{21}$

Cooling ponds are expensive to build, require a lot of land, and are not technically feasible for most U.S. sites. Where they can be applied, they have great advantages in reduced water consumption rates, and reduced O\&M demands and costs in relation to cooling towers.

2: Site uses once-through cooling on a man-made cooling pond that has been judged to be "waters of the U.S." and thus not exempt from CWA § 316(b) requirements.

Most of these sites have all the reduced water consumption rate and reduced O\&M advantages of those in the 1B category above. They only differ in relation to their CWA compliance obligations. It turns out that many of these facilities opted to stock their cooling ponds and make them available to the public for recreation and fishing. That action sometimes had the effect of defaulting cooling ponds to "waters of the U.S." status, since the water quality standards invoked by the CWA would help ensure a larger fish population, and ensure the fish were safe for human consumption. Subsequently, some of these plants have had to restrict access to these cooling ponds for security reasons (post-9/11 requirements), and no longer allow fishing (restricted public access to pond, halted the stocking of fish, etc.).

Most of these sites would face serious technical challenges from a mandate to retrofit cooling towers, primarily because many of them have limited makeup water sources to maintain full pond water level. Increased water consumption associated with cooling towers could severely constrain operations of these plants, especially during drought conditions. Further, mandating the retrofitting of cooling towers at these sites would typically preclude the option to add more generating capacity on the same source water body, because of this higher water consumption dilemma.

\footnotetext{
${ }^{21}$ Note that sites assigned to this category by this report involve no judgments by the author on the criteria for, or the appropriateness of an exemption from $\S 316(\mathrm{~b})$. Rather, these assignments represent situations where the requesting utility and the water authority with jurisdiction have agreed to this exemption status.
} 


\section{3: Site uses once-through cooling on a multi-purpose reservoir (in-line with source river)}

Many of these sites have a close working relationship with the federal and state agencies with jurisdiction over the dam or dams that maintain reservoir water level (which are licensed by FERC). This is essential to maintaining adequate water flow past the site, adequate water level in relation to intake and discharge structures, etc.

Most of these sites focus on drought management, and especially would be concerned about drought mitigation if cooling towers were imposed. In some cases, authorities responsible for reservoir maintenance need to place a higher priority on either dredging to remove accumulated silt and debris, or on dam maintenance that would allow operations at a higher lake level. These actions would increase reservoir storage capacity, which is essential to improved drought mitigation.

The three sites in this situation with nearby pumped storage capability are quite satisfied with how well nuclear plant operations and pumped storage operations are coordinated, both in terms of electricity generation and reservoir water level management.

\section{4: Site uses once-through cooling on an ocean or bay open to the ocean}

Some of these sites have employed elaborate deep-water intake and discharge structures, where feasible, to minimize impacts on marine life. Others have used long intake canals with capability for capture and release of important species.

Cooling towers in an ocean environment can cause serious problems with salt drift, impacting plant and switchyard operations, fragile coastal environments, and nearby farms, roads and communities. Further, blowdown of concentrated brine from cooling towers back into the ocean would also be problematic, since it may be toxic to some marine life. Such discharges would violate the CWA, so retrofitting cooling towers in an ocean environment would likely require the construction of wastewater treatment plants that would treat the blowdown to meet water quality standards and permitting limits. (Rapid mixing might reduce this toxicity problem, but little experience exists to confirm this strategy as a viable option.)

One highly unattractive alternative that utilities may be forced to consider, if cooling towers are mandated at coastal sites that cannot obtain environmental permits for either the resulting salt drift emissions or the salt brine blowdown, would be to seek local freshwater makeup options (in lieu of ocean water) to the mandated cooling towers. Not only would this option be cost prohibitive at most sites, but in many regions where freshwater resources are already scarce (e.g., California, Florida, New England), this solution would further strain local municipal water supplies.

The implementation of $\S 316$ (b) Phase I requirements for cooling towers creates large uncertainties for ocean sites regarding environmental consequences, switchyard reliability, costs, permitting, etc., all of which will work to discourage coastal siting. There is no experience with ocean water cooling towers at nuclear power plants in the United States or elsewhere, and very little experience with fossil plants using salt water towers. For example, two coal plants at the Progress Energy Crystal River site have used 
natural draft salt water cooling towers since the mid-1980s. Interviewees generally agreed that Phase I requirements make coastal zone sites less attractive as potential locations for new thermoelectric power plants. Among the 22 active $\mathrm{COL}$ applications undergoing review by NRC, one site is proposing to use salt water cooling towers - Progress Energy's Levy County site. This will become the first nuclear reactor in the world sited on or near an ocean that will use salt water towers that are exposed to full ocean salinity levels ( $35 \mathrm{ppt}$ ). Requirements that discourage new plant siting in coastal regions could have a negative impact on electricity reliability and energy security over time as electricity demand continues to grow in these regions.

Unfortunately, new screen technologies (e.g., fine mesh or wedge wire) are predicted by some interviewees to be difficult to implement at most ocean sites, because of difficulties in screen cleaning in waters with little or no net flow away from intake structures.

\section{5: Site uses once-through cooling on an estuary or tidal river}

Cooling towers on these sites can also present problems with salt drift, due to the brackish water at the site, but these problems are less severe than at ocean sites. The Hope Creek reactor has operated a cooling tower successfully in brackish waters for over two decades, with salinity levels ranging from zero to $20 \mathrm{ppt}$ (annual averages from $\sim 5 \mathrm{ppt}$ to $\sim 8 \mathrm{ppt}$ ). Constellation is planning their new Calvert Cliffs Unit 3 reactor with a hybrid cooling tower operating in a salinity range from $\sim 5 \mathrm{ppt}$ to $\sim 20 \mathrm{ppt}$ (annual average $\sim 15 \mathrm{ppt}$ ). There are also examples of fossil plants operating cooling towers in brackish waters.

These sites have the distinct advantage of being far enough down river to have access to cooling water for which there is little competition due to its brackish quality (i.e., undesirable for municipal water supplies or irrigation) - yet far enough upstream from the ocean to have slightly fewer complications from salt water use. Unfortunately the variety and density of aquatic life at these sites where fresh and salt water intermingle is typically larger, which complicates impingement and entrainment management.

Fine mesh and/or wedge wire screens have worked adequately at some of these sites, but require frequent maintenance. Both types of screens experience poor performance at low flow or slack tide conditions or high debris conditions, when fouling of the screens can be an issue. Further, corrosion of cooling system components is an issue in brackish water with varying salinities, roughly equivalent to corrosion issues in ocean environments.

\section{6: Site uses once-through cooling on a freshwater river (free flowing)}

Seasonal differences in water flow and water quality are significant at these sites, driving a seasonsbased operating strategy for cooling systems. Some of these sites use helper towers during summer months, primarily to manage discharge temperatures within limits. These sites also face issues with drought management. At some sites, cooling tower retrofits or expanded use of helper towers would exacerbate drought management due to higher water consumption rates. 


\section{7: Site uses once-through cooling on a Great Lake}

The Great Lakes Water Commission is aggressively seeking ways to "protect, conserve and restore the Waters of the Great Lakes." In 2001, it developed an Annex to the Great Lakes Compact, which all eight states bordering on the lakes have ratified into their state constitutions. That Annex establishes policies to reduce water usage on the Great Lakes, and implicitly establishes priorities via conservation requirements among types of usages, in order to focus the greatest attention on the usages with the most "... significant adverse impacts of withdrawals and losses on the Basin and its watersheds." "Diversion" ${ }^{22}$ is considered the most serious threat to conserving Great Lakes waters, and has been effectively eliminated as a major threat. Water consumption (as occurs with cooling towers) is considered the next worst type of usage; and water withdrawal and return (as occurs with once-through cooling) is considered the least damaging to the environment. In the case of closed-cycle cooling with cooling towers, much of the water consumed by evaporation precipitates back to earth outside the Great Lakes watershed, creating a type of diversion. For these reasons, greater use of once-through cooling may be a more acceptable strategy for new capacity on these lakes because of its reduced water consumption rate. States on the upper Great Lakes, especially surrounding Lake Michigan, already recognize this fact and generally favor once through cooling with deep-water intakes using best screen technology available, over cooling towers. ${ }^{23}$ Note that this option is currently prohibited by the "fast track" option within the Phase I rule. A difficult "demonstration track" is required for this option. Also note that the general principles of the Great Lakes Compact that favor once-through cooling (with BTA screens and/or deep water intakes) applies to all five Great Lakes. However, as a practical matter, States surrounding the lower Great Lakes (e.g., New York), are less concerned about minimizing the excessive consumptive use of water resulting from cooling towers, than are upper Great Lake States.

Deep-water intakes are a good option at many of these sites (less so for the shallower Lake Erie, where extending intake and discharge structure piping doesn't significantly reduce potential aquatic life impacts.). Although expensive and difficult to install, intake structures in deeper water where fish populations are typically smaller can reduce impingement and entrainment. Deep-water intakes have the added advantage of providing access to cooler circulating water, which improves thermal performance, plant efficiency and margins to operating limits, particularly during summer months.

\footnotetext{
${ }^{22}$ Diversion is permanent withdrawal of water for transport outside the Great Lakes watershed. For example, bottling companies are no longer allowed to remove Great Lakes water for use in bottled water, soft drinks, etc.

${ }^{23}$ The State of Wisconsin recently approved the retrofitting of the once-through cooling system at the Wisconsin Energy (WE) Oak Creek Plant - a four-unit coal plant - based on constructing a deep water intake.
} 


\section{DISCUSSION: WHAT NEXT AFTER THE U.S. SUPREME COURT DECISION?}

[The following analysis focuses on the key practical and public policy implications of the Supreme Court remand of the Second Circuit decision. As noted in Chapter 3, this report avoids comment on the legal arguments, instead focusing on the implications of the decision process to future actions for ensuring a "balanced" outcome that simultaneously respects the nation's energy supply needs, water needs, and its environmental protection imperatives. It is difficult for industry to take major actions that involve commitment of significant resources until EPA promulgates a revised rule. To the degree that proactive steps (e.g., R\&D) can be taken in the near term, the following analysis should prove useful.]

Two factors suggest that EPA could take an approach that closely mirrors the 2004 rule:

- EPA's technical analysis fundamentally supports the 2004 rule and EPA's conclusion that a combination of technologies is much more appropriate than a single BTA determination (e.g., closed-cycle cooling);

- The Supreme Court not only reversed the Second Circuit on the matter of cost-benefit analysis it also explicitly restored the EPA's ability to make site-specific decisions: "...and in providing for cost-benefit variances from those standards."

One factor suggests a possibility for a more standardized approach - the posture taken by the Federal Government in its brief in opposition to the petition for certiorari, which might be seen as a preference to continue or expand a "national performance standard" approach that might limit state permitting authority ability to make site-specific decisions.

From a purely public policy perspective, as articulated by the key reports summarized in Chapter 1 (DOE's 2006 Report to Congress, the 2007 Interagency Report produced by the OSTP Subcommittee ("SWAQ"), the World Energy Forum reports, etc.), it is essential that the Federal government take a holistic approach to water issues - one that balances the many competing environmental protection and water conservation objectives that deserve priority consideration. The Second Circuit decision effectively made such a holistic approach unachievable, primarily because it mandates what amounts to a one-size-fits-all approach (i.e., cooling towers) to managing a single issue - impingement and entrainment - in isolation, and elevates this one issue over all other competing environmental priorities. As a result, the Second Circuit decision exacerbates water consumption issues in those regions of the country with water shortages, anticipated water shortages in the future, or droughts.

As discussed in Chapter 6, there are a number of examples of BTA determinations at one facility that cannot practically be applied at another facility, or BTA determinations at a specific facility based solely on impingement and entrainment considerations that would create more serious environmental impacts in other environmental areas than those avoided by a choice aimed solely at impingement and entrainment. Such unintended outcomes would be widespread and consequential, if a single BTA approach is taken throughout the U.S., or if permitting authorities are not given flexibility to make BTA decisions that meet local conditions and limitations. 
Simply stated, closed-cycle cooling is not necessarily the BTA for every U.S. site from an impingement and entrainment perspective. When other environmental impacts (e.g., consumptive use of water, tower particulate drift) are considered, then closed-cycle cooling is no longer the BTA for many U.S. sites. And when other societal impacts are considered (e.g., water use conflicts, climate change, land use, cost of electricity to consumers, etc.), then closed cycle cooling is no longer the BTA for many more U.S. sites. Unfortunately, the U.S. government currently lacks the means to evaluate these trade-offs holistically, and the courts (and a few states) have effectively imposed a "one-size-fits-all" approach.

This is not to suggest that closed cycle cooling is not appropriate for any U.S. sites. There are many situations, most frequently driven by discharge temperature concerns, low flow concerns on a river, water resource limitations that require use of non-traditional water sources, etc., where cooling towers are clearly appropriate. However, given the evolution of alternative technologies such as wedgewire screens, fine mesh screens, velocity caps, deep water intakes, etc., it is becoming increasingly obvious that these less expensive and more flexible alternatives are equivalent (if not superior) to cooling tower technology, in situations where no other motivation (such as the water resource or temperature issues noted above) exists to justify rejecting once-through cooling. These decisions must be site-specific.

It is important to repeat the observation made in Chapter 3 regarding the Supreme Court decision: the court did not mandate the use of cost-benefit analysis by EPA in decision-making under $\S 316(b)$. Rather, it said that the EPA is allowed to use cost-benefit analysis in deciding what cooling water intake structure performance standards must be used by operating thermo-electric plants. However, costbenefit analysis is central to any holistic decision process. It is therefore incumbent on industry, Federal Agencies, individual state permitting authorities, and policy leaders on water issues to be prepared to provide timely input to EPA when it reissues its Phase II rule for public comment.

An integrated national strategy for water management that addresses conflicting issues in a balanced and holistic manner is not likely to come from the courts. As argued by Entergy in its petition for certiorari,

"In a world of finite resources on which competing demands are placed, consideration of what is "best" necessarily includes a weighing of factors broader than the Second Circuit's "cost effectiveness" test allows. The court's conclusion that BTA is the technology that saves 102 fish, instead of 99-101 fish, so long as it does not bankrupt the industry, disregards the plain fact that electricity is an essential service, not to mention the sensible possibility that the money spent saving that extra fish might someday be needed for other purposes, e.g., ensuring the reliability of the nation's electricity supply. Clearly, the "best" technology is not necessarily that which leaves industry unduly financially burdened. The decision below underscores the judiciary's unsuitability to manage these highly technical and policy-laden trade-offs in any kind of systematic fashion. ${ }^{53}$

\subsection{National Performance Standards}

As discussed in Chapter 3, the draft final Phase II Rule included a national performance standard for reducing impingement mortality (by $80 \%-95 \%$ ) and entrainment (by $60 \%-90 \%$ ). Although this performance standard was one of the many parts of the draft rule that was remanded by the Second 
Circuit, it is possible that this standard or a similar national performance standard could appear in the final rule, especially if EPA opts to not impose a single BTA (e.g., cooling towers) on all thermoelectric power plants. Importantly, a national performance standard aimed at a specific BTA outcome, although potentially simplifying compliance monitoring, provides limited flexibility to deal with site-specific and regional conditions.

There are limitations associated with a national performance standard that is focused narrowly on impingement and entrainment metrics to the exclusion of broader criteria aimed at the overall environmental health of the source water body. Further, national performance standards necessarily involve a number of "rules" and simplifying assumptions to ease evaluation and standardize implementation. These simplifying assumptions are typically conservative and often not scientifically accurate or validated by real data. Examples of over-generalizations in EPA analyses include:

- Assumption that $100 \%$ of aquatic organisms that are entrained through a plant cooling system are killed. (Note that this assumption is certainly true for cooling systems with cooling towers, but is overly conservative as an assumption for once-through cooling systems.)

- Assumption that environmental impacts on the source water body are proportional to (or can be estimated by) the reduction in impingement and entrainment at the intake structure. There is ample evidence that for most cases, this assumption is not accurate, given the history of continued health of ecosystems in source water bodies for which data have been collected. Individual fish mortality is not an accurate indicator of the standing crop of aquatic species in a source water body. Scientific studies consistently show that fish mortality resulting from impingement and entrainment is a small percentage of total fish and larvae mortality.

- Assumption that impingement and entrainment are proportional to flow rate.

- Assumption that all fish and larval species have the same value in the context of the performance of technologies aimed at reducing impingement and entrainment.

- Assumption that closed cycle cooling is the "best technology available" for all sites in the U.S.

Energy technology decisions are necessarily trade-offs among competing goals. The science and industrial maturity of each technology is not the same, nor is the science behind the environmental impacts associated with that technology. How should policy makers value human life in relation to animal life? Or what criteria should be used to balance clean air/climate change goals and clean water goals when a particular strategy or technology places them in conflict? These decisions are made more difficult by varying levels of uncertainty in the science and/or unwillingness to use the best science available in decision-making. For example, we know much more about the effects of fossil fuel emissions $\left(\mathrm{SO}_{\mathrm{x}}\right.$ and $\mathrm{NOX}$ ) on the environment than we do about the effects of $\mathrm{CO}_{2}$ on climate.

We have ample data that confirms thermoelectric power plant cooling water intakes can cause fish mortality, sometimes in very large numbers. But we also have ample data to show that local effects at the plant's intake structure don't prove anything about the health of source water body ecosystems. 
Site-specific data consistently show that today's total source water body ecosystem performance is as good (or sometimes even better) than performance prior to plant construction.

We also have ample data that show that closed-cycle cooling consumes about twice as much water (perhaps more, per section 7.3 below) as does once-through cooling, and that imposing closed-cycle cooling on all U.S. thermoelectric power plants would have adverse consequences on water resources and clean air in many regions of the country, as well as climate change mitigation generally. However, no Federal policy or decision mechanism exists today that enables weighing these facts in a holistic manner that allows trade-off decisions in the national interest. A science-based methodology for evaluating issues at the energy-water nexus is particularly important, because policies, programs and legal decisions have too often been made in isolation, unaware of unintended consequences being created in other areas.

EPA methodologies are limited to evaluating the relative value of impingement and entrainment decisions within the constraints of current EPA rules and precedents, but lack the ability to evaluate impacts on overall energy security. In most cases, relative economics does a good job at assessing these trade-offs in the public interest. But decision-makers need a better understanding of these trade-offs, and higher confidence that the existing economics and associated incentives are effectively addressing these competing factors, with an appropriate balance among outcomes.

The relative costs of various options should be evaluated, seeking least cost means to achieve the best overall combination of energy security and environmental quality results. This holistic approach is difficult for state permitting authorities to develop and implement on a state-by-state basis, because of the lack of decision criteria and tools, and associated resource constraints. However, a holistic Federal methodology that is sufficiently flexible for regional use or even site-specific applications would be a very valuable tool. The optimal approach will likely be a suite of technologies tailored to regional conditions and site specific needs. The EPRI studies discussed in Chapter 5 are relevant inputs to this effort, but since their purpose was to evaluate the implications of a particular Phase II technology approach (closed-cycle cooling retrofitting), they don't look broadly enough to fully satisfy this need for holistic decision tools. Earlier work by EPRI is also relevant to this area. A collaborative effort between Federal agencies and industry is needed.

\section{$\underline{7.2}$ Restoration}

Another area of the remand of critical importance to some specific sites and individual states is the ability to use restoration and remediation to mitigate the effects of impingement and entrainment. In its March 2008 legal brief on granting of certiorari, EPA agreed with the Utility Water Act Group and PSEG that the Second Circuit erred in holding that restoration measures may not be used to minimize the adverse effects of cooling water intake structures. EPA provided a clear and convincing case, based on both technical results and policy rationale for including restoration as one option available to permitting authorities in establishing the BTA for a particular site. However, EPA decided not to oppose the Second Circuit prohibition against restoration activities, arguing that it should wait for another Circuit Court to determine that restoration is appropriate before coming to the Supreme Court. "While 
the court of appeals' decision has the potential to be disruptive and to require inefficient and wasteful results at existing facilities that had intended to rely upon restoration measures, the issue is not so exceptionally important as to warrant review in the absence of a circuit conflict." ${ }^{154}$

Second Circuit opposition to the use of restoration was based on "...the court of appeals' view [that] such mitigation measures do not "minimize" adverse environmental impacts within the meaning of Section 316(b), but instead "substitute after-the-fact compensation for adverse environmental impacts that have already occurred." 55 The Second Circuit's rationale also seemed to hinge largely on a fear that facilities might be allowed to achieve compliance with $\S 316(\mathrm{~b})$ solely on the basis of restoration activities. However, the practice and precedent for the use of restoration and mitigation over many years has been the opposite: compliance is typically reached by a combination of technology solutions plus restoration activities (where effective) - a two-pronged strategy, not an "either-or."

A related consequence of the Second Circuit's decision with adverse public policy implications is the possibility that thermoelectric power plants would terminate fish restoration and remediation programs, given the court's decision to prohibit the use of variances or restorative measures to achieve compliance with the regulation. Most experts concede that the Supreme Court's narrow review of the Second Circuit's decision relative to whether EPA can rely on cost-benefit analysis means that the Supreme Court took no position on restoration measures, which would leave the Second Circuit decision to stand. A plausible but unlikely alternative interpretation might be that the Supreme Court's permission to use cost-benefit considerations could be interpreted to allow remediation programs to provide for supplemental assurance of minimizing environmental impact, concurrent with the determination that the intake is the best technology available at a cost that is not wholly disproportionate to the benefits. However, it is not likely that the EPA would invoke this interpretation without Congressional action to clarify or modify the CWA. It is interesting to note that at least one state, California, has already taken a position on the Second Circuit's prohibition against the use of restoration as a compliance measure. The recently issued "Policy on the Use of Coastal and Estuarine Waters for Power Plant Cooling" explicitly allows for "mitigation projects" as an element of compliance.

Many nuclear plants have historically maintained programs to stock the rivers, lakes reservoirs, estuaries or oceans that they withdraw from, with recreationally or commercially important aquatic species. Policymakers and regulators should anticipate a strong negative reaction from local communities to decisions to terminate such programs at existing plants, or to forgo such programs at new plants.

Therefore it is possible that other states that currently allow restoration as part of BTA determinations would continue this policy and practice, in a manner similar to California. The CWA allows state permitting authorities to establish requirements that are more stringent than the Federal statutes. However, doing so without crediting the action toward the benefits to be gained would constitute double compliance without legal justification (a precedent that industry will likely object to in California and elsewhere, if replicated). Hence, situations where states require continued use of restoration, while the Second Circuit forbids its use as a compliance measure, could result in court challenges in other Circuit Courts. Hence, this issue may not be a permanently settled matter. 
As a matter of sound public policy, it is hard to argue against restoration as a key element of a sound environmental strategy for aquatic life. Restoration has been a cornerstone tool of the U.S. Fish and Wildlife Service since its inception, and has been practiced by the Corps of Engineers and others in managing hydroelectric dams, dredging activities, etc. Selectively disallowing restoration activities at thermoelectric power plants would remove one of the most effective programs that utilities can use to maintain an optimum balance among aquatic species and to support local commercial fishermen and sportsmen. However, action by Congress or other Circuit Courts is probably needed at this point to enable continued use of these programs.

\subsection{Water Consumption}

As another matter of sound public policy, it is critical that $\S 316(\mathrm{~b})$ implementation become increasingly sensitive to water consumption issues. At shown in Chapters 1 and 2, demand for energy, water, food and other basic staples of life will continue to grow, while water resources will remain essentially constant. This obviously means that thermoelectric power plants - one of the key users of water - will come under increasing pressure to reduce their consumption of water. Given that closed-cycle systems consume approximately twice as much water (or more) as do once-through systems, we should anticipate increasing instances where state and regional water authorities press for curbing the trend toward closed-cycle cooling, especially at sites where once-through cooling is environmentally compatible, and where water resource adequacy is a concern. For example, concerns for the negative environmental impacts of closed-cycle cooling are beginning to emerge in the Great Lakes region, particularly the Upper Great Lakes region, because of concerns over water consumption and its impact on conserving Great Lakes waters. Clearly, efforts to reduce the environmental impacts of excessive water consumption and efforts to avoid impingement and entrainment of aquatic species will increasingly come into conflict. It is not beyond the realm of possibility that a plant that is required to transition to closed-cycle cooling to resolve one issue might be required some years into the future to shift back to once-through cooling to resolve the other one. This possibility should give pause to policymakers and regulators, and encourage a thoughtful review of all the issues in a holistic manner, before permanent solutions are mandated.

The focus on energy-water conflicts between water consumption policy and impingement/entrainment policy will demand more accurate data on the relative water consumption rates for closed-cycle cooling vs. once-through cooling. As mentioned in Section 2.5, this report has attempted to update these data. Water consumption rates for closed-cycle cooling can be determined from empirical data with reasonable accuracy, relying on makeup and blowdown rates, rainfall data, etc. Water consumption rates for once-through cooling, on the other hand, have traditionally been estimated using computer models that estimate the higher rate of evaporation that occurs from the source water body during the period of time between discharge of a "thermal plume" and attainment of thermal equilibrium. This evaporation rate is highly dependent on site conditions (meteorological conditions, plume mixing and dispersion, etc.). These computer-generated estimates are inaccurate and largely unverified. 
The EPRI reports discussed in Chapter 5 contain projected water consumption data for 24 plants at freshwater sites, following retrofitting of cooling towers ( 6 nuclear plants and 18 fossil plants). The average values for closed-cycle cooling water consumption rates from these EPRI reports follow:

- Nuclear water consumption rate (cooling tower retrofits):

- Fossil water consumption rate (cooling tower retrofits):
886 gallons per MWh

597 gallons per MWh

Note that these values are higher than those displayed in Section 2.5. For the nuclear value, spot checking of water consumption data, when included in Environmental Reports to NRC, confirm numbers in the $900 \mathrm{gal} / \mathrm{MWh}$ range.

An attempt has been made in the preparation of this report to determine water consumption rates for once-through cooling on an empirical basis. The strategy for doing this is to find data for plants operating on cooling ponds, which in theory have the ability to determine water consumption rates empirically, using makeup and blowdown data, rainfall data, etc., similar to how closed-cycle plants can develop these data. Since makeup to cooling ponds is not continuous (typically intermittent and/or seasonal), the methodology requires determining a full power water consumption rate and a zeropower water consumption rate, and subtracting the latter from the former to determine the amount of water consumption due to evaporation that results from warmer discharge temperatures. Obtaining zero power water consumption data is problematic, unless quality data were obtained during an extended outage at the site (or during pre-commercial pond operations, if monitored).

Data points have been obtained from two plants using the above approach that suggest that oncethrough cooling water consumption rates are lower than displayed in Section 2.5, in the range of 300 gal/MWh. These two preliminary data points are insufficient for underpinning any decision-making, so further data is being sought from other cooling pond plants that may have sufficient historical data to perform the above calculations. This report will be updated if such data can be obtained.

Nevertheless, this very preliminary and meager data suggest that it is possible that water consumption rates for closed-cycle cooling might be as much as three times greater than water consumption rates for once-through cooling. If confirmed, this would strengthen the argument that once-through cooling deserves a second look on environmental grounds, especially in regions of the country with limited water resources, but the capability to use once-through cooling on a large water body (Great Lakes, large rivers, large reservoirs, cooling ponds, etc.) sufficient to support its higher flow rates. Obviously, this second look will require the capability to make decisions on the relative trade-offs among energy supply sustainability policy, water consumption policy, impingement/entrainment policy, etc.

It is interesting to note that most of the states that argued in favor of the Riverkeeper and the Second Circuit approach are states with adequate water resources - with less likelihood that water consumption issues will become a near term problem (water consumption is not an issue when water is withdrawn from oceans or estuaries/tidal rivers). In contrast, many of the 18 states that argued for more discretion under the NPDES for the ability to make BTA determinations that fit their state's hydrology are states with water shortages that need to balance water consumption rates with other criteria. 


\section{$\underline{7.3}$ Short Term Planning Assumptions}

Based on the above analysis, and without a clear picture of how EPA rulemaking will proceed following the Supreme Court decision on $\S 316(b)$, the appropriate strategy in terms of R\&D priorities is one that keeps "all options open." There is a potential that some existing plants would be mandated to install cooling towers. Therefore, further progress on cooling tower design enhancement is appropriate. Improvements in cooling tower designs are underway today; R\&D should focus on the following:

- $\quad$ Reduced water consumption rates

- Reduced electric power demand (reducing the parasitic loads associated with cooling towers) primarily through efficiency improvements, improved fan designs, reduced impacts of wind, etc.

- Improved cooling tower drift elimination capabilities (reducing particulate matter release), as discussed in Section 6.3.

There is also a strong potential for the flexibility imbedded in the 2004 Phase II rule that allowed for a range of technologies to address impingement and entrainment to be included in future BTA determinations at many existing U.S. sites. These options, discussed previously include:

- $\quad$ Fine mesh passive screens, double-entry single-exit traveling screens, wedge-wire screens

- Relocation of intakes (e.g., deeper water intakes)

- Barrier nets, velocity caps, etc.

- Technologies to "scare" fish away from intakes (sound, strobe lights, air bubbles, etc.).

These and other options have been studied and attempted in specific applications over the last 2-3 decades, some with more success than others. Enough has been learned from these applications to plan and scope a renewed R\&D effort to adapt these concepts to broader use. Experience to date shows that each site is different, and that some technologies work at one site but not at other sites. Chapter 9 contains recommendations for a proactive approach to these issues.

In keeping with the holistic approach discussed previously, these technology options should be viewed in terms of crafting integrated approaches, not just picking a single option as the BTA. An R\&D program that fosters a package approach to optimum technologies is most likely to produce the best results at the least cost. However this multiple pathway approach is difficult to evaluate and subject to challenge by special interest groups. The resources required to implement this optimized approach are often not available at the state level. Hence, the holistic approach is probably impractical without some nationwide effort to create a consensus framework for holistic decision-making - while preserving regional and site-specific flexibility. 


\section{PLANNING ASSUMPTIONS AND STRATEGIC PRIORITIES}

This chapter addresses long term planning assumptions, siting of new reactors, High Temperature Gas Reactor (HTGR) considerations, and strategic planning.

\subsection{Long Term Planning Assumptions: Estimating Freshwater Needs for Thermoelectric Generation}

It is important to the nuclear industry and to DOE to appreciate the long term water requirements for nuclear plant operations. To assess this need, one needs to estimate the projected growth in nuclear energy in the U.S. on both a national and regional basis, as well as to project the outcomes of current legal and policy debates regarding the mix of cooling technologies that will be used.

Some of this analysis has already been done by the National Energy Technology Laboratory (NETL), a national laboratory operated by DOE's Office of Fossil Energy. NETL has issued and periodically updated a report entitled, "Estimating Freshwater Needs to Meet Future Thermoelectric Generation Requirements." 56 The last report is dated Sept. 2008, and contains estimates for five scenarios with data presented on both a national average and regional basis. The regional assessment is done on the basis of North American Electric Reliability Corporation (NERC) regions, and includes projections on population growth and electricity demand for each NERC region. Data are presented for all thermoelectric power plants in the U.S. (which includes nuclear), as well as for various breakdowns in fossil technologies.

Water requirements are projected by NETL out to 2030 and utilize EIA data. Nuclear-specific water needs are not broken out explicitly in the report, and EIA projections tend to be conservative with regard to both nuclear plant license renewal and new plant construction. Nevertheless, the NETL report is an excellent basis for understanding future water requirements.

NETL estimates future water requirements (both withdrawal and consumption needs) for five scenarios:

- Case 1-Additions and retirements are proportional to current water source and type of cooling system.

- Case 2 - All additions use freshwater and wet recirculating cooling, while retirements are proportional to current water source and cooling system.

- Case $3-90 \%$ of additions use freshwater and wet recirculating cooling, and $10 \%$ of additions use saline water and once-through cooling, while retirements are proportional to current water source and cooling system.

- Case $4-25 \%$ of additions use dry cooling and $75 \%$ of additions use freshwater and wet recirculating cooling. Retirements are proportional to current water source and cooling system.

- Case 5-Additions use freshwater and wet recirculating cooling, while retirements are proportional to current water source and cooling system. Five percent of existing freshwater 
once-through cooling capacity is retrofitted with wet recirculating cooling every five years starting in 2010.

The following table from the NETL report explains the rationale for these five cases:

\section{Table 8-1 - Case Descriptions for the Water Needs Analysis ${ }^{57}$}

\begin{tabular}{|l|l|}
\multicolumn{1}{|c|}{ Case Description } & \multicolumn{1}{c|}{ Rationale } \\
\hline $\begin{array}{l}\text { Case 1: Additions and retirements proportional to } \\
\text { current water source and type of cooling system. }\end{array}$ & $\begin{array}{l}\text { Status quo scenario case. Assumes additions and } \\
\text { retirements follow current trends. }\end{array}$ \\
\hline $\begin{array}{l}\text { Case 2: All additions use freshwater and wet } \\
\text { recirculating cooling, while retirements are } \\
\text { proportional to current water source and cooling } \\
\text { system. }\end{array}$ & $\begin{array}{l}\text { Regulatory-driven case. Assumes } \$ 316(\mathrm{~b}) \text { and } \\
\text { future regulations dictate the use of recirculating } \\
\text { systems for all new capacity. Retirement decisions } \\
\text { hinge on age and operational costs rather than } \\
\text { water source and type of cooling system. }\end{array}$ \\
\hline $\begin{array}{l}\text { Case 3: } 90 \% \text { of additions use freshwater and wet } \\
\text { recirculating cooling, and 10\% of additions use } \\
\text { saline water and once-through cooling, while } \\
\text { retirements are proportional to current water } \\
\text { source and cooling system. }\end{array}$ & $\begin{array}{l}\text { Regulatory-light case. New additions favor the use } \\
\text { of freshwater recirculating systems, but some } \\
\text { saline capacity is permitted. Retirement decisions } \\
\text { remain tied to age and operational costs, tracking } \\
\text { current source withdrawals. }\end{array}$ \\
\hline $\begin{array}{l}\text { Case 4: 25\% of additions use dry cooling and 75\% } \\
\text { of additions use freshwater and wet recirculating } \\
\text { cooling. Retirements are proportional to current } \\
\text { water source and cooling system. }\end{array}$ & $\begin{array}{l}\text { Dry cooling case. Regulatory and public pressures } \\
\text { result in significant market penetration of dry } \\
\text { cooling technology. Retirement decisions remain } \\
\text { tied to age and operational costs, tracking current } \\
\text { source withdrawals. }\end{array}$ \\
\hline $\begin{array}{l}\text { Case 5: Additions use freshwater and wet } \\
\text { recirculating cooling, while retirements are } \\
\text { proportional to current water source and cooling } \\
\text { system. 5\% of existing freshwater once-through } \\
\text { cooling capacity retrofitted with wet recirculating } \\
\text { cooling every 5 years starting in 2010. }\end{array}$ & $\begin{array}{l}\text { Conversion case. Same as Case 2, except } \\
\text { regulatory and public pressures compel state } \\
\text { agencies to dictate the conversion of a significant } \\
\text { amount of existing freshwater once-through } \\
\text { cooling systems to wet recirculating. }\end{array}$ \\
\hline
\end{tabular}

Of these five cases, Cases 2 and 5 are the most relevant for nuclear plants. Case 2 represents a situation where EPA's Phase I requirements remain in effect for new plants, but current plant requirements revert back to the EPA's 2004 Phase II rule. Case 5 most closely represents the situation where EPA retains its current Phase I requirements for new plants, and aligns requirements for current plants to the Second Circuit decision. Case 1 represents a roll-back of Phase I rulemaking requirements for new plants such that current ratios of once-through vs. closed-cycle cooling remain in effect. Case 3 is only credible if the Second Circuit decision is not followed by EPA and if Phase II rules similar to the 2004 rule, except that some new additions, particularly at coastal sites, would be permitted to use once-through cooling. Case 4 is not feasible on a large scale for nuclear plants, for the reasons discussed in Chapter 2.

National Average Results: Because of the trend away from once-through cooling in all cases except Case 1, water withdrawal rates decline in Cases 2-5. As expected, water consumption rates increase in all five cases, with Case 5 providing the most extreme water consumption impacts: the percent of total 
U.S. water consumption attributable to thermoelectric power plants rises from $3.7 \%$ in 2005 to $5.5 \%$ in 2030. Given the large demand on water by irrigation ( $>80 \%$ of U.S. freshwater consumption), this $\sim 50 \%$ increase in water consumption by thermoelectric power plants is likely to create water use conflicts with domestic and industrial water use needs.

Regional Results: The impacts on water consumption rates for these five cases are more dramatic when analyzed on a regional basis, with the greatest impacts evident in regions with high projected population growth and freshwater supply limitations. The following table highlights the NERC regions with the highest projected impacts on water consumption rates, focused on NETL's Case 2 and Case 5 scenarios:

TABLE 8-2: Selected Regional Water Consumption Data from NETL Report

\begin{tabular}{|c|c|c|c|}
\hline \multirow[b]{2}{*}{ NERC Region } & \multicolumn{2}{|c|}{$\begin{array}{l}\text { \% increase in Water } \\
\text { Consumption, 2005-2030 }\end{array}$} & \multirow[b]{2}{*}{ Impacted States } \\
\hline & Case 2 & Case 5 & \\
\hline NPCC/NY & 207 & 387 & New York \\
\hline FRCC & 336 & 337 & Florida \\
\hline NPCC/NE & 93 & 103 & $\begin{array}{l}\text { Maine, New Hampshire, Vermont, Massachusetts, } \\
\text { Connecticut, Rhode Island }\end{array}$ \\
\hline WECC/NWPP & 80 & $\sim 40$ & $\begin{array}{l}\text { Washington, Oregon, Idaho, Nevada, Montana, Utah, } \\
\text { Wyoming }\end{array}$ \\
\hline SERC & \# & \# & $\begin{array}{l}\text { Virginia, North Carolina, South Carolina, Georgia, } \\
\text { Mississippi, Alabama, Tennessee, Arkansas, Louisiana }\end{array}$ \\
\hline WECC/RM & \# & \# & Arizona, New Mexico, Colorado \\
\hline ERCOT & \# & \# & Texas \\
\hline ECAR & \# & \# & Michigan, Indiana, Ohio, Kentucky, West Virginia \\
\hline
\end{tabular}

\# Most of these increases in water consumption range from $20 \%-40 \%$, but these NERC regions are listed here because NETL data show these regions are impacted the most on an absolute (billion gallon/day) basis. For example, SERC has the highest current water consumption levels among NERC regions today, and will experience the largest overall increase in water consumption over the 2005-2030 period, even though its percentage increase is 'only' estimated to be about $40 \%$.

Note that California, although challenged significantly for water resources, does not show up as a significant water consumption problem region because the analysis assumes that all 2005-2030 generating capacity additions will use combined cycle gas plants (without $\mathrm{CO}_{2}$ sequestration). ${ }^{24}$

The NETL report contains much more detail than presented here, including data for both withdrawal and consumption for all regions and all cases, with a breakdown for various fossil technologies. No other nuclear-specific insights are presented, but the overall thermoelectric plant data are very informative.

\footnotetext{
${ }^{24}$ Without coal with $\mathrm{CO}_{2}$ sequestration and nuclear energy (still prohibited in CA by statute), California will not be able to meet its own climate change goals.
} 


\subsection{Long-Term Planning Assumptions: Expansion of Nuclear Energy - National Picture}

Following is a more nuclear-specific set of "optimistic yet realistic" planning assumptions for use in this report. For purposes of this report, this "optimistic yet realistic" approach was taken, in order to highlight the challenges that nuclear power plants may face with regard to cooling water needs. This approach includes rough estimates of how long the current fleet of nuclear plants will continue to operate, as well as how many new nuclear plants will be built.

There have been a number of recent studies using advanced econometric computer models to assess the relative economics of energy technology options. Some of these studies have included some modest policy incentives in their analyses (e.g., future climate change legislation); while other studies have avoided projecting policy incentives, in order to assess relative economics on an "apples-to-apples" basis. Using either approach, emission-free nuclear energy performs well in most studies, and expands relative to most other options. This is despite the high capital costs and financing hurdles that face nuclear energy. Nuclear's advantages in low production costs, low and stable fuel costs, consistently high availability under all daily and seasonal weather conditions, and technology readiness today without significant R\&D, are all factors in how these models predict expanded growth for nuclear energy. For example, these models often differ on when they can assume that a technically feasible and economically competitive option for carbon capture and sequestration (CCS) of fossil fuel emissions will be available on a widespread basis.

Various recent studies and analyses project about $30 \%$ of U.S. electricity generation from nuclear energy by 2050 . If life extension of the current fleet for an additional license renewal period (from 60 to 80 years) is assumed, the total U.S. nuclear generation could approach $40 \%$ by $2050 .{ }^{25}$ Given the active consideration of life extension of the current fleet beyond the initial license renewal period by both industry and government, along with the launch of R\&D programs at DOE, EPRI, and NRC to examine this option, it is reasonable to include longer life for most of the current fleet in planning assumptions for this report.

Following are some recent references that lend support to roughly $30 \%$ market share (not including a second phase of license renewals) from nuclear energy by 2050 (note that EIA does not project that far into the future). As noted, some of these studies appear to limit nuclear growth or incent other climate mitigation options preferentially in some manner, via the technology assumptions they adopt. Fewer artificial constraints on nuclear energy invariably allow for stronger nuclear growth in these models.

\footnotetext{
${ }^{25}$ Continued operation of the current fleet to 80 years would contribute roughly an additional $~ 10 \%$ of total U.S. generation in the 2050 timeframe. This number decreases from the current $\sim 20 \%$ because of the larger denominator in 2050. Note that no one can predict at this point that all of the existing fleet would operate to 80 years. It is likely that some existing plants would not operate that long. For this discussion of long-term planning assumptions, it is assumed that most existing plants would operate to 80 years. (If not, even more new plants would likely be needed.)
} 
- EPRI analysis performed out to 2050 shows a major expansion of nuclear energy, based on its work with a broadly used economic model (MERGE) ${ }^{26}$ EPRI's MERGE analysis contrasts two technology scenarios: a "Limited Portfolio" scenario representing incremental technology improvements, and a "Full Portfolio" scenario representing the electricity technology advances described in its earlier PRISM analysis. MERGE assessed the economic value of deploying the full technology portfolio analyzed in the PRISM analysis, and projected the least-cost combination of technologies needed to meet a specified $\mathrm{CO}_{2}$ emission reduction requirement. The MERGE results project new nuclear energy plants would be built at a rate to reach about $30 \%$ of U.S. generation by 2050 , based on an assumed levelized electricity cost of $\$ 80 / \mathrm{MWh}$ (corresponding to a $\$ 5100 / \mathrm{kW}$ capital cost) for new construction units. ${ }^{58}$

- The April 2007 report of the National Commission on Energy Policy (NCEP) ${ }^{59}$ modeled a policy case out to 2030 that included CO2 trading plus a package of policy incentives to promote energy efficiency, CCS, and renewable energy (e.g., continued 1.5 cent production credit through 2030), but no equivalent incentives for nuclear. In that analysis, nuclear generation still grew by $\sim 30 \%$ between 2005 and 2030, but not as fast as renewables.

- The July 2007 U.S. Climate Change Science Program (CCSP) report, "Scenarios of Greenhouse Gas Emissions and Atmospheric Concentrations" ${ }^{60}$ reported the results of five different climate mitigation strategies, as modeled by three integrated assessment models (MIT's IGSM, EPRI/Stanford's MERGE, and PNNL/U. of Maryland's miniCAM). IGSM severely limited the growth of nuclear energy based on "concerns such as safety, waste, and proliferation." MERGE allowed nuclear to expand assuming relative economics as the primary constraint, while miniCAM constraints on nuclear were somewhere in between the other two models. Both MERGE and miniCAM forecast steady nuclear growth in the first half of the century and major nuclear growth in the second half. Both forecast nuclear growth under various scenarios at $25 \%$ to $40 \%$ by 2050, if adjusted for continued operation of the current fleet through 2050.

- The June 2008 IEA/OECD study, Energy Technology Perspectives, Scenarios and Strategies to $2050,{ }^{\prime 61}$ modeled an increase in global nuclear energy supply of about a factor of 2.5 to 3.5 by 2050 under its two climate change mitigation scenarios (emissions stabilization and $50 \%$ emissions reduction). A substantial but non-quantified portion of this growth would be in the United States. The IEA limits nuclear energy growth to a cumulative total of $1250 \mathrm{GWe}$ installed global capacity by 2050, " “... in order to reflect growth limitations based on past experience of maximum annual reactor construction rates..." In contrast, the IEA study imposed no comparable growth constraints on other mitigation options. As a result, IEA projected both fossil fuels with CCS and renewables exceeding nuclear generation by 2050 , with renewables increasing by a factor of roughly 30 and fossil fuels with CCS surpassing nuclear by 2050 .

${ }^{26}$ MERGE is a general equilibrium economic model that has been used for more than a decade to analyze the cost of $\mathrm{CO} 2$ emissions mitigation as a function of technology cost, availability, and performance. It has been used extensively by climate change researchers. MERGE models long time horizons to capture economic effects of potential climate change and encompasses all major greenhouse gases and all emitting sectors of the economy. 
Sensitivity analyses were conducted on a number of base scenario variations, with a high nuclear case (global nuclear capacity capped at $2000 \mathrm{GWe}$ ) valued as the low cost option.

- The June 2009 report of the Business Roundtable, "The Balancing Act: Climate Change, Energy Security and the U.S. Economy," used the University of Maryland's Long Term Inter-industry Forecasting Tool (LIFT), a dynamic general equilibrium model of the U.S. economy that uses a unique bottom-up technique to simulate economic, environmental and energy impacts. It modeled two climate change scenarios - "Policy Inertia" and "Policy Leadership," in addition to "business-as-usual." The total nuclear capacity projections for 2050, based on median cost assumptions, are $27 \%$ and $34 \%$ respectively. As with all econometric modeling efforts above, the Business Roundtable assumed that all existing reactors would be decommissioned after 60 years of operation, with no further life extension options. Including the option for a second round of license renewals for most current plants would raise these percentages to $~ 37 \%$ and $\sim 44 \%$, respectively. The report projected a build rate during the period 2030 to 2050 of 6-11 reactors per year, under the "Policy Leadership" scenario. As with most of the above models, steep declines in real GDP are predicted if anything less than a full portfolio of technology options are made available:

○ "In the absence of policies that remove barriers to technology development and deployment, imposing a price on carbon is likely to result in significantly lower U.S. economic growth in coming decades.

- A balanced portfolio approach is likely to be the only approach that has the potential to achieve the large-scale reductions in GHG emissions advocated by many policymakers."

Growth in nuclear energy to about $30 \%$ market share by 2050 would entail construction of roughly 125 to 150 new reactors (assuming Advanced Light Water Reactors (ALWRs), averaging about $1500 \mathrm{MWe}$ each). This new construction estimate does not include new non-LWR plants, such as high temperature gas reactors (discussed later) that might be built for process heat generation, electricity generation, or other missions.

The potential for even greater growth in nuclear energy might result from a credible scenario that involves greater electrification of the transportation sector to reduce emissions and dependency on foreign oil (i.e., shift toward high percentage of plug-in hybrids [requiring massive battery charging power, much of it at night], major increases in mass transit, etc.). Another scenario that would drive higher nuclear growth would be complications or delays in achieving cost effective carbon capture and sequestration technology deployment for fossil fuel generation, resulting in increased reliance on nuclear and renewable energy. Other scenarios that could influence growth in nuclear energy include greater use of heat pumps to replace fossil fuels for home heating, hydrogen generation by electrolysis, and desalination of seawater for potable water by reverse osmosis.

\subsection{Siting of New Reactors}

Some of the new reactors projected by the above studies could be built on existing sites; others would be built on new or "greenfield" sites, depending on a number of factors, such as available land, water 
access, transmission access, etc. There are a number of advantages to adding new units to existing sites where the space and infrastructure is sufficient to support additional units. As discussed earlier, over $2 / 3$ of the COL Applications filed to date with NRC are for reactors to be built on existing sites; slightly less than $1 / 3$ of these applications are for reactors on greenfield sites.

The following provides some rough estimates of the potential for building new reactors on existing sites:

- There are a number of sites with currently operating reactors that were originally planned for more reactor units than were ultimately built. Situations where a formal order was placed but then cancelled are indicative of situations where new construction is possible today on a proven site - issues of land availability, adequacy of water and transmission were previously resolved, and may remain within acceptable parameters today. There are 25 previously planned reactors in this situation, of which 10 are now proceeding in some form in the COL application process.

- There are a number of existing nuclear sites with adequate space for new units, even though no formal plans or orders were ever executed for additional units. There are roughly 10 to 15 existing sites in this situation (not including any sites in the formal order situation above). It is important to note that many of these potentially viable siting options would not be able to support additional units if cooling towers were imposed on the existing operating plants. The primary reason for this is the fact that much of the available space for new units would be taken up by cooling towers, creating sufficient loss of space as to make any new units problematic. In a few cases, the increased water consumption rates needed to support cooling towers would reduce the assured cooling water availability for new units below prudent levels. On the other hand, if new units were added using once-through cooling, there could be adequate water supply for new units, after which other site limitations for additional units would come into play in decision-making (land availability, thermal discharge limits, transmission access, etc.).

- There are a number of "brownfield" sites with fossil generating plants (either operating or shutdown) that could support the addition of nuclear units. Such sites already have water and transmission access, although perhaps not sufficient to support a large reactor addition.

Given the above, it is unlikely that existing sites could support more than about 50 new reactors, relative to the roughly 150 reactors that would be needed to reach about $30 \%$ nuclear market share by 2050 .

Roughly 100 nuclear reactors on about 40 new sites were ordered but cancelled in the 1970s and 1980s due to diminished demand, financing issues, pre-1972 oil embargo growth projections, reaction to the TMI accident and other factors. Included in these numbers are a few sites where construction permits were issued and construction was well underway before the unit was cancelled. Many of these greenfield sites are either no longer available for construction of new reactors, or are no longer optimally located relative to current population growth trends and anticipated electricity demand. Although a few of these previously identified sites may still be viable hosts for new reactors, it is more likely that new nuclear capacity additions will often require new greenfield sites that were not associated with prior reactor orders or construction permits. 
Population growth projections for the 21st Century suggest that the greatest needs for new baseload capacity will be in the South and West - two regions that are currently experiencing water shortages or are expected to face water shortages in the decades to come.

In summary, siting of new reactors to support a $30 \%$ market share for new nuclear power plants in the 2050 timeframe will be very challenging. A few recommendations are offered to prepare for these challenges in the next chapter.

\subsection{High Temperature Gas Reactor (HTGR) Considerations:}

DOE is currently investigating the development of small and medium-sized reactors (SMRs) for a variety of applications, including process heat, electricity, etc. Some of these small reactor concepts include innovative means of achieving plant cooling, including dry cooling. These small reactor concepts are primarily either small light water reactors or high temperature gas reactors.

HTGRs are often discussed as a solution to water conflicts because they require much less water for cooling than light water reactors (LWRs). The reason is that light water reactors, just like fossil fired thermoelectric power plants, use the Rankine steam cycle, which depends on water (boiling and condensing) to transfer the heat used to generate electricity to the environment. Modern HTGR technology operates at very high temperatures, using the Brayton cycle, which does not depend on condensing steam, and is thus more conducive to dry cooling to realize much greater cycle efficiency ( $\sim 50 \%$ to $\sim 55 \%$ or more, instead of $\sim 33 \%$ to $35 \%$ for the Rankine cycle).

To date, HTGR technology has not proven its ability to compete directly with LWR technology for baseload electricity generation. However, the HTGR shows great promise for near term missions that require higher operating temperatures, most involving high temperature "process heat" for industrial processes. In the long term, HTGR technology will be an important contributor to large-scale hydrogen generation, a prerequisite to hydrogen-fueled vehicles - the next evolution beyond plug-in hybrids.

Plug-in hybrid vehicles are not entirely emission free, since they rely on an onboard engine that burns gasoline or natural gas to recharge batteries if they become depleted before the next opportunity to recharge. The next technology step beyond plug-in hybrids to further reduce emissions is to convert onboard engines to fuel cells that use hydrogen, which produces only water vapor when burned. Hydrogen production, storage and transportation are currently too expensive to support this fuel option for the transportation sector. The most promising emission-free heat source for production of costcompetitive hydrogen at the scale required is the HTGR. Various technical processes can use the HTGR's high temperature to split water into its constituent elements of hydrogen and oxygen. The two most promising are high temperature electrolysis and a Sulfur-lodide catalytic process.

It will take decades to modify the transportation sector's infrastructure to a "hydrogen economy." However, as this future vision for the transportation sector is investigated and developed, the hydrogen generation portion of the required infrastructure - the HTGR - will likely proceed commercially, based on other missions for which it is competitive today, primarily in support of the petrochemical industry: 
- "Downstream" petroleum operations such as hydrogen for refining (sweetening crude oil)

- Chemical industry applications such as hydrogen for fertilizers, ammonia, methanol, ethylene.

- "Upstream" petroleum operations such as tertiary oil recovery oil sands and oil shale recovery, and production of oxygen and hydrogen from coal and gas using the Fischer-Tropsch process.

Most of these HTGR functions supporting process heat missions will also need electricity, so HTGRs are likely to co-generate electricity along with process heat, providing at a minimum the on-site power demands for the industrial operation. Some of these HTGRs, particularly ones sited in regions with limited cooling water resources, are likely to be used to supply electricity to residential, commercial and industrial customers in the area. Growth in HTGR deployment for these smaller missions should help build an experience base to achieve high reliability and low cost operations, preparing the technology for the larger transportation sector mission that will likely evolve by mid-century or sooner.

How do these future nuclear missions for the HTGR fit into the water issue? Although the HTGR provides a great opportunity to reduce the water consumption rate of nuclear energy, its optimal use is not in regions with the greatest shortages of water. This is because dry cooling or air cooling works best in cool climates, where fresh water is typically more available. The hotter climates of the West and South are much less conducive to dry cooling. Despite this disadvantage, HTGRs are likely to be deployed increasingly in coming years, in part because of their water use advantages - not only for process heat missions, but also for electricity generation in regions with severely limited water supplies. Deployment is most likely in regions of the country with higher concentrations of petrochemical industrial operations (e.g., upper Midwest, Gulf Coast).

\subsection{Strategic Planning}

The electric utility industry will experience growing pressure to reduce water consumption. Even though both water and electricity are essential for sustainable development, the general public will likely focus first on municipal water supply needs as top priority when water use conflicts develop. Agriculture will

continue to demand a large share of available fresh water as well. At a minimum electric utilities will be asked to "do their share" in addressing water shortages.

The implementation of a new $\S 316(\mathrm{~b})$ rule is likely to impact the continued delivery of reliable and affordable energy to the nation. The impacts could be modest or severe, depending on the actual requirements of the rule. Even though the ultimate authority for decisions under the new rule will reside with EPA and state permitting authorities, DOE has a responsibility for ensuring the impacts of the rule on the nation's energy supplies are clearly understood and determined to be in the national interest from an energy security perspective. If the new $\S 316($ b) Phase II rule aligns closely with the Second Circuit decision, the impacts on energy would likely be serious, weakening the nation's electricity infrastructure capacity, reliability and affordability.

If $\S 316(b)$ regulations and implementation remain in turmoil or evolve into impractical or unworkable requirements, electric utilities will be forced to invoke strategies for continued generation and delivery 
of essential electricity that either rely on closed-cycle cooling (with its higher water consumption rates), or that avoid the use of fresh water - an option that is not available to most existing plants. For new plants, non-freshwater options, as discussed in Section 6.3, are limited in the U.S., restricted to a few unique siting opportunities. This policy outcome is not in the best interest of the U.S., especially for the operating fleet, in that it will negatively impact energy security in many parts of the country. In the long run, CWA compliance will likely drive water resource considerations to the top of the list of criteria for new plant siting in most regions of the country, and may push siting away from regions of greatest need for more electricity, further complicating transmission systems and grid reliability. Clearly, the Federal Government needs a holistic approach to managing the energy-water interface. This might involve new legislation, especially if the courts are unable to settle continued challenges to CWA implementation in a manner that is compatible with national energy security and electricity reliability needs.

Even though DOE is not in a position of authority over water as an environmental issue, it is in a unique position as the government's advocate for energy (e.g., reliability, independence, affordability), to engage water issues from an energy perspective. It is well-positioned as a sponsor of energy R\&D to work toward better science-based strategies for managing energy-water conflicts. And given the expected timing of a new $\S 316$ (b) rule in early 2011, DOE has an opportunity to propose R\&D in the FY 2011 or FY 2012 budgets (prior to rule issuance or during the initial consideration and public comment period on the draft rule) that could facilitate science-based technology options and strategies that can address CWA objectives in ways that also maintain energy reliability and security.

The existence of a robust R\&D program at DOE aimed at "best science" to address CWA issues should give national environmental policy leaders and decision-makers greater confidence in the range of technology options that could be used to implement a new Phase II rule and how well each will perform. This in turn would give policy-makers greater confidence in success paths that are in the overall national interest. Timely engagement in CWA implementation technologies would set the stage for engagement in issues such as future water consumption requirements of energy facilities, drought mitigation, etc.

Greater cooperation and integration of energy and water resource planning is inevitable, especially between electric utilities and water utilities and those entities that regulate each. Since water is essential to energy production and energy is essential to water production, treatment and transport, these two utility groups can benefit greatly from joint efforts to conserve strategic resources, both at the local/regional level and at the national level. Cooperation is likely to extend beyond joint planning into more integrated operations, co-location of facilities, etc., to achieve greater efficiency and cost savings in respective operations.

The nuclear industry will need to be open to a range of creative strategies to address future energywater issues. DOE will be an important partner in enabling these creative strategies, especially if energy-water issues become obstacles to expansion of nuclear energy and coal with carbon capture and sequestration. Visionary strategies, such as large energy parks that host multiple facilities for electricity generation, hydrogen and/or process heat generation, desalination, recycled water processing and storage, etc., will need Federal Government support to succeed. Recommendations for R\&D to address energy-water interface issues follow in the next chapter. 


\section{RECOMMENDATIONS}

Based on the planning assumptions presented in the previous chapter, the following recommendations are proposed. Most of these recommendations came from individual industry experts, as discussed in Chapter 6, initially without the benefit of broad industry screening and prioritization. However, most were later validated by an expert industry group assembled for a cooling water strategy meeting cosponsored by EPRI and INL in April 2010. Although the following recommendations were generally validated by that group, some still need additional development and evaluation, to ensure feasibility and to prioritize the more promising ones on the bases of urgency and resource allocation.

The Department of Energy has a strong interest in water issues, since water is critical to energy system operations and ultimately to national energy security. DOE has a specific interest in addressing energywater conflicts, as requested by Congress in its 2004 letter to the Secretary and in its 2005 Energy Policy Act (both discussed in Chapter 1, page 9). Given DOE's interest in promoting resolutions to energywater conflicts and energy-environment interface issues in a manner that assures continued delivery of reliable and affordable energy to the nation, the following recommendations are intended to be "energy-mission-oriented," while at the same time being sensitive to the nation's environmental goals. It is assumed that DOE will work with other Federal Agencies and Congress toward balanced resolutions of any energy-water conflicts when they occur, in the overall best interests of the nation.

Also, although this report has been prepared for DOE's Office of Light Water Reactor Technologies within the Office of Nuclear Energy, many of the recommendations are applicable to DOE's Office of Fossil Energy, DOE's Office of Electricity, other Federal and State agencies, and/or industry. It is assumed that DOE will work with industry and other agencies to decide which actions are appropriate for DOE to take and which ones are best addressed by other agencies or by industry.

These recommendations are organized in six broad categories:

1. Water Conservation and Siting Strategies, Including Appropriate Use of Once-Through Cooling

2. Energy/Water Nexus, Water Use Conflicts, and R\&D to Support Water-Related Policy Initiatives

3. Cooling System Technologies, including R\&D Opportunities

4. Alternate or "Non-Traditional" Sources of Cooling Water

5. Fish and Aquatic Species Protection, §316(B) Issues

6. Collaboration, Benchmarking, and Coordination Initiatives

\subsection{Water Conservation and Siting Strategies, Including Appropriate Use of Once-Through Cooling}

Many industry experts expect that water resources will emerge as a critical (or the critical) factor in future thermoelectric power plant siting decisions. Anticipating that new nuclear power plants will be designed to operate over many decades (e.g., 60-80 years or more), it is critical that sites selected for nuclear plants have ample and assured water resources for an indefinite period of time. 
Since siting decisions are being made today, the following recommendations, although long-term and strategic in their impacts, are urgent matters that require near term attention.

Chapter 8 shows that a significant number of new greenfield sites will be needed in the future for new nuclear plant siting, even if utilities make maximum use of available space at existing sites. Further, population density and commercial/industrial expansion will continue to be somewhat concentrated along the nation's coastlines (including the Great Lakes), or within a few hundred miles of these coastlines. However, due largely to $\S 316(\mathrm{~b})$ Phase I rulemaking for new thermoelectric capacity additions, siting of new plants on oceans, estuaries, tidal rivers and the Great Lakes raises large project uncertainties, reliability issues, and increased financial risks. This is because Phase 1 mandates cooling towers for all new facilities, but salt water cooling towers are problematic from both an operational and environmental perspective (e.g., ambient air quality; extensive salt drift on nearby electrical equipment, communities, and fragile coastal environments).

Recommendation 1: Conduct a study of siting options in coastal regions, seeking solutions to future energy needs in these regions that are difficult for thermoelectric power plant siting.

Even though from a strictly engineering perspective it is relatively easier and less expensive to transport electricity over significant distances than it is to transport water, the options for remote siting of thermoelectric power plants closer to assured water resources to help resolve coastal power requirements is politically difficult. This is because of the tremendous difficulty in expanding transmission capacity, especially if it entails new transmission right-of-way access.

Recommendation 2: Examine the potential for selective use of once-through cooling (with BTA protections tailored for coastal use) in restricted coastal environments that meet appropriate siting criteria. This option could be facilitated via a baseline standardized or regional "Comprehensive Demonstration Study" approach (as discussed in Chapter 3 as a Phase I Rule option), and developed with stakeholder involvement that is aimed at achieving an industrygovernment consensus.

Another region of the country that would benefit from a focused analysis is the Great Lakes. As discussed in Chapters 6 and 7, regional water authorities are beginning to come to the realization that cooling towers may be exacerbating water consumption rates in the upper Great Lakes. When new generating capacity is added in the Great Lakes region, once-through cooling with the appropriate intake structure protections against impingement and entrainment, potentially in combination with deep water intakes where feasible, is likely to be preferred by state and regional water managers over cooling towers, especially on the upper Great Lakes.

Recommendation 3: Examine the water resource and cooling technology options for future thermoelectric power plant construction in the Great Lakes region, with a focus on the relative advantages of closed-cycle cooling vs. once-through cooling in this region. If this study indicates that future capacity additions in the Great Lakes region should allow for once-through cooling options (with appropriate BTA protections), then consider developing an exemption from Phase I 
requirements for this region (e.g., via a baseline standardized or regional "Comprehensive Demonstration Study" approach as in Recommendation 2 above).

Examining the science more closely in the case of the Great Lakes region should be a high priority, given growing concerns in that region that water consumption rates are an important (perhaps more important) environmental impact to be addressed. It is possible that the new Phase II rulemaking might recognize the appropriateness of exemptions for once-through cooling in this region for existing plants. If so, the flexibility established in the Phase II rule might serve as an appropriate precedent for Phase I exemptions. Conversely, a "baseline CDS" approach to assessing alternatives to cooling towers under the Phase I Rule might be useful for facilitating options for Phase II assessments of existing facilities on the Great Lakes, or potentially other water bodies (recognizing of course that once-through cooling is not appropriate for many sites, e.g., ones that require cooling towers to manage thermal discharges).

Recommendation 4: If focused R\&D efforts on coastal and Great Lakes regions is successful in reestablishing once-through cooling (with BTA protections) as a viable option for those aquatic environments, then other hydrology situations should also be examined on a selective basis. First priority should go to reexamining the once-through cooling option on large lakes and multipurpose reservoirs, and large rivers with high flow rates sufficient to assure good thermal mixing.

Another new plant siting option that deserves further study is the use of cooling ponds as closed cycle cooling systems in lieu of cooling towers. The advantage of cooling ponds is that they consume less water than cooling towers (approaching water consumption rates of once-through cooling). Unfortunately, there are limited sites in the country where cooling ponds are practical options. They require a lot of land and are capital intensive. Once in operation, they have much lower O\&M needs than cooling towers, and offer assured access to cooling water on an indefinite basis. Since the full range of options for this cooling technology may not have been explored, it merits a study.

Recommendation 5: Examine cooling pond options for new plant siting, including both technology and hydrology considerations for various regions of the country.

As discussed in Chapters 2, 4, and 7, preliminary data obtained during the preparation of this report suggests that the water consumption rates at plants using cooling towers, long recognized as somewhat greater than consumption rates at plants using once-through cooling, may in fact be worse than currently recognized. Instead of 50\% - 100\% greater water losses from cooling towers, the actual disadvantage of cooling towers in relation to once-through cooling may be as great as a factor of two or three in water consumption rates, depending on the region of the country. If confirmed, this larger difference would have a major impact on siting decisions and cooling system design choices. More empirical data is needed to better define the water consumption rate advantages of once-through cooling, allowing for less reliance on ambiguous computer modeling.

Recommendation 6: Better define the relative water consumption rates between closed cycle cooling systems and once-through cooling systems. 
Experience to date with nuclear power plants sited on reservoirs that also provide hydropower generation via pumped storage (between adjacent reservoirs at different elevations) shows that thermoelectric power plant cooling and pumped storage operations are highly compatible. Given the likely need for increased energy storage capacity as renewable energy expands, the full promise of co-locating nuclear power plants with pumped storage systems should be examined.

\section{Recommendation 7: Examine the potential for expanded siting of nuclear power plants on reservoirs capable of providing pumped storage generation.}

Most regions of the country have experienced drought conditions in recent history, some of which have impacted the performance of thermoelectric power plants. Although programs from recent initiatives are in place, more work needs to be done. For example, DOE, state permitting authorities and industry should work with the Corps of Engineers to help prioritize its projects associated with the nation's reservoirs from an energy security perspective - dam maintenance and expansion, dredging, and related projects that would expand the nation's storage capacity for fresh water.

\section{Recommendation 8: Examine the nation's drought mitigation plans on a region-by-region basis, and identify opportunities for engagement between Federal agencies and industry to enhance those plans to better assure continued delivery of electricity in the case of severe drought. Working with the Corps of Engineers, prioritize opportunities to expand freshwater storage capacity where needed for energy security.}

Another area that deserves some attention by Energy-Water R\&D programs is the possibility of conserving water through the use of "bottoming cycles" that make productive use of "waste heat" instead of rejecting all the residual heat in the steam cycle to the environment. Studies performed to date in this area include use of low pressure steam for desalination systems to produce potable water, use of heated water to encourage algae growth that could be used for bio-fuels production, etc. Utility experts interviewed were divided on the prospects for R\&D in this area. A working group with broad expertise in this area should be formed to evaluate options in greater detail.

\section{Recommendation 9: Examine opportunities for cost-effective uses of waste heat from} thermoelectric power plants, in support of water conservation objectives.

\subsection{Energy/Water Nexus, Water Use Conflicts, \& R\&D to Support Water-Related Policy Initiatives}

The Federal decision process for CWA implementation fails to recognize in a holistic matter the other environmental trade-offs associated with CWA implementation beyond impingement and entrainment concerns, including impacts on clean air, water consumption impacts of closed-cycle cooling on water resources, climate change implications, etc. Thus, we have a situation where there is (or could soon be) sufficient data to form the basis for results-based policy-setting by Federal and state agencies, but a failure to use that data. Historically, the reasons for not using that data in decision-making have largely centered on the added resources required to manage site-specific decision-making, which typically requires a number of expert technical judgments and resolution of complex trade-offs. A science-based evaluation methodology should be developed that weighs 
these factors in a simple, objective and transparent manner. If such a methodology could be developed and demonstrated to provide relative ease of use by affected stakeholders within reasonable time and resource constraints, it would provide a powerful tool for resolving energywater conflicts. This is a challenging recommendation, since such a methodology, to be successful, must avoid one-size-fits-all answers, and possess the flexibility to deal with significant regional and water-body differences, while, at the same time, be easy to use by decision makers.

Recommendation 10: Develop a science-based decision methodology for energy-water interface issues that helps decision-makers weigh the competing environmental goals of clean air, clean water, climate change mitigation, water resource conservation, and other relevant national objectives associated with energy supply, and apply it urgently to the conflicts and trade-offs associated with CWA § 316(b) implementation and water consumption issues for electricity generating plants.

A results-oriented methodology for evaluating energy and environmental objectives and their reliance on limited water resources (for fuel, cooling, energy transport, etc.) should enable holistic decision-making - especially when objectives end up in conflict with each other (e.g., through the political or legal process).

Next, R\&D programs can support strategic initiatives to bolster the nation's ability to resolve energywater conflicts on a best science and site-specific basis. As discussed in Chapter 1, DOE issued a report to Congress in 2006 that defined the issues and needs to address energy-water conflicts.

DOE's Offices of Nuclear Energy and Fossil Energy could take the next step, and develop an R\&D plan that would facilitate the development of solutions to near term and longer term energy-water conflict issues that are impacting both fossil and nuclear thermoelectric power plants. That plan should include both technology R\&D and strategic planning components. Collaboration with DOE's Office of Electricity Delivery and Energy Reliability (DOE-OE) could be included as appropriate, in order to incorporate grid reliability perspectives into the plan.

Recommendation 11: DOE's Offices of Nuclear Energy, Fossil Energy, and Electricity Delivery and Energy Reliability should consider developing a plan to address energy-water conflict issues impacting thermoelectric power plant reliability and performance.

\subsection{Cooling System Technologies, including R\&D Opportunities}

Anticipating continued pressure to increase the use of cooling towers for thermoelectric power plant cooling (even in situations where they are inferior options), continued work on cooling tower technology is essential. A comprehensive R\&D program is needed, building on extensive work already completed, to advance cooling tower technology to achieve multiple goals, including reduced water consumption rates, reduced drift and air emission rates, improved reliability, improved economic performance, etc. This R\&D may include obtaining better data on the performance of existing tower designs to help prioritize best approaches. In addition, this R\&D should address the lack of experience with cooling towers in salt water environments and focus specifically on how to best deploy cooling towers in that challenging environment. 


\section{Recommendation 12: Initiate a comprehensive R\&D program aimed at improving the}

environmental performance of cooling towers, targeted at reducing water consumption rates and air emissions rates, and at preparing for expanded use of towers in salt water environments.

Although a shift toward dry cooling of nuclear plants is unlikely for safety, reliability, and economic reasons, the selective use of indirect dry cooling as part of hybrid cooling systems or for purposes of plume abatement is a likely need for future nuclear plants. An R\&D effort in this area is needed.

Recommendation 13: Include in the cooling tower R\&D program recommended above a limited and focused effort in those applications of hybrid dry cooling (e.g., plume abatement) most likely to be needed for future nuclear plant applications.

One of the insights gained in the utility interview process discussed in Chapter 6 was that operating experience with cooling systems occasionally reveals problems that would benefit from greater information sharing among thermoelectric power plants. The nuclear industry has outstanding operating experience sharing programs that alert all plants to experience at one plant that might be relevant to other plants. The Institute of Nuclear Power Operations maintains such a program for the nuclear industry, while the NRC independently monitors operating experience and provides information to its inspectors and directly to licensees regarding relevant events, equipment issues, etc. Both the INPO program and NRC's activities in operating experience evaluation are focused on nuclear safety. When cooling system issues have the potential to impact nuclear safety, these programs are effective in promulgating information and recommendations, as evidenced by a recent Significant Operating Experience Report by INPO on intake structure blockage. (Note that EPRI has established an Interest Group to address intake blockage, coordinating with INPO.) However, some of the problems encountered with cooling system performance have no direct impact on safety, and thus may not be captured by existing operating experience review programs. Further, there is valuable experience and "lessons learned" to be shared between fossil plants and nuclear plants, and with international counterparts.

Cooling towers are particularly challenging from an operations and maintenance (O\&M) perspective. Maintaining cooling towers at high efficiency is a complex and expensive undertaking, and is susceptible to surprises when extreme weather conditions occur, including freezing conditions. Hot summer weather and drought conditions present unique challenges to cooling tower systems.

Further, experience reveals a steep learning curve with other cooling system equipment, such as new intake screen technologies. This area is being addressed by INPO and EPRI, but operating experience with other cooling systems are not. For example, there are important opportunities to share best practices in the area of coordination with dams and pumped storage operations, including reservoir water level and flow management. Each utility has learned how to manage its site-specific systems under a range of climatic and water resource conditions, but a more robust operating experience sharing program would be valuable. These types of initiatives should come from industry, but DOE could participate and maintain connectivity with its larger R\&D programs. 
Recommendation 14: Expand existing operating experience programs to address cooling water systems and their operations at both fossil and nuclear plants under a range of climatic conditions.

(Note that technology R\&D in the area of aquatic species protection is covered in Section 9.5 below.)

\subsection{Alternate or "Non-Traditional" Sources of Cooling Water}

Assurance of reliable water supply to thermoelectric power plants is even more important when one considers the likelihood that the cost of water will increase over time. Utilities may be willing to forego water quality for sustained water resource reliability, meaning that they would be willing to accept the often poorer quality of non-traditional sources of water for cooling in some regions of the U.S., in order to ensure guaranteed long term water commitments. This includes options such as brackish water, saline aquifers, reclaimed municipal ("gray") water effluent, "produced" water from prior usage by agriculture or mining industries, etc.

Recommendation 15: Continue research already begun by NETL, Argonne National Laboratory ${ }^{62}$, EPRI and others, into alternate sources of cooling water for thermoelectric power plant cooling, with a focus on which options are most promising for specific regions of the country.

\subsection{Fish and Aquatic Species Protection; §316(B) Issues}

There are two primary ways to inject a greater degree of science-based decision-making into the EPA's $\S 316(b)$ rulemaking process. The first is to engage the mindset emanating from the courts that a single "one-size-fits-all" technology solution can be identified for avoiding fish impingement and entrainment. It is clear from the information collected in this report that the BTA for one site is not necessarily the BTA for another site. Worse, the BTA for one site could - in some cases - pose a serious safety or environmental or reliability threat to continued operation of a facility, if duplicated at other sites where it won't work. Fine mesh or wedgewire screens may work well at some sites with continuous water flow past the screens, but could create cooling water flow blockage problems at low flow sites, due to inability of screen cleaning systems (typically air bursts) to clear debris, without immediate re-clogging. Cooling tower retrofitting could lead to greater environmental impacts than an existing once-through system at some sites, especially ones with limited water resources. So a primary focus of R\&D programs should be to inform the $\S 316$ (b) Phase II rule implementation in ways that prevent adverse or unintended consequences from the imposition of technologies that are not appropriate at specific sites.

This evaluation methodology should also help answer the question, "Do once-through cooling systems actually adversely impact fish populations?" The Phase I rulemaking was based on the premise that observed impingement and entrainment at the intake structure was sufficient proof that fish populations were being degraded in the entire water body.

Recommendation 16: Pursue a short term R\&D program to evaluate the range of technology approaches to minimizing potential impacts to aquatic life from thermoelectric power plant intake 
structures, aimed specifically at determining which approaches work best for various types of water bodies in various regions of the country, and then advancing those technologies to improve their performance, minimize their adverse impacts on plant reliability, and resolve their implementation obstacles for execution in untested applications and environments.

Recommendation 17: In parallel with the comprehensive assessment of technology options above, engage selectively in near term demonstration projects that test the most promising technologies in strategic siting applications of urgent importance (e.g., tidal rivers).

The pending Phase II CWA rulemaking could have a major impact on energy security, thermoelectric power plant reliability, grid reliability, and other strategic matters of critical importance to DOE.

Recommendation 18: Engage in the § 316(b) revised rule inter-agency review process as an advocate for continued delivery of reliable and affordable energy from the nation's thermoelectric power plants, in a manner that avoids unintended or adverse energy security and environmental consequences from decisions that prevent Best Technology Available (BTA) determinations being made on a balanced, holistic and site-specific basis.

R\&D programs should enable better site-specific decision-making, and provide confidence to national decision-makers in the range of available technology options and how well they perform. These R\&D programs should attempt to be all-inclusive with regard to the range of technology options, the range of water body types, the range of climatic and hydrological conditions that exist throughout the U.S., the various species of aquatic life to be protected in different environments, etc. The technologies to be evaluated should include all those cited in the EPA final Phase II rule of 2004 , along with any new technology concepts or recent evolutions of those previously cited. The technologies to be evaluated should include cooling towers, cooling ponds, and alternatives to towers that can be retrofitted at once-through cooled sites. These R\&D programs should collect and analyze data that are most relevant to CWA decisions and make them available to policymakers. Also key is better site-specific impingement and entrainment data and standing crop data indicating species abundance to better inform decision-makers.

Much impingement and entrainment data have been accumulated over the years that clearly show that thermoelectric power plant operations rarely if ever negatively impact the balance in aquatic life in the host water body. Such data also help correct a number of misperceptions and overconservative assumptions in CWA implementation, such as the assumption that $100 \%$ of entrained organisms are killed, impingement and entrainment are proportional to flow rate, all aquatic species have the same value in the context of BTA determinations, etc. Scientific data that challenge the premise that local effects at the intake structure are representative of the entire host water body have been collected, but have not been persuasive to date. Hence, it is imperative that such data are reviewed for adequacy and quality, and updated as needed in a manner that supports sciencebased decision making by policy-makers on the future of once-through cooling. Entrainment survivability data should be included explicitly in this review, not only to refute the assumption that 
no larvae survive transit through the cooling system, but also to identify design features and/or operational practices that appear to contribute positively to entrainment survival.

Recommendation 19: Organize an aquatic species data collection and updating effort aimed at validating entrainment survivability, and at demonstrating the true impact on source water bodies from various cooling system technology choices and strategies.

\subsection{Collaboration, Benchmarking, and Coordination Initiatives}

DOE could take advantage of the infrastructure created to support the development of the DOE Report to Congress and the Energy-Water R\&D Roadmap in "jump-starting" a robust R\&D program on energy-water issues. The effort to date to prepare these documents brought together experts from DOE Headquarters and all of the National Laboratories, as well as state-level and private sector experts. The process included follow-up activities that collected extensive public input from a broad range of stakeholders attending regional and national workshops. This work represents an excellent starting point for a science-based approach to energy-water issues. The network of National Lab experts remains intact and active, prepared to take on additional work.

In addition, many of the nation's colleges and universities have excellent programs on energy and/or environment issues, some of which focus in part on water issues. These resources can be brought to bear on an energy-water R\&D program. These university programs are likely to have a unique perspective on the water issues in their region, and thus can be very helpful in shaping regional solutions as discussed in Recommendation 16 above.

\section{Recommendation 20: Industry and government should facilitate a broad collaboration among} experts in energy and water matters, as they develop robust energy-water R\&D action plans. Much work has already been done that can be built upon to quickly address current energy-water issues. Broad stakeholder outreach and engagement should be reestablished, similar to that which was assembled by these experts in the 2006-2007 timeframe.

There are a number of programmatic initiatives that could build on the energy-water nexus initiatives described in the DOE Report to Congress. The titles of Chapters 1, 2, and 3 of that DOE Report were "Energy and Water are essential, interdependent resources," "Supplying energy requires water," and "Supplying water requires energy." This suggests an inevitable growth in partnerships between electric utilities and water utilities across the country. This natural relationship is one that also came up in the utility interviews covered in Chapter 6 as one that deserves more attention in the future.

Partnerships between electric and water utilities might lead to a range of mutual support initiatives. The most obvious opportunities are in conservation and integrated resource planning. Together, these utilities can figure out how electricity generating facilities could consume less water and how water facilities could consume less electricity. Also, the electric utility industry has years of experience working on demand-side management initiatives with its commercial and residential customers. This experience could be transferred and adapted by water utilities to similar programs 
for water customers. These partnerships are also likely to identify more opportunities for alternative cooling water options for thermoelectric power plants, including use of wastewater effluent from water utility facilities. The more these two types of utilities communicate and collaborate, the more opportunities are likely to emerge.

Industry should take the lead on developing these relationships. However, some of these ideas have already been explored in the DOE Report to Congress and follow-on activities, and the teams assembled included experts from industry in both the electric utility and water utility categories. Therefore, DOE could play an initial role in facilitating some early partnerships in this area.

\section{Recommendation 21: Facilitate industry collaborations between electric utilities and water utilities, in order to foster local and regional water conservation initiatives.}

The preferred low-cost technology option today for desalination appears to be reverse-osmosis, not basic evaporative cycle desalination. This appears to be true, even when a source of low cost low pressure steam is available. ${ }^{27}$ Nuclear plants are likely to play an increasingly important role in water desalination as drinking water becomes more expensive, but that role is most likely to be through generating the electricity used by reverse-osmosis desalination plants, not through use of waste heat. This is another example of an opportunity for collaboration between electric utilities and water utilities, since co-locating desalination plants with electric generating plants offers some opportunities for efficiency and cost savings. These efficiency opportunities might include, for example, shared use of intake and discharge structures for their respective facilities (including associated $\S 316($ b) features), shared use of water storage and water treatment facilities, etc.

\section{Recommendation 22: Collaborative R\&D initiatives between electric utilities and water utilities should include a strategic examination of U.S. needs for desalination services on a regional and national basis, preferred desalination technologies, and the role that thermoelectric power plants can play in this enterprise.}

A related collaboration that could be beneficial is one among the state permitting authorities. Communications among these state agencies occurs regularly from the perspective of NPDES implementation, but a more in-depth focus on the nation's energy needs would be a valuable addition to their existing communications. Collaboration with state permitting authorities on decision tools could be helpful to their BTA determinations (see Recommendation 16 above). In addition, a benchmarking effort that compares the policies and practices of these state agencies with each other - with a focus on energy and impacts of state actions on energy reliability and security - is an area that electric utilities and DOE could support jointly.

Recommendation 23: Facilitate collaborations and benchmarking activities among state permitting authorities with a focus on energy reliability and security, assisted by utilities.

\footnotetext{
${ }^{27}$ An emerging technology may be on the horizon that changes this picture. "Membrane distillation" is an idea that uses both waste heat and reverse osmosis principles to achieve greater efficiency in desalination processes.
} 


\subsection{Collaboration with Industry}

Much of the work on water issues facing the electricity industry is being done by the private sector. In many cases, this should continue, based on the short term nature of the R\&D or the need for close interactions with and among plant operators. However, the growing challenges at the intersection of energy and water issues demands more timely and coordinated action, particularly at the policy and regulatory level, and particularly in situations where pursuit of single issues or single solutions have created conflicting strategies or unintended consequences. The most efficient strategy for attacking these issues in a timely and cost-effective manner is through government-industry joint strategic planning and R\&D collaboration.

As discussed above, there is definitely a need for Federal investment in energy-water nexus R\&D, including demonstration activities. Further, DOE definitely has a major role to play, given the need for a stronger energy security perspective to energy-water nexus issues.

Given the research work to date by industry (primarily EPRI), as well as the national laboratories and some universities, it is important that Federal agencies reach out and thoroughly understand what has already been done, what is underway, and what remains to be done before embarking on a new or expanded R\&D program. Federal agencies are generally more familiar with the work of the labs and universities, since much of their work is Federally-funded. Federal agencies are generally less familiar with private sector research on the opportunities presented in this Chapter, and would therefore benefit from a series of briefings and information exchanges with EPRI and key commercial vendors.

As is the case with many areas of strategic R\&D in the energy field, the necessary work on the energywater nexus would benefit greatly from joint planning between public and private sector researchers and research sponsors, in order to understand and build consensus on research priorities and timing of needs, to avoid R\&D gaps or duplication of effort, to better coordinate demonstration and technology transfer, etc. DOE and industry would also benefit from reaching agreement on which areas of research are best handled by industry, which areas are best handled by government, and which areas present opportunities for joint efforts, including cost-sharing and technology transfer demonstrations.

Recommendation 24: DOE and industry should seek opportunities to collaborate on R\&D initiatives at the nexus of energy and water, such as those recommended above. Joint planning and prioritization should be a central part of this collaboration, to ensure R\&D objectives are aligned, to avoid gaps and duplication of effort, to leverage limited resources, and to accelerate technology transfer. 


\section{Appendix A: U.S. Nuclear Reactor Listing, by Unit and by USGS Water Resource Region}

\begin{tabular}{|c|c|c|c|c|c|c|c|c|c|}
\hline Reactor & Operator / Licensee & State & Cooling Water Source & Cooling System Type & \begin{tabular}{|l|} 
Condenser \\
Flow Rate \\
$(1000$ gpm) \\
(NUREG- \\
$1437)$ \\
\end{tabular} & \begin{tabular}{|l} 
\\
RX Type / \\
NSSS \\
Supplier
\end{tabular} & \begin{tabular}{|c} 
Summer \\
Capacity, \\
MWe \\
(NUREG- \\
1350 ) \\
\end{tabular} & $\begin{array}{l}\text { Thermal } \\
\text { Output } \\
\text { MWth } \\
\text { Original / } \\
\text { Uprated }\end{array}$ & $\begin{array}{c}\text { Operating } \\
\text { License Issued / } \\
\text { Expires (NUREG } \\
\text { 1350) [or COL } \\
\text { subm. date] }\end{array}$ \\
\hline \multicolumn{10}{|c|}{ 1. NEW ENGLAND REGION: 5 OPERATING REACTOR UNITS AT FOUR SITES } \\
\hline Seabrook & FPL Group & $\mathrm{NH}$ & Atlantic Ocean & Once-Through & 399 & PWR-West. & 1244 & $3411 / 3648$ & $1990 / 2030 \#$ \\
\hline Pilgrim-1 & Entergy Nuclear & MA & Cape Cod Bay/Atlantic Ocean & Once-Through & 311 & BWR-GE & 685 & $1998 /$ & 1972 / $2012 \#$ \\
\hline Millstone-2 & Dominion Generation & CT & Niantic Bay/L.I. Sound/Atlantic & Once-Through & 523 & PWR-CE & 822 & $2530 / 2700$ & $1975 / 2035$ \\
\hline Millstone-3 & Dominion Generation & CT & Niantic Bay/L.I. Sound/Atlantic & Once-Through & 907 & PWR-West. & 1155 & $3411 /$ & $1986 / 2045$ \\
\hline Vermont Yankee & Entergy Nuclear & VT & Vernon Pool on Connecticut River & O-T plus towers (mechanical) & 366 & BWR-GE & 620 & $1593 / 1912$ & $1973 / 2012 \#$ \\
\hline \multicolumn{10}{|c|}{ 2. MID-ATLANTIC REGION: 19 OPERATING REACTOR UNITS AT TEN SITES -- PLUS 3 NEW UNITS PLANNED (does not include new PSEG unit) } \\
\hline Indian Point-2 & Entergy Nuclear & NY & Hudson River & Once Through & 840 & PWR-West. & 1020 & $2758 / 3216$ & $1973 / 2013 \#$ \\
\hline Indian Point-3 & Entergy Nuclear & NY & Hudson River & Once Through & 840 & PWR-West. & 1025 & $3025 / 3067$ & $1976 / 2015 \#$ \\
\hline Susquehanna-1 & PPL Susquehanna LLC & $\mathrm{PA}$ & Susquehanna River & Tower (1; natural draft) & 448 & BWR-GE & 1135 & $3293 / 3441$ & $1982 / 2042$ \\
\hline Susquehanna-2 & PPL Susquehanna LLC & $\mathrm{PA}$ & Susquehanna River & Tower (1; natural draft) & 448 & BWR-GE & 1140 & $3293 / 3441$ & $1983 / 2044$ \\
\hline Bell Bend (one unit) & PPL Susquehanna LLC & $P A$ & Susquehanna River & Towers (2; natural draft) & & $E P R$ & $\sim 1600$ & & COL: $10 / 2008$ \\
\hline Limerick-1 & Exelon Generation & $\mathrm{PA}$ & Schuylkill River & Tower (1; natural draft) & 450 & BWR-GE & 1134 & $3293 / 3458$ & $1984 / 2024$ \\
\hline Limerick-2 & Exelon Generation & PA & Schuylkill River & Tower $(1 ;$ natural draft $)$ & 450 & BWR-GE & 1134 & $3293 / 3458$ & $1989 / 2029$ \\
\hline Peach Bottom-2 & Exelon Generation & PA & Conowingo Pond on Susquehanna & O-T (mech. towers available) & 750 & BWR-GE & 1112 & $3293 / 3514$ & $1973 / 2033$ \\
\hline Peach Bottom-3 & Exelon Generation & PA & Conowingo Pond on Susquehanna & O-T (mech. towers available) & 750 & BWR-GE & 1112 & $3293 / 3514$ & $1974 / 2034$ \\
\hline TMI-1 & Exelon Generation & PA & Susquehanna River & Towers (2; natural draft) & 430 & PWR-B\&W & 786 & $2535 / 2568$ & 1974 / 2034 \\
\hline Oyster Creek & Exelon Generation & NJ & Barnegat Bay & Once Through & 480 & BWR-GE & 619 & $1930 /$ & $1969 / 2029$ \\
\hline Salem-1 & PSEG Nuclear LLC & NJ & Delaware River & Once Through & 1100 & PWR-West. & 1174 & $3411 / 3459$ & $1976 / 2016 \#$ \\
\hline Salem-2 & PSEG Nuclear LLC & NJ & Delaware River & Once Through & 1100 & PWR-West. & 1130 & $3411 / 3459$ & $1981 / 2020 \#$ \\
\hline Hope Creek & PSEG Nuclear LLC & NJ & Delaware River & Tower (1; natural draft) & 552 & BWR-GE & 1061 & $3293 / 3393$ & $1986 / 2026 \#$ \\
\hline (new unit @ Salem/H.C. & PSEG Nuclear LLC & NJ & Delaware River & $T B D$ & & $T B D$ & & & ESP plan - 2010 \\
\hline Calvert Cliffs-1 & Constellation Energy & $\mathrm{MD}$ & Chesapeake Bay & Once Through & 1200 & PWR-CE & 873 & $2560 / 2700$ & $1974 / 2034$ \\
\hline Calvert Cliffs-2 & Constellation Energy & $\mathrm{MD}$ & Chesapeake Bay & Once Through & 1200 & PWR-CE & 862 & $2560 / 2700$ & $1976 / 2036$ \\
\hline Calvert Cliffs-3 & UNISTAR/Constellation & $M D$ & Chesapeake Bay & \multicolumn{2}{|l|}{1 mech tower w/plume abatement } & $E P R$ & $\sim 1600$ & & COL: $3 / 2008$ \\
\hline North Anna-1 & Dominion Generation & VA & Lake Anna (fed by N. Anna River) & Once Through & 940 & PWR-West. & 924 & $2775 / 2893$ & $1978 / 2038$ \\
\hline North Anna-2 & Dominion Generation & VA & Lake Anna (fed by N. Anna River) & Once Through & 940 & PWR-West. & 910 & $2775 / 2893$ & $1980 / 2040$ \\
\hline North Anna-3 & Dominion Generation & $V A$ & Lake Anna (fed by N. Anna River) & Hybrid (wet/dry combo) tower & & US-APWR & $\sim 1700$ & ESP issued & COL: $11 / 2007$ \\
\hline Surry-1 & Dominion Generation & VA & James River & Once Through & 840 & PWR-West. & 799 & $2441 / 2546$ & $1972 / 2032$ \\
\hline Surry-2 & Dominion Generation & VA & James River & Once Through & 840 & PWR-West. & 799 & $2441 / 2546$ & $1973 / 2033$ \\
\hline
\end{tabular}

Note: Total sites $=68$; does not include planned new units that lack NSSS selection, COLA, or both

(e.g., Amarillo, Payette, Green River, Piketon, or future Duke, PSEG and Southern Co. units) 


\begin{tabular}{|c|c|c|c|c|c|c|c|c|c|}
\hline Reactor & Operator / Licensee & State & Cooling Water Source & Cooling System Type & \begin{tabular}{|l|} 
Condenser \\
Flow Rate \\
$(1000 \mathrm{gpm})$ \\
(NUREG- \\
$1437)$ \\
\end{tabular} & \begin{tabular}{|l} 
\\
RX Type / \\
NSSS \\
Supplier \\
\end{tabular} & \begin{tabular}{|c|} 
Summer \\
Capacity, \\
MWe \\
(NUREG- \\
1350) \\
\end{tabular} & $\begin{array}{l}\text { Thermal } \\
\text { Output } \\
\text { MWth } \\
\text { Original / } \\
\text { Uprated } \\
\end{array}$ & \begin{tabular}{|c|} 
Operating \\
License Issued / \\
Expires (NUREG- \\
1350 ) [or COL \\
subm. date] \\
\end{tabular} \\
\hline \multicolumn{10}{|c|}{ 3. SOUTH ATLANTIC-GULF REGION: 23 OPERATING REACTOR UNITS AT 13 SITES - PLUS 12 NEW UNITS PLANNED (Note: 15 total sites including Lee \& Levy; doesn't include future Duke \& Southern sites) } \\
\hline McGuire-1 & Duke Energy & NC & Lake Norman on Catawba River & Once Through & 675 & PWR-West. & 1100 & $3411 /$ & $1981 / 2041$ \\
\hline McGuire-2 & Duke Energy & NC & Lake Norman on Catawba River & Once Through & 675 & PWR-West. & 1100 & $3411 /$ & $1983 / 2043$ \\
\hline Catawba-1 & Duke Energy & SC & Lake Wylie on Catawba River & Towers (mechanical) & 660 & PWR-West. & 1129 & $3411 /$ & $1985 / 2043$ \\
\hline Catawba-2 & Duke Energy & SC & Lake Wylie on Catawba River & Towers (mechanical) & 660 & PWR-West. & 1129 & $3411 /$ & $1986 / 2043$ \\
\hline Oconee-1 & Duke Energy & SC & Lake Keowee (fed by Keowee \& Little Rivers) & Once Through & 680 & PWR-B\&W & 846 & $2568 /$ & $1973 / 2033$ \\
\hline Oconee-2 & Duke Energy & SC & Lake Keowee (fed by Keowee \& Little Rivers) & Once Through & 680 & PWR-B\&W & 846 & $2568 /$ & $1973 / 2033$ \\
\hline Oconee-3 & Duke Energy & SC & Lake Keowee (fed by Keowee \& Little Rivers) & Once Through & 680 & PWR-B\&W & 846 & $2568 /$ & $1974 / 2034$ \\
\hline William S. Lee-1 & Duke Energy & SC & Broad River & Towers ( 3 ; mechanical) & & AP1000 & $\sim 1150$ & & COL: $12 / 2007$ \\
\hline William S. Lee-2 & Duke Energy & $S C$ & Broad River & Towers (3; mechanical) & & AP1000 & $\sim 1150$ & & COL: $12 / 2007$ \\
\hline (Davie County) & Duke Energy & $N C$ & & $T B D$ & & $T B D$ & & & $T B D$ \\
\hline (Oconee County) & Duke Energy & $S C$ & & $T B D$ & & $T B D$ & & & $T B D$ \\
\hline Harris-1 & Progress Energy & NC & Lake Harris (fed by Buckhorn Creek) & Tower (1; natural draft) & 483 & PWR-West. & 900 & $2775 / 2900$ & $1987 / 2046$ \\
\hline Harris-2 & Progress Energy & $N C$ & Lake Harris (will raise level 20 ft.) & Towers (1; natural draft) & & AP1000 & $\sim 1150$ & & COL: $2 / 2008$ \\
\hline Harris-3 & Progress Energy & NC & Lake Harris (will raise level $\sim 20 \mathrm{ft}$.) & Towers (1; natural draft) & & AP1000 & $\sim 1150$ & & COL: $2 / 2008$ \\
\hline Robinson-2 & Progress Energy & SC & Lake Robinson on Black Creek & Once Through & 482 & PWR-West. & 710 & $2200 / 2339$ & $1970 / 2030$ \\
\hline Brunswick-1 & Progress Energy & NC & Cape Fear River & Once Through & 675 & BWR-GE & 938 & $2436 / 2923$ & $1976 / 2036$ \\
\hline Brunswick-2 & Progress Energy & $\mathrm{NC}$ & Cape Fear River & Once Through & 675 & BWR-GE & 900 & $2436 / 2923$ & $1974 / 2034$ \\
\hline Summer-1 & South Carolina E\&G & SC & Lake Monticello (drains to Broad River) & Once Through & 485 & PWR-West. & 966 & $2775 / 2900$ & $1982 / 2042$ \\
\hline Summer-2 & South Carolina E\&G & SC & Lake Monticello (drains to Broad River) & Towers (mechanical) & & AP1000 & $\sim 1150$ & & COL: $3 / 2008$ \\
\hline Summer-3 & South Carolina E\&G & $S C$ & Lake Monticello (drains to Broad River) & Towers (mechanical) & & AP1000 & $\sim 1150$ & & COL: $3 / 2008$ \\
\hline Vogtle-1 & Southern Nuclear & GA & Savannah River & Tower (1; natural draft) & 510 & PWR-West. & 1152 & $3411 / 3565$ & 1987 / 2047 \\
\hline Vogtle-2 & Southern Nuclear & GA & Savannah River & Tower (1; natural draft) & 510 & PWR-West. & 1149 & $3411 / 3565$ & 1989 / 2049 \\
\hline Vogtle-3 & Southern Nuclear & GA & Savannah River & Tower (1; natural draft) & & AP1000 & $\sim 1150$ & ESP issued & COL: $3 / 2008$ \\
\hline Vogtle-4 & Southern Nuclear & GA & Savannah River & Tower (1; natural draft) & & AP1000 & $\sim 1150$ & ESP issued & COL: $3 / 2008$ \\
\hline Hatch-1 & Southern Nuclear & GA & Altamaha River & Towers (4; mechanical) & 556 & BWR-GE & 876 & $2436 / 2763$ & $1974 / 2034$ \\
\hline Hatch-2 & Southern Nuclear & GA & Altamaha River & Towers (4; mechanical) & 556 & BWR-GE & 883 & $2436 / 2763$ & $1978 / 2038$ \\
\hline Farley-1 & Southern Nuclear & $\mathrm{AL}$ & Chattahoochee River & Towers ( 3 ; mechanical) & 635 & PWR-West. & 851 & $2652 / 2775$ & $1977 / 2037$ \\
\hline Farley-2 & Southern Nuclear & $\mathrm{AL}$ & Chattahoochee River & Towers ( 3 ; mechanical) & 635 & PWR-West. & 860 & $2652 / 2775$ & $1981 / 2041$ \\
\hline$(T B D)$ & Southern Nuclear & $T B D$ & $T B D$ & & & $T B D$ & & & COL: plan 2011 \\
\hline Crystal River-3 & Progress Energy & $\mathrm{FL}$ & Gulf of Mexico & Once Through & 680 & PWR-B\&W & 838 & $2544 /$ & $1977 / 2016 \#$ \\
\hline Levy County-1 & Progress Energy & $F L$ & Cross Florida Barge Canal (to Gulf) & Towers (mechanical) & & AP1000 & $\sim 1150$ & & COL: $7 / 2008$ \\
\hline Levy County-2 & Progress Energy & $F L$ & Cross Florida Barge Canal (to Gulf) & Towers (mechanical) & & AP1000 & $\sim 1150$ & & COL: $7 / 2008$ \\
\hline St. Lucie-1 & Florida Power \& Light & $\mathrm{FL}$ & Atlantic Ocean & Once Through & 491 & PWR-CE & 839 & $2560 / 2700$ & $1976 / 2036$ \\
\hline St. Lucie-2 & Florida Power \& Light & $\mathrm{FL}$ & Atlantic Ocean & Once Through & 491 & PWR-CE & 839 & $2560 / 2700$ & $1983 / 2043$ \\
\hline Turkey Point-3 & Florida Power \& Light & $\mathrm{FL}$ & closed canal system (off Biscayne Bay) & Once Through & 624 & PWR-West. & 693 & $2200 / 2300$ & $1972 / 2032$ \\
\hline Turkey Point-4 & Florida Power \& Light & $\mathrm{FL}$ & closed canal system (off Biscayne Bay) & Once Through & 624 & PWR-West. & 693 & $2200 / 2300$ & $1973 / 2033$ \\
\hline Turkey Point- 6 & Florida Power \& Light & $F L$ & Municipal effluent from Miami/Dade + & saltwater from collector wells & & AP1000 & $\sim 1150$ & & COL: 6/2009 \\
\hline Turkey Point-7 & Florida Power \& Light & $F L$ & (Same) & Towers (mechanical; both units) & & AP1000 & $\sim 1150$ & & COL: $6 / 2009$ \\
\hline
\end{tabular}




\begin{tabular}{|c|c|c|c|c|c|c|c|c|c|}
\hline Reactor & Operator / Licensee & State & Cooling Water Source & Cooling System Type & \begin{tabular}{|l} 
Condenser \\
Flow Rate \\
(1000 gpm) \\
(NUREG- \\
$1437)$ \\
\end{tabular} & \begin{tabular}{|l} 
\\
RX Type / \\
NSSS \\
Supplier \\
\end{tabular} & \begin{tabular}{|c|} 
Summer \\
Capacity, \\
MWe \\
(NUREG- \\
1350 ) \\
\end{tabular} & $\begin{array}{l}\text { Thermal } \\
\text { Output } \\
\text { MWth } \\
\text { Original / } \\
\text { Uprated }\end{array}$ & $\begin{array}{c}\text { Operating } \\
\text { License Issued / } \\
\text { Expires (NUREG } \\
\text { 1350) [or COL } \\
\text { subm. date] }\end{array}$ \\
\hline \multicolumn{10}{|c|}{ 4. TENNESSEE REGION + OHIO REGION: 8 OPERATING REACTOR UNITS AT FOUR SITES -- PLUS 3 NEW UNITS PLANNED (Note: 5 total sites, including Bellefonte) } \\
\hline Beaver Valley-1 & FirstEnergy Nuclear & PA & Ohio River & Tower (1; natural draft) & 480 & PWR-West. & 849 & $2652 / 2900$ & $1976 / 2036$ \\
\hline Beaver Valley-2 & FirstEnergy Nuclear & PA & Ohio River & Tower (1; natural draft) & 480 & PWR-West. & 832 & $2652 / 2900$ & $1987 / 2047$ \\
\hline Browns Ferry-1 & Tennessee Valley Authority & $\mathrm{AL}$ & Tennessee River & O- $\mathrm{T}+$ Helper Towers (mechanical) & 630 & BWR-GE & 1065 & $3293 /$ & $1973 / 2033$ \\
\hline Browns Ferry-2 & Tennessee Valley Authority & $\mathrm{AL}$ & Tennessee River & O- $\mathrm{T}+$ Helper Towers (mechanical) & 630 & BWR-GE & 1118 & $3293 / 3458$ & 1974 / 2034 \\
\hline Browns Ferry-3 & Tennessee Valley Authority & $\mathrm{AL}$ & Tennessee River & O-T + Helper Towers (mechanical) & 630 & BWR-GE & 1114 & $3293 / 3458$ & $1976 / 2036$ \\
\hline Sequoyah-1 & Tennessee Valley Authority & TN & Chickamauga Lake on Tennessee River & O-T + Helper Tower (natural draft) & 522 & PWR-West. & 1150 & $3411 / 3455$ & $1980 / 2020$ \\
\hline Sequoyah-2 & Tennessee Valley Authority & TN & Chickamauga Lake on Tennessee River & O-T + Helper Tower (natural draft) & 522 & PWR-West. & 1127 & $3411 / 3455$ & $1981 / 2021$ \\
\hline Watts Bar-1 & Tennessee Valley Authority & TN & Chicka mauga Lake on Tennessee River & Tower $(1 ;$ natural draft $)$ & 410 & PWR-West. & 1166 & $3411 / 3459$ & $1996 / 2035$ \\
\hline Watts Bar-2 (complete) & Tennessee Valley Authority & TN & Chickamauga Lake on Tennessee River & Tower (1; natural draft) & & PWR-West. & $\sim 1180$ & & const. restart ' 07 \\
\hline Bellefonte-1\&2 (complete?) & Tennessee Valley Authority & $A L$ & Guntersville Lake on Tennessee River & Tower (1; natural draft) & 410 & $P W R-B \& W$ & $\sim 1250$ & & $T B D$ \\
\hline Bellefonte-3 & Tennessee Valley Authority & $A L$ & Guntersville Lake on Tennessee River & Tower (1; natural draft) & & AP1000 & $\sim 1150$ & & COL: $10 / 2007$ \\
\hline Bellefonte-4 & Tennessee Valley Authority & $A L$ & Guntersville Lake on Tennessee River & Tower (1; natural draft) & & AP1000 & $\sim 1150$ & & COL: $10 / 2007$ \\
\hline Piketon & Southern Ohio Clean Energy & $\mathrm{OH}$ & & $T B D$ & & $T B D$ & & & $T B D$ \\
\hline
\end{tabular}

\section{Park Alliance}

5. GREAT LAKES REGION: 13 OPERATING REACTOR UNITS AT TEN SITES -- PLUS 2 NEW UNITS PLANNED (Note: adjacent plants at NMP \& Fitzpatrick treated as separate sites)

\begin{tabular}{|c|c|c|c|c|c|c|c|c|c|}
\hline Kewaunee & Dominion Generation & WI & Lake Michigan & Once Through & 420 & PWR-West. & 556 & $1650 /$ & $1973 / 2013 \#$ \\
\hline Point Beach-1 & Florida Power \& Light & WI & Lake Michigan & Once Through & 350 & PWR-West. & 512 & $1518 /$ & $1970 / 2030$ \\
\hline Point Beach-2 & Florida Power \& Light & WI & Lake Michigan & Once Through & 350 & PWR-West. & 514 & $1518 /$ & $1973 / 2033$ \\
\hline Palisades & Entergy Nuclear & $\mathrm{Ml}$ & Lake Michigan & Towers (mechanical) & 405 & PWR-CE & 778 & $2530 / 2565$ & $1971 / 2031$ \\
\hline DC Cook-1 & AEP / Indiana \& Michigan & $\mathrm{Ml}$ & Lake Michigan & Once Through & 800 & PWR-West. & 1029 & $3250 / 3304$ & $1974 / 3034$ \\
\hline DC Cook-2 & AEP / Indiana \& Michigan & $\mathrm{Ml}$ & Lake Michigan & Once Through & 800 & PWR-West. & 1077 & $3391 / 3411$ & $1977 / 2037$ \\
\hline Fermi-2 & Detroit Edison & $\mathrm{Ml}$ & Lake Erie & Towers (2; natural draft) & 837 & BWR-GE & 1122 & $3292 / 3430$ & $1985 / 2025$ \\
\hline Fermi-3 & Detroit Edison & $M I$ & Lake Erie & Tower (1; natural draft) & & ESBWR & $\sim 1500$ & & COL: $9 / 2008$ \\
\hline Davis Besse & FirstEnergy Nuclear & $\mathrm{OH}$ & Lake Erie & Tower (1; natural draft) & 480 & PWR-B\&W & 889 & $2772 / 2817$ & $1977 / 2017$ \\
\hline Perry-1 & FirstEnergy Nuclear & $\mathrm{OH}$ & Lake Erie & Towers (2; natural draft) & 545 & BWR-GE & 1231 & $3579 / 3758$ & $1986 / 2026$ \\
\hline Ginna & Constellation Energy & NY & Lake Ontario & Once Through & 356 & PWR-West. & 498 & $1300 / 1775$ & $1969 / 2029$ \\
\hline Nine Mile Point-1 & Constellation Energy & NY & Lake Ontario & Once Through & 250 & BWR-GE & 621 & $1850 /$ & 1974 / 2034 \\
\hline Nine Mile Point-2 & Constellation Energy & NY & Lake Ontario & Tower (1, natural draft) & 580 & BWR-GE & 1135 & $3467 /$ & $1987 / 2046$ \\
\hline Nine Mile Point-3 & UNISTAR/Constellation & NY & Lake Ontario & Tower $(1 ;$ mechanical) & & $E P R$ & $\sim 1600$ & (temp. susp.) & COL: $10 / 2008$ \\
\hline Fitzpatrick & Entergy Nuclear & NY & Lake Ontario & Once Through & 353 & BWR-GE & 852 & $2436 / 2536$ & 1974 / 2034 \\
\hline
\end{tabular}

Note: Total sites $=68$; does not include planned new units that lack NSSS selection, COLA, or both

(e.g., Amarillo, Payette, Green River, Piketon, or future Duke, PSEG and Southern Co. units) 


\begin{tabular}{|c|c|c|c|c|c|c|c|c|c|}
\hline Reactor & Operator / Licensee & State & Cooling Water Source & Cooling System Type & \begin{tabular}{|l|} 
Condenser \\
Flow Rate \\
$(1000$ gpm $)$ \\
(NUREG- \\
$1437)$ \\
\end{tabular} & \begin{tabular}{|l} 
\\
RX Type / \\
NSSS \\
Supplier \\
\end{tabular} & \begin{tabular}{|c|}
$\begin{array}{c}\text { Summer } \\
\text { Capacity, } \\
\text { MWe } \\
\text { (NUREG- } \\
\text { 1350) }\end{array}$ \\
\end{tabular} & $\begin{array}{l}\text { Thermal } \\
\text { Output } \\
\text { MWth } \\
\text { Original / } \\
\text { Uprated }\end{array}$ & $\begin{array}{c}\text { Operating } \\
\text { License Issued / } \\
\text { Expires (NUREG } \\
\text { 1350) [or COL } \\
\text { subm. date] }\end{array}$ \\
\hline \multicolumn{10}{|c|}{ 6. UPPER MISSISSIPPI REGION: 15 OPERATING REACTOR UNITS AT NINE SITES } \\
\hline Monticello & Xcel Energy & $\mathrm{MN}$ & Mississippi River & O- $\mathrm{T}+$ Helper Towers (mechanical) & 280 & BWR-GE & 572 & $1670 / 1755$ & $1970 / 2030$ \\
\hline Prairie Island-1 & Xcel Energy & $\mathrm{MN}$ & Mississippi River & O-T + Helper Towers (mechanical) & 294 & PWR-West. & 551 & $1650 /$ & $1973 / 2013 \#$ \\
\hline Prairie Island-2 & Xcel Energy & $\mathrm{MN}$ & Mississippi River & O-T + Helper Towers (mechanical) & 294 & PWR-West. & 545 & $1650 /$ & $1974 / 2014 \#$ \\
\hline Duane Arnold & Florida Power \& Light & $\mathrm{IA}$ & Cedar River & Towers $(2 ;$ mechanical) & 290 & BWR-GE & 581 & $1658 / 1912$ & $1974 / 2014 \#$ \\
\hline Quad Cities-1 & Exelon Generation & $\mathrm{IL}$ & Mississippi River & Once Through & 471 & BWR-GE & 867 & $2511 / 2957$ & $1972 / 2032$ \\
\hline Quad Cities-2 & Exelon Generation & $\mathrm{IL}$ & Mississippi River & Once Through & 471 & BWR-GE & 867 & $2511 / 2957$ & $1972 / 2032$ \\
\hline Byron-1 & Exelon Generation & $\mathrm{IL}$ & Rock River & Tower (1; natural draft) & 632 & PWR-West. & 1164 & $3411 / 3587$ & $1985 / 2024$ \\
\hline Byron-2 & Exelon Generation & IL & Rock River & Tower (1; natural draft) & 632 & PWR-West. & 1136 & $3411 / 3587$ & $1987 / 2026$ \\
\hline Dresden-2 & Exelon Generation & $\mathrm{IL}$ & Cooling Lake (off Illinois River) & Once Through (w/helpers) & 471 & BWR-GE & 867 & $2597 / 2957$ & $1969 / 2029$ \\
\hline Dresden-3 & Exelon Generation & IL & Cooling Lake (off Illinois River) & Once Through (w/helpers) & 471 & BWR-GE & 867 & $2597 / 2957$ & $1971 / 2031$ \\
\hline La Salle-1 & Exelon Generation & IL & Cooling Lake (off Illinois River) & Once Through & 645 & BWR-GE & 1118 & $3323 / 3489$ & $1982 / 2022$ \\
\hline La Salle-2 & Exelon Generation & IL & Cooling Lake (off Illinois River) & Once Through & 645 & BWR-GE & 1120 & $3323 / 3489$ & $1983 / 2023$ \\
\hline Braidwood-1 & Exelon Generation & $\mathrm{IL}$ & Braidwood Lake (Kankakee River) & Once Through & 730 & PWR-West. & 1178 & $3411 / 3587$ & $1987 / 2026$ \\
\hline Braidwood-2 & Exelon Generation & $\mathrm{IL}$ & Braidwood Lake (Kankakee River) & Once Through & 730 & PWR-West. & 1152 & $3411 / 3587$ & $1988 / 2027$ \\
\hline Clinton-1 & Exelon Generation & $\mathrm{IL}$ & Clinton Lake (off Salt Creek) & Once Through & 569 & BWR-GE & 1043 & $2894 / 3473$ & $1987 / 2026$ \\
\hline Clinton-2 & Exelon Generation & IL & Clinton Lake (off Salt Creek) & TBD & & & & ESP issued & $T B D$ \\
\hline \multicolumn{10}{|c|}{ 7. LOWER MISSISSIPPI REGION + TEXAS GULF REGION: 7 OPERATING REACTOR UNITS AT FIVE SITES -- PLUS 6 NEW UNITS PLANNED (GG-3 \& RB-3 not included; 6 total sites, including Victoria County) } \\
\hline Grand Gulf-1 & Entergy Nuclear & MS & Coll. wells near Mississippi River & Towers (1 natural, 1 mechanical) & 572 & BWR-GE & 1266 & $3833 / 3898$ & $1984 / 2024$ \\
\hline Grand Gulf-3 & Entergy Nuclear / NuStart & MS & Coll. Wells near Mississippi River & Towers (1 natural, 1 mechanical) & \multicolumn{3}{|c|}{ NRC review suspended } & ESP issued & COL: $2 / 2008$ \\
\hline River Bend-1 & Entergy Nuclear & LA & Mississippi River & Towers (mechanical) & 508 & BWR-GE & 967 & $2894 / 3091$ & $1985 / 2025$ \\
\hline River Bend-3 & Entergy Nuclear & $\angle A$ & Mississippi River & Towers (1 natural, 1 mechanical) & \multicolumn{3}{|c|}{ NRC review suspended } & & COL: $9 / 2008$ \\
\hline Waterford-3 & Entergy Nuclear & LA & Mississippi River & Once-Through & 975 & PWR-CE & 1152 & $3390 / 3716$ & $1985 / 2024$ \\
\hline Comanche Peak-1 & Luminant / TXU & $\mathrm{TX}$ & Squaw Creek Res. (fm Lake Granbury) & Once-Through & 1030 & PWR-West. & 1150 & $3411 / 3458$ & $1990 / 2030$ \\
\hline Comanche Peak-2 & Luminant / TXU & $\mathrm{TX}$ & Squaw Creek Res. (fm Lake Granbury) & Once-Through & 1030 & PWR-West. & 1150 & $3411 / 3458$ & $1993 / 2033$ \\
\hline Comanche Peak-3 & Luminant / TXU & $T X$ & Lake Granbury & Towers (mechanical) & & US-APWR & $\sim 1700$ & & COL: $9 / 2008$ \\
\hline Comanche Peak-4 & Luminant / TXU & $T X$ & Lake Granbury & Towers (mechanical) & & US-APWR & $\sim 1700$ & & COL: $9 / 2008$ \\
\hline South Texas-1 & STP Nuclear & $\mathrm{TX}$ & Cooling Res. w/m/u fm Colorado River & Once-Through & 907 & PWR-West. & 1280 & $3800 / 3853$ & $1988 / 2027$ \\
\hline South Texas-2 & STP Nuclear & $T X$ & Cooling Res. w/ m/u fm Colorado River & Once-Through & 907 & PWR-West. & 1280 & $3800 / 3853$ & $1989 / 2028$ \\
\hline South Texas-3 & NRG Energy / STP Nuclear & $T X$ & Cooling Res. w/ m/u fm Colorado River & Once-Through & & $A B W R$ & $\sim 1350$ & & COL: $9 / 2007$ \\
\hline South Texas-4 & NRG Energy / STP Nuclear & $T X$ & Cooling Res. $w / m / u$ fm Colorado River & Once-Through & & $A B W R$ & $\sim 1350$ & & COL: $9 / 2007$ \\
\hline Victoria County-1 & Exelon Generation & $T X$ & Cooling Lake w/ m/u fm Guadalupe River) & Once-Through & & $T B D$ & $\sim 1350$ & & ESP: $3 / 2010$ \\
\hline Victoria County-2 & Exelon Generation & $T X$ & Cooling Lake w/m/u fm Guadalupe River) & Once-Through & & $T B D$ & $\sim 1350$ & & ESP: $3 / 2010$ \\
\hline
\end{tabular}

Note: Total sites $=68$; does not include planned new units that lack NSSS selection, COLA, or both

(e.g., Amarillo, Payette, Green River, Piketon, or future Duke, PSEG and Southern Co. units) 


\begin{tabular}{|c|c|c|c|c|c|c|c|c|c|}
\hline Reactor & Operator / Licensee & State & Cooling Water Source & Cooling System Type & \begin{tabular}{|l|} 
Condenser \\
Flow Rate \\
$(1000$ gpm) \\
(NUREG- \\
$1437)$ \\
\end{tabular} & \begin{tabular}{|l} 
\\
RX Type / \\
NSSS \\
Supplier
\end{tabular} & \begin{tabular}{|c} 
Summer \\
Capacity, \\
MWe \\
(NUREG- \\
1350 ) \\
\end{tabular} & $\begin{array}{l}\text { Thermal } \\
\text { Output } \\
\text { MWth } \\
\text { Original / } \\
\text { Uprated }\end{array}$ & \begin{tabular}{|c|} 
Operating \\
License Issued / \\
Expires (NUREG \\
1350) [or COL \\
subm. date]
\end{tabular} \\
\hline \multicolumn{10}{|c|}{ 8. MISSOURI REGION + ARKANSAS-WHITE-RED REGION: 6 OPERATING REACTOR UNITS AT FIVE SITES -- (does not include Callaway-2 and Amarillo) } \\
\hline Ft. Calhoun & Omaha Public Power Dist. & $\mathrm{NE}$ & Missouri River & Once Through & 360 & PWR-CE & 478 & $1420 / 1524$ & $1973 / 2033$ \\
\hline Cooper & Nebraska PPD / Entergy & $\mathrm{NE}$ & Missouri River & Once Through & 631 & BWR-GE & 760 & $2381 /$ & $1974 / 2014 \#$ \\
\hline Callaway-1 & AmerenUE & $\mathrm{MO}$ & Missouri River & Tower (1; natural draft) & 530 & PWR-West. & 1190 & $3411 / 3565$ & $1984 / 2024$ \\
\hline Callaway-2 & AmerenUE & MO & Missouri River Alluvial Aquifer & Towers (2; natural draft) & & \multicolumn{2}{|c|}{ WRC review suspended } & & \\
\hline Wolf Creek & Wolf Creek Nuclear & KS & Coffey County Lake & Once Through & 500 & PWR-West. & 1166 & $3411 / 3565$ & $1985 / 2045$ \\
\hline Arkansas Nuclear One-1 & Entergy Nuclear & $A R$ & Dardanelle Reservoir on Arkansas Rive & Once Through & 765 & PWR-B\&W & 836 & $2568 /$ & $1974 / 2034$ \\
\hline Arkansas Nuclear One-2 & Entergy Nuclear & $A R$ & Dardanelle Reservoir on Arkansas Rive & Tower (1; natural draft) & 422 & PWR-CE & 998 & $2815 / 3026$ & $1978 / 2038$ \\
\hline Amarillo (1 unit) & Amarillo Power & $T X$ & $T B D$ & $T B D$ & & $E P R$ & $\sim 1600$ & & $T B D$ \\
\hline \multicolumn{10}{|c|}{ 9. CALIFORNIA REGION + UPPER and LOWER COLORADO REGIONs + PACIFIC NORTHWEST REGION: 8 OPERATING REACTOR UNIT AT FOUR SITES -- (does not include Green River \& Payette) } \\
\hline Columbia & Energy Northwest & WA & Columbia River & Towers (6; mechanical) & 550 & BWR-GE & 1131 & $3323 / 3486$ & 1984 / 2023 \# \\
\hline Diablo Canyon-1 & Pacific Gas \& Electric & CA & Pacific Ocean & Once Through & 863 & PWR-West. & 1122 & $3338 / 3411$ & $1984 / 2024 \#$ \\
\hline Diablo Canyon-2 & Pacific Gas \& Electric & CA & Pacific Ocean & Once Through & 863 & 3 PWR-West. & 1118 & $3411 /$ & $1985 / 2025 \#$ \\
\hline San Onofre-2 & Southern California Edison & CA & Pacific Ocean & Once Through & 797 & PWR-CE & 1070 & $3390 / 3438$ & $1982 / 2022$ \\
\hline San Onofre-3 & Southern California Edison & $\mathrm{CA}$ & Pacific Ocean & Once Through & 797 & PWR-CE & 1080 & $3390 / 3438$ & $1983 / 2022$ \\
\hline Palo Verde-1 & Arizona Public Service & $A Z$ & Wastewater effluent fm Phoenix & Towers (3; mechanical) & 560 & PWR-CE & 1314 & $3800 / 3990$ & $1985 / 2025 \#$ \\
\hline Palo Verde-2 & Arizona Public Service & $\mathrm{AZ}$ & Wastewater effluent fm Phoenix & Towers ( 3 ; mechanical) & 560 & PWR-CE & 1314 & $3800 / 3990$ & $1986 / 2026 \#$ \\
\hline Palo Verde-3 & Arizona Public Service & $\mathrm{AZ}$ & Wastewater effluent fm Phoenix & Towers ( 3 ; mechanical) & 560 & PWR-CE & 1247 & $3800 / 3990$ & $1987 / 2027 \#$ \\
\hline Green River & Blue Castle Holdings & UT & & $T B D$ & & $T B D$ & & & $T B D$ \\
\hline Payette County (I unit) & Alternate Energy Holdings & ID & Snake River & $T B D$ & & $T B D$ & $\sim 1600$ & & $T B D$ \\
\hline
\end{tabular}




\section{Appendix B: U.S. Nuclear Reactor Listing, by Site and by Site Situation/Cooling Method}

BREAKDOWN OF US NUCLEAR PLANT SITES BY SITUATION (RELATIVE TO 316(b))

Total number of U.S. Sites: 69

(this number includes all currently operating plant sites, plus planned sites for new plants for which a COL or ESP application has been filed.

Therefore, new sites without a COL or ESP application currently on file with NRC are not included below (Amarillo, Payette, Green River, Piketon, etc.)

This listing includes three "greenfield" sites based on COL applications (Levy, Lee, Bellefonte) and one "greenfield" site based on ESP application (Victoria County)

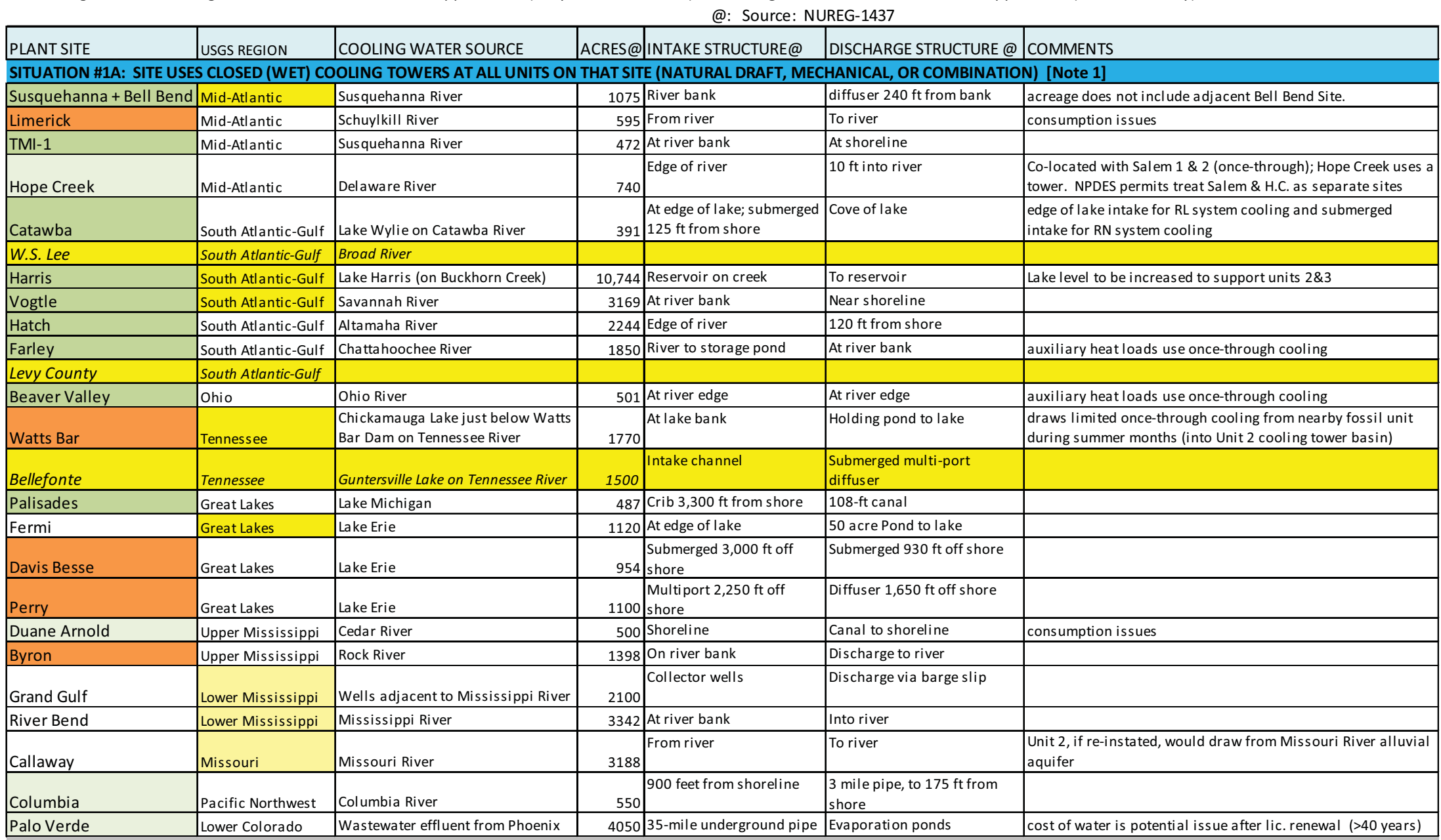

NOTES: 25 sites in this situation. (22 existing sites, 3 new greenfield sites) Total existing reactors $=32$ (+ NMP- 2 \& ANO-2 = 34) Total new Rx = 13 (includes WB- 2 but not suspended COLAs (3))

Note 1: for sites with multiple units, with some units using once-through cooling and some units using closed cooling (towers), the site is listed below in the appropriate once-through categorv

Color code: New Plants are yellow (full row = greenfield, second column only = on existing site; light = not active COL). Plants with 60 year License Renewal are green (dark = LR complete; light = EIS only).

$$
\text { Sites without recent EIS (via COL or LR) are orange }
$$




\begin{tabular}{|c|c|c|c|c|c|c|}
\hline PLANT SITE & USGS REGION & COOLING WATER SOURCE & ACRES@| & |INTAKE STRUCTURE@ & DISCHARGE STRUCTURE @ & COMMENTS \\
\hline \multicolumn{7}{|c|}{ SITUATION \#1B SITE USES ONCE THROUGH COOLING ON A MAN-MADE COOLING POND THAT IS EXEMPT FROM CWA 316(b) (Pond Not Classified as "Waters of the U.S.") } \\
\hline Turkey Point & South Atlantic-Gulf & $\begin{array}{l}\text { closed canal system off Biscayne } \\
\text { Bay }\end{array}$ & 24,000 & $\begin{array}{l}\text { Intake canal and barge } \\
\text { canal }\end{array}$ & 4000 acre Canal system & $\begin{array}{l}\text { Units } 3 / 4 \text { used closed canal system; units } 6 / 7 \text { will use Dade } \\
\text { County water treatment effluent }\end{array}$ \\
\hline La Salle (\%) & Upper Mississippi & Cooling Lake (off Illinois River) & 3060 & $\begin{array}{l}\text { From cooling pond; } m / u \\
\text { from river }\end{array}$ & To cooling pond & \\
\hline Braidwood (\%) & Upper Mississippi & Braidwood Lake (off Kankakee River) & 4457 & At lake shore & Surface flume & \\
\hline South Texas (\%) & Texas Gulf & $\begin{array}{l}\text { Cooling Res. with } \mathrm{m} / \mathrm{u} \text { fm Colorado } \\
\text { River }\end{array}$ & 12,350 & $\begin{array}{l}\text { from cooling res.; } \mathrm{m} / \mathrm{u} \\
\text { from bank of river }\end{array}$ & $\begin{array}{l}\text { to reservoir; } m / u \text { to bank of } \\
\text { river }\end{array}$ & $\begin{array}{l}\text { Units } 3 \& 4 \text { will use main cooling reservoir (MCR), with an } \\
\text { increased depth of } \sim 2 \text { feet }\end{array}$ \\
\hline Victoria County & Texas Gulf & $\begin{array}{l}\text { Cooling Lake with } \mathrm{m} / \mathrm{u} \mathrm{fm} \\
\text { Guadalupe River }\end{array}$ & 11,532 & & & \\
\hline
\end{tabular}

\begin{tabular}{|c|c|c|c|c|c|c|}
\hline North Anna & Mid-Atlantic & Lake Anna (fed by North Anna River) & 18,643 & Lake shore & Via 3400 acre cooling pond & $\begin{array}{l}\text { Units } 1 \& 2 \text { use once-through; unit } 3 \text { will use a hybrid tower. } \\
\text { Acreage includes entire Lake + shoreline }\end{array}$ \\
\hline Robinson (\%) & South Atlantic-Gulf & Lake Robinson on Black Creek & 5,000 & Edge of lake & 4.2 mile canal & acreage includes lake plus shoreline \\
\hline Summer (\%) & South Atlantic-Gulf & $\begin{array}{l}\text { Dissipates heat to Lake Monticello; } \\
\text { make-up from Parr Reservoir }\end{array}$ & 2200 & Intake at shoreline & Discharge pond to lake & $\begin{array}{l}\text { Unit } 1 \text { uses once-through; units } 2 \& 3 \text { will use towers. Units } \\
\text { operate in conjunction with pumped storage }\end{array}$ \\
\hline Dresden (\%) & Upper Mississippi & Cooling Lake (off Illinois River) & 2227 & Canal from Kankakee River & Cooling lake to Illinois River & $\begin{array}{l}\text { acreage includes } 1274 \text { acre cooling lake and spray canal; uses } \\
\text { Helper Towers }\end{array}$ \\
\hline Clinton (\%) & Upper Mississippi & Clinton Lake (off Salt Creek) & 14,090 & Shoreline of creek & 3-mile flume & \\
\hline Comanche Peak & Texas Gulf & $\begin{array}{l}\text { Squaw Creek Reservoir/Lake } \\
\text { Granbury }\end{array}$ & 7699 & Shore of reservoir & Canal to reservoir & $\begin{array}{l}\text { Units } 1 \& 2 \text { use once-through from Squaw Creek Res.; Units } 3 \& \\
4 \text { will use towers \& get } \mathrm{m} / \mathrm{u} \text { fm Lake Granbury } \\
\end{array}$ \\
\hline Wolf Creek (\%) & Arkansas-White-Red & $\begin{array}{l}\text { Dissipates heat to Coffey County } \\
\text { Lake on Wolf Cr.; make-up from John } \\
\text { Redmond Res. }\end{array}$ & 9818 & Cooling lake & Cooling lake to embayment & NRC LR: I\&E Moderate impact \\
\hline
\end{tabular}

NOTES: 7 sites in this situation. Note: ones marked (\%) are considered cooling ponds by NRC (NUREG-1437). Note 2.

Note 2: NRC defines Cooling Pond as "a man-made impoundment that does not impede the flow of a navigable system and that is used primarily to remove waste heat from condenser water prior to recirculating the water back to the main condenser" (ORNL/NUREG/TM-226).

\begin{tabular}{|c|c|c|c|c|c|c|}
\hline Vermont Yankee & New England & $\begin{array}{l}\text { Vernon Pool behind Vernon Dam on } \\
\text { Connecticut River }\end{array}$ & 125 & Edge of river & $\begin{array}{l}\text { Aerating structure at edge of } \\
\text { river }\end{array}$ & $\begin{array}{l}\text { Uses mech. cooling towers in summer; avg. consumption }<0.1 \% \\
\text { in tower mode. Max consumption on hottest day is }<1.5 \%\end{array}$ \\
\hline Peach Bottom & Mid-Atlantic & \begin{tabular}{|l|} 
Conowingo Pond behind Conowingo \\
Dam on Susquehanna River
\end{tabular} & 620 & Small intake pond & $5,000-\mathrm{ft}$ canal to pond & \begin{tabular}{|l|} 
Mech. cooling towers installed but not used ( 5 previously \\
used in summer, 3 now retained operable for contingency)
\end{tabular} \\
\hline Browns Ferry & Tennessee & $\begin{array}{l}\text { Wheeler Reservoir behind Wheeler } \\
\text { Dam on Tennessee River }\end{array}$ & 840 & $\begin{array}{l}\text { In small river inlet via } \\
\text { skimmer wall \& forebay }\end{array}$ & Diffuser pipes to river & $\begin{array}{l}\text { Uses mechanical "helper" towers during warm parts of year. } \\
\text { Cannot operate totally in closed cycle mode. }\end{array}$ \\
\hline Sequoyah & Tennessee & $\begin{array}{l}\text { Chickamauga Lake on Tennessee } \\
\text { River }\end{array}$ & 525 & $\begin{array}{l}\text { From lake via skimmer } \\
\text { wall \& forebay }\end{array}$ & $\begin{array}{l}\text { To lake/river via diffuser } \\
\text { pipes }\end{array}$ & $\begin{array}{l}\text { Uses natural draft towers as "helpers" during warmer months } \\
\text { for large portion of cooling; cannot operate totally in closed } \\
\text { cycle mode. Auxiliary heat loads use once-through cooling }\end{array}$ \\
\hline McGuire & South Atlantic-Gulf & $\begin{array}{l}\text { Lake Norman behind Cowans Ford } \\
\text { Dam on Catawba River }\end{array}$ & 30,000 & $\begin{array}{l}\text { Submerged and surface at } \\
\text { shoreline }\end{array}$ & 2,000-ft canal discharge & $\begin{array}{l}\text { capability to mix hypolimnetic water with surface water for } \\
\text { cooling }\end{array}$ \\
\hline Oconee & South Atlantic-Gulf & $\begin{array}{l}\text { Lake Keowee behind Keowee Dam } \\
\text { (fed by Keowee \& Little Rivers) }\end{array}$ & 510 & 710-ft deep skimmer wall & $765 \mathrm{ft}$ deep & $\begin{array}{l}\text { hypolimnetic water exclusively used for cooling. Units } \\
\text { operate in conjunction with pumped storage. }\end{array}$ \\
\hline Arkansas Nuclear One & Arkansas-White-Red & $\begin{array}{l}\text { Dardanelle Reservoir on Arkansas } \\
\text { River }\end{array}$ & 1160 & $3220-\mathrm{ft}$ canal & $520-\mathrm{ft}$ canal & Unit 1 uses once-through; unit 2 uses a tower \\
\hline
\end{tabular}




\begin{tabular}{|c|c|c|c|c|c|c|}
\hline PLANT SITE & USGS REGION & COOLING WATER SOURCE & ACRES@ & INTAKE STRUCTURE@ & DISCHARGE STRUCTURE @ & COMMENTS \\
\hline \multicolumn{7}{|c|}{ SITUATION \#4: SITE USES ONCE THROUGH COOLING ON AN OCEAN OR BAY OPEN TO THE OCEAN } \\
\hline Seabrook & New England & Atlantic Ocean & 896 & $\begin{array}{l}3 \text { deep structures, } 7,000 \mathrm{ft} \\
\text { off shore }\end{array}$ & diffuser, $5,500 \mathrm{ft}$ off shore & \\
\hline Pilgrim & New England & Cape Cod Bay/Atlantic Ocean & 517 & $\begin{array}{l}\text { Edge of bay (protected by } \\
\text { breakwater) }\end{array}$ & $850-\mathrm{ft}$ canal & NRC LR: I\&E Moderate impact \\
\hline Millstone & New England & Niantic Bay/Long Is. Sound/Atlantic & 500 & Niantic Bay & Via holding pond & NRC LR: I\&E Moderate impact \\
\hline Crystal River & South Atlantic-Gulf & Gulf of Mexico & 4738 & $16,000 \mathrm{ft}$ from shore & $13,000 \mathrm{ft}$ canal & acreage includes fossil units \\
\hline St. Lucie & South Atlantic-Gulf & Atlantic Ocean & 1132 & $1,200 \mathrm{ft}$ off shore & $1,200 \mathrm{ft}$ \& $3000 \mathrm{ft}$. off shore & \\
\hline Diablo Canyon & California & Pacific Ocean & 750 & At shore with break wall & Surface to ocean & \\
\hline San Onofre & California & Pacific Ocean & & $\begin{array}{l}\text { velocity cap 3,400 ft off } \\
\text { shore }\end{array}$ & 3,800 to $8,500 \mathrm{ft}$ from shore & \\
\hline
\end{tabular}

\section{SITUATION \#5: SITE USES ONCE-THROUGH COOLING ON AN ESTUARY OR TIDAL RIVER}

\begin{tabular}{|l|l|l|r|l|l|l|}
\hline Indian Point & Mid-Atlantic & Hudson River & 239 & At river bank & Channel to river & NRC LR: I\&E Moderate impact; NPDES treats units as separate \\
\hline Oyster Creek & Mid-Atlantic & Barnegat Bay & 1416 & $\begin{array}{l}\text { Forked River from bay } \\
\text { (reverse flow) }\end{array}$ & Oyster Creek to bay & NRC LR: I\&E Moderate impact \\
\hline Salem & Mid-Atlantic & Delaware River & 740 & Edge of river & $500 \mathrm{ft}$ into river & $\begin{array}{l}\text { Co-located with Hope Creek (uses a tower). NPDES permits } \\
\text { treat Salem \& Hope Creek as separate sites }\end{array}$ \\
\hline Calvert Cliffs & Mid-Atlantic & Chesapeake Bay & 2070 & $560 \mathrm{ft}$ from shore & $850 \mathrm{ft}$ from shore & $\begin{array}{l}\text { Units } 1 \text { \& 2 use once-through; unit 3 will use a mechanical } \\
\text { tower with plume abatement }\end{array}$ \\
\hline Surry & Mid-Atlantic & James River & 840 & 1.7 -mile canal & 2900 -ft canal & \\
\hline Brunswick & South Atlantic-Gulf & Cape Fear River & 1200 & 3 -mile canal from river & 6-mile canal to Atlantic & \\
\hline
\end{tabular}

NOTES: 6 sites in this situation.

\begin{tabular}{|c|c|c|c|c|c|c|}
\hline Monticello & Upper Mississippi & Mississippi River & 2150 & Canal & Canal & $\begin{array}{l}\text { Uses mechanical "helper" towers during warm parts of year. } \\
\text { Cannot operate in total closed cycle mode. }\end{array}$ \\
\hline Prairie Island & Upper Mississippi & Mississippi River & 560 & Short canal & Basin to towers and/or river & $\begin{array}{l}\text { Uses mechanical "helper" towers during warm parts of year. } \\
\text { Cannot operate in total closed cycle mode. }\end{array}$ \\
\hline Ft. Calhoun & Missouri & Missouri River & 660 & At shore & At shore & \\
\hline Cooper & Missouri & Missouri River & 1359 & At shoreline & At shoreline & $<5 \%$ mean annual river flow \\
\hline Waterford & Lower Mississippi & Mississippi River & 3561 & At river bank & At river bank & acreage includes fossil units \\
\hline
\end{tabular}

\section{SITUATION \#7: SITE USES ONCE-THROUGH COOLING ON A GREAT LAKE}

\begin{tabular}{|c|c|c|c|c|c|c|}
\hline Kewaunee & Great Lakes & Lake Michigan & 908 & $\begin{array}{l}1,750 \mathrm{ft} \text { from shore, } 22 \mathrm{ft} . \\
\text { deep }\end{array}$ & At shoreline & \\
\hline Point Beach & Great Lakes & Lake Michigan & 2065 & $1,750 \mathrm{ft}$ from shore & 2 Flumes $150 \mathrm{ft}$ from shore & \\
\hline DC Cook & Great Lakes & Lake Michigan & 650 & $2,250 \mathrm{ft}$ from shore & $1,250 \mathrm{ft}$ from shore & \\
\hline Ginna & Great Lakes & Lake Ontario & 488 & $\begin{array}{l}\text { Lake bottom, } 3100 \mathrm{ft} \text {. from } \\
\text { shore }\end{array}$ & Open canal & \\
\hline Fitzpatrick & Great Lakes & Lake Ontario & 702 & $\sim 850 \mathrm{ft}$. from shore & To lake, 1150 ft. from shore & \\
\hline Nine Mile Point & Great Lakes & Lake Ontario & 900 & Pipelines $1,000 \mathrm{ft}$ off shore & $555 \mathrm{ft}$. long diffuser pipe & $\begin{array}{l}\text { Unit } 1 \text { uses once-through; unit } 2 \text { uses a natural draft tower; } \\
\text { unit } 3 \text { will use a mechanical tower }\end{array}$ \\
\hline
\end{tabular}


APPENDIX C: Summary Tabulation of Number of NPPs in Each Situation (per App. B)

Summary of EPA 316(b) Phase 2 Applicability by Site and Unit

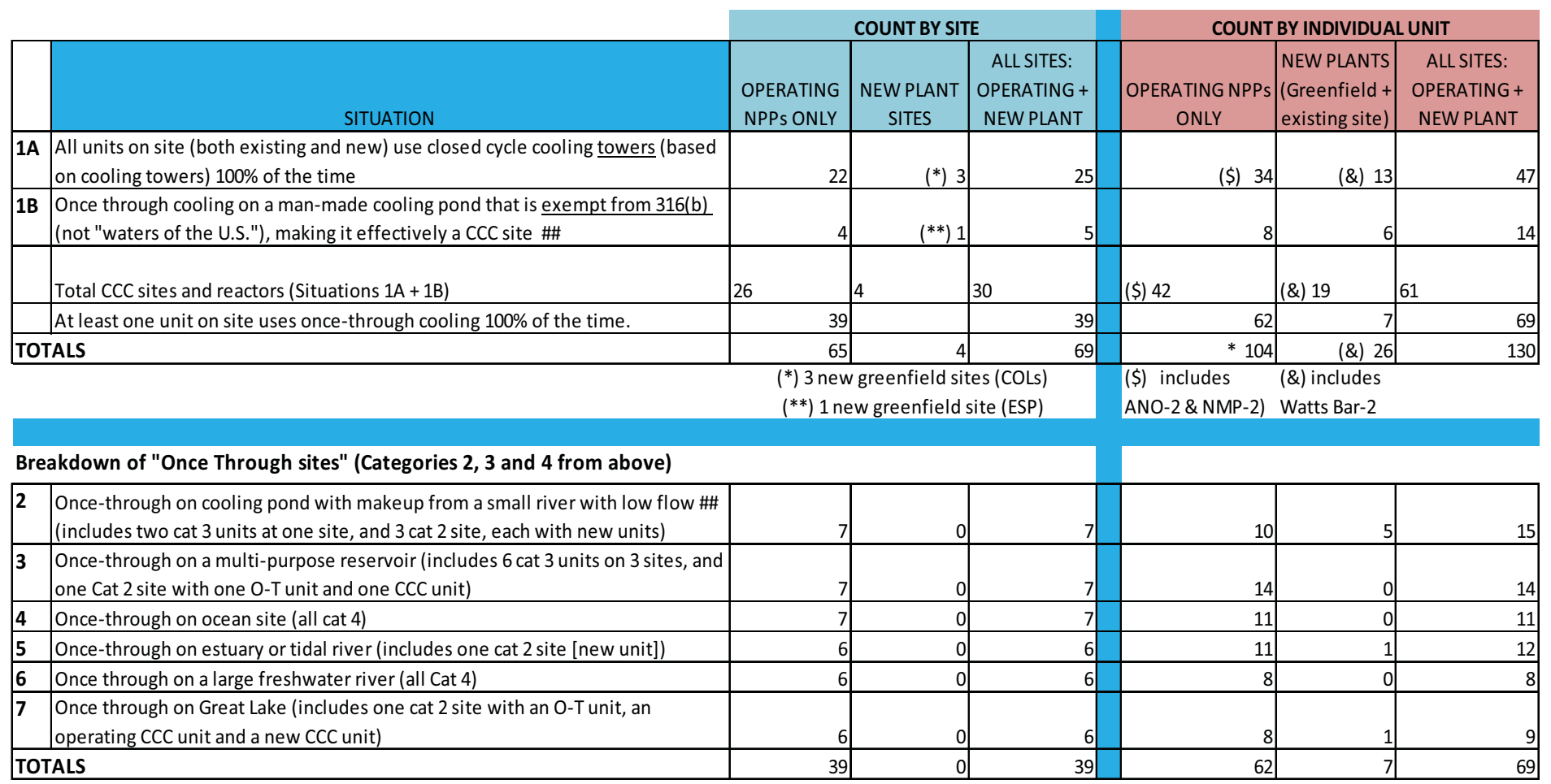

NOTES:

OPERATING PLANTS:

Only currently operating plants with a full power operating license are listed (no shutdown plants)

Adjacent plants NMP and Fitzpatrick considered separate sites because of different ownership and licensees

Adjacent Salem and Hope Creek units operated by PSEG considered separate sites because of different ownership history

Once-through site \& unit listings include 12 reactors on 6 sites with helper towers that augment OTC during summer months

\section{NEW PLANTS}

Only new plants with a COL or ESP application currently on file with NRC are included in this data (i.e., Clinton-2, Payette, Amarillo, Green River, etc. are not included) New units with their COLA reviews suspended at NRC are not included (e.g., Callaway-2, Grand Gulf-3, River Bend-3)

This listing considers the following new sites to be "greenfield" based on COLAs: Lee, Levy, and Bellefonte; and Victoria Station based on ESP application.

This listing considers adjacent Susquehanna (operating) and Bell Bend (planned) to be on the same site. All other new units on existing sites are obvious

Completion of Watts Bar- 2 is included with new plants. Potential completion of Bellefonte $1 \& 2$ is not included in data

\#\# Note that many of these units on a cooling pond (especially those that are totally man-made or ones created by damming a small river or creek at its headwaters with diverted off-stream makeup water) are effectively closed cycle systems equivalent to cooling tower technology for purposes of 316(b). 


\section{APPENDIX D: GLOSSARY}

\begin{tabular}{|c|c|}
\hline ALWR & Advanced Light Water Reactor \\
\hline BOP & Balance of Plant \\
\hline BTA & Best Technology Available \\
\hline CAA & Clean Air Act \\
\hline CCS & Carbon Capture and Sequestration \\
\hline CDS & Comprehensive Demonstration Study \\
\hline CEO & Chief Executive Officer \\
\hline CERA & Cambridge Energy Research Associates \\
\hline $\mathrm{CO}_{2}$ & Carbon Dioxide \\
\hline COL & Combined Operating License \\
\hline CWA & Clean Water Act \\
\hline DOE & Department of Energy \\
\hline DOE-FE & Department of Energy - Office of Fossil Energy \\
\hline DOE-NE & Department of Energy - Office of Nuclear Energy \\
\hline EEI & Edison Electric Institute \\
\hline EIA & Energy Information Administration \\
\hline EIS & Environmental Impact Statement \\
\hline EPA & Environmental Protection Agency \\
\hline EPRI & Electric Power Research Institute \\
\hline ESP & Early Site Permit \\
\hline GAO & Government Accountability Office \\
\hline GEIS & Generic Environmental Impact Statement \\
\hline HTGR & High Temperature Gas Reactor \\
\hline IEA & International Energy Agency \\
\hline IGCC & Integrated Gasification Combined Cycle \\
\hline IM\&E & Impingement Mortality and Entrainment \\
\hline INPO & Institute of Nuclear Power Operations \\
\hline MWe & Megawatt (electric) \\
\hline NCEP & National Commission on Energy Policy \\
\hline NEI & Nuclear Energy Institute \\
\hline NEPA & National Environmental Policy Act \\
\hline NERC & North American Electric Reliability Corporation (previously Council) \\
\hline NETL & National Energy Technology Laboratory \\
\hline NGCC & Natural Gas Combined Cycle \\
\hline NPDES & National Pollutant Discharge Elimination System \\
\hline NRC & Nuclear Regulatory Commission \\
\hline OECD & Organization for Economic Cooperation and Development \\
\hline OSTP & Office of Science Technology Policy \\
\hline ppt & parts per thousand \\
\hline$R \& D$ & Research and Development \\
\hline SWAQ & Subcommittee on Water Availability and Quality \\
\hline TDS & Total dissolved solids \\
\hline TVA & Tennessee Valley Authority \\
\hline USGS & U.S. Geologic Survey \\
\hline UWAG & Utility Water Act Group \\
\hline WEF & World Economic Forum \\
\hline
\end{tabular}


D-2 


\section{APPENDIX E: REFERENCES:}

1 “International Energy Outlook 2009," EIA, May 2010.

2 "Energy Vision Update 2009 - Thirsty Energy: Water and Energy in the $21^{\text {st }}$ Century," World Economic Forum, Dec. 2008.

3 "Running Dry" The Economist, 21 August 2008

4 "Electricity Reliability Impacts of a Mandatory Cooling Tower Rule for Existing Steam Generation Units" DOE, October 2008; DOE website: http://www.oe.energy.gov/information_center/reports.htm\#de.

5 "Program on Technology Innovation: An Energy/Water Sustainability Research Program for the Electric Power Industry," EPRI 000000000001015371 , July 2007

6 "Water Use, Electric Power and Nuclear Energy: A Holistic Approach to Environmental Stewardship" NEI, June 2009; NEI website.

7 "Water Requirements for Existing and Emerging Thermoelectric Plant Technologies" DOE/NETL-402/080108, August 2008

8 "The Energy Challenge," Nature, March 2008

9 "The Energy Challenge," Nature, March 2008

10 "Energy Demands on Water Resources: Report to Congress on the Interdependency of Energy and Water," DOE, Dec. 2006.

11 "Managing Our Future Water Needs for Agriculture, Industry, Human Health and the Environment: The Bubble Is Close to Bursting: A Forecast of the Main Economic and Geopolitical Water Issues Likely to Arise in the World during the Next Two Decades," Jan. 2009.

${ }^{12}$ DOE Report to Congress, Dec. 2006

${ }^{13}$ DOE Report to Congress, Dec. 2006

${ }^{14}$ DOE Report to Congress, Dec. 2006, p. 14

${ }^{15}$ DOE Report to Congress, Dec. 2006, p. 33

${ }^{16}$ DOE Report to Congress, Dec. 2006

17 " The Energy Challenge," Nature, March 2008

${ }^{18}$ Nuclear Energy Institute (NEI) and Energy Information Administration (EIA) websites

${ }^{19}$ Nuclear Energy Institute (NEI) website, original data from Ventyx Velocity Suite

${ }^{20}$ World Nuclear Association (WNA) website

${ }^{21}$ Nuclear Energy Institute (NEI), "Status and Outlook for Nuclear Energy in the U.S. (July 2010; Att. 2)

${ }^{22}$ Nuclear Energy Institute (NEI), "Status and Outlook for Nuclear Energy in the U.S. (July 2010; Att. 2)

23 "Estimating Freshwater Needs to Meet Future Thermoelectric Generation Requirements." DOE/NETL400/2008/1339, Sept. 30, 2008.

24 "Running Dry at the Power Plant" EPRI Journal, Summer 2007; http://my.epri.com/portal/server.pt?

${ }^{25}$ Program on Technology Innovation: An Energy/Water Sustainability Research Program for the Electric Power Industry" EPRI Topical Report 1015371, July 2007

${ }^{26}$ EPRI Journal Article, p.22.

${ }^{27}$ North Anna Early Site Permit Application, NRC website

${ }^{28}$ Water \& Sustainability (Volume 1): Research Plan" EPRI Topical Report 1006784, March 2002

${ }^{29}$ DOE Report to Congress, p.65

30 "Water Requirements for Existing and Emerging Thermoelectric Plant Technologies" DOE/NETL-402/080108, August 2008

31 "Thirsty Water," WEF, p. 42

32 "Thirsty Water," WEF, p. 41

${ }^{33} \mathrm{EPRI}, \mathrm{EIA}$, various sources (wind capacity factor is highly reliant on regional differences in wind quality)

${ }^{34}$ Sandia presentation, "Energy and Water: Issues, Trends and Challenges" by Mike Hightower to EPRI Workshop on Advanced Cooling Technologies, July 8-9, 2008

${ }^{35}$ Water \& Sustainability (Volume 4): U.S. Electricity Consumption for Water Supply \& Treatment - The Next Half Century," EPRI Topical Report 1006787, March 2002

36 "Thirsty Water" WEF, 2008 
37 "WEF Water Initiative" 2009

38 2009-2014 EPA Strategic Plan: Change Document for Public Review, Sept. 30, 2008

${ }^{39}$ EPA Website http://www.epa.gov/lawsregs/laws/cwa.html

4040 CFR Parts 9, 122, et al. National Pollutant Discharge Elimination System: Regulations Addressing Cooling Water Intake Structures for New Facilities; Final Rule, Dec. 2001.

${ }^{41}$ EPA Website: http://www.epa.gov/waterscience/316b/basic.htm

${ }^{42}$ See Seacoast Anti-Pollution League v. Costle, 597 F.2d 306 (1st Cir. 1979).

${ }^{43}$ Amicus Curiae Brief of the State of Nebraska, et al. [18 States] in Support of the Utility Water Act Group, on Writs of Certiorari to the United States Court of Appeals for the Second Circuit, July 2008

${ }^{44}$ EPA Website: http://cfpub.epa.gov/npdes/

${ }^{45}$ EPA Website: http://www.epa.gov/waterscience/316b/phase2/phase2final-fs.htm

${ }^{46}$ EPA Final Rule, CWA Phase 2, 9 July 2004

${ }^{47}$ Brief for the Federal Parties (by EPA and Justice Dept.) on Writ of Certiorari to the Second Circuit Court of Appeals, July 2008

${ }^{48}$ NRC Website, http://www.nrc.gov/about-nrc/governing-laws.html\#natl-environ-policy-act

${ }^{49}$ NRC Website, http://www.nrc.gov/reading-rm/doc-collections/cfr/part051/part051-appb.html

50 e.g., EPRI Journal Article (Attachment 3)

${ }^{51}$ USGS Website

52 "Energy Vision Update 2009 - Thirsty Energy: Water and Energy in the $21^{\text {st }}$ Century," World Economic Forum, Dec. 2008.

${ }^{53}$ Petition for a Writ of Certiorari, Entergy, 1 Nov. 2007

${ }^{54}$ Petition for a Writ of Certiorari, Brief for the Federal Respondents in Opposition, March 2008

${ }^{55}$ Petition for a Writ of Certiorari, Brief for the Federal Respondents in Opposition, March 2008

56 "Estimating Freshwater Needs to Meet Future Thermoelectric Generation Requirements." DOE/NETL400/2008/1339, Sept. 30, 2008

${ }^{57}$ NETL, op.cit., page 25

58 The Power to Reduce CO2 Emissions: the Full Portfolio 2008 Economic Sensitivity Studies 1018431, Dec. 2008

59 NCEP, op.cit.

60 CCSP, op.cit.

61 IEA/OECD, op.cit.

62 "Use of Reclaimed Water for Power Plant Cooling" ANL (under contract to NETL), August 2007 